\title{
Enhanced triplex hybridization of DNA and RNA via syndiotactic sidechain presentation in minimal bPNAs
}

\author{
Sarah Rundell, Oliver Munyadradzi and Dennis Bong* \\ Department of Chemistry \& Biochemistry, The Ohio State University, \\ 100 W. 18th Avenue, Columbus, Ohio 43210
}

${ }^{*}$ Corresponding Author

Email: bong.6@osu.edu

Section

Page

S1 Materials, instrumentation, and general protocols

S2 Tabulated thermodynamic data for bPNA hybrids

S3 Thermal denaturation raw data

S4 Synthetic protocols

S5 HPLC/MS characterization of bPNAs

S25

S6 References 


\section{S1. Materials, instrumentation, and general protocols}

For all solutions, deionized water filtered through a $0.2 \mu \mathrm{m}$ filter was used. All DNA and RNA samples were acquired from Integrated DNA Technologies (IDT) Inc. as dry pellets, rehydrated, and used without further processing. 5X PBS buffer (50 mM sodium phosphate, $500 \mathrm{mM} \mathrm{NaCl}, \mathrm{pH} 7.3$ ) was prepared and filtered. To determine peptide and oligonucleotide stock concentrations, the absorbance values were measured on a Thermo Fisher NanoDrop 2000c. DNA and RNA stocks were measured at $A_{260}$ and their concentrations determined with the molar absorptivities provided by IDT. The bPNA concentrations were determined under acidic conditions at $A_{238}$ by dilution of aqueous stocks with $0.1 \mathrm{M} \mathrm{HCl}$ using melamine extinction coefficient $\left(9,700 \mathrm{M}^{-1} \mathrm{~cm}^{-1}\right)$; for each $4 \mathrm{M}$ bPNA peptide this is multiplied by 4 for each melamine $\left(\varepsilon=38,800 \mathrm{M}^{-1} \mathrm{~cm}^{-1}\right)$.

\section{S1.1. Sample preparation for thermal denaturation (UV-melting)}

UV-melting curves were measured on a Cary-100 UV-vis spectrophotometer equipped with a $6 \times 6$ Multicell Holder Peltier accessory and a coolant circulating temperature controller. All measurements were recorded at $260 \mathrm{~nm}$ with a temperature change of $1^{\circ} \mathrm{C} / \mathrm{min}$ and data points collected at every degree from $0^{\circ} \mathrm{C}$ to $80^{\circ} \mathrm{C}$. Low headspace quartz cuvettes with PTFE stoppers were used for data collection and sealed parafilm. All samples were prepared at $1: 1 \mathrm{bPNA}: X N A$ stoichiometry and annealed $\left(95^{\circ} \mathrm{C}, 5\right.$ minutes, slow cool to RT) in $1 \mathrm{X}$ PBS (100 mM NaCl, $10 \mathrm{mM}$ phosphate, $\mathrm{pH}=7.5$ ). The hybrid concentrations analyzed were 2, 3.5, 5, 7.5, 10, 15, 20 and $25 \mu \mathrm{M}$. The nucleic acid sequences used were $d\left(\mathrm{~T}_{4} \mathrm{C}_{4} \mathrm{~T}_{4}\right), r\left(\mathrm{U}_{4} \mathrm{C}_{4} \mathrm{U}_{4}\right), r\left(\mathrm{U}_{4} \mathrm{GUGA} \mathrm{U}_{4}\right), \mathrm{d}\left(\mathrm{U}_{4} \mathrm{C}_{4} \mathrm{U}_{4}\right)$, $\mathrm{d}\left(\mathrm{U}_{4} \mathrm{C}_{4} \mathrm{~T}_{4}\right)$, and $\mathrm{d}\left(\mathrm{U}_{2} \mathrm{~T}_{2} \mathrm{C}_{4} \mathrm{~T}_{2} \mathrm{U}_{2}\right)$. Three independent runs at each concentration were collected for each bPNA variant.

\section{S1.2. Data treatment to acquire thermodynamic parameters from optical melting experiments}

The melting transition temperature was acquired either by first derivative analysis of the absorbance trace or by direct fitting of the melting curve, as described below. Both methods yielded comparable results and the same general trends. The $T_{m}$ value was then used in van't Hoff analysis to obtain thermodynamic data. The tripeptide data set was analyzed using first derivative analysis while subsequent data was analyzed using direct fitting. All bPNAs used in comparative datasets were analyzed in the same way. For example the Ala tripeptide $\left(\mathrm{K}^{2 \mathrm{M}} \mathrm{AK} \mathrm{K}^{2 \mathrm{M}}\right)$ was analyzed using both methods used as a reference bPNA.

S1.2.1 $1^{\text {st }}$-derivative method to determine $T_{m}$

The $1^{\text {st }}$ derivative of the melt curve was calculated (OriginPro 9.0). The raw melt data was normalized from 0 to 100 (a.u.) along with the $1^{\text {st }}$ derivative data (Figure S3.1). The $T_{m}$ is defined by the peak of the $1^{\text {st }}$ derivative plot which is the inflection point of the melt.

51.2.3. Direct (non-linear) fit method to determine $T_{m}$ Optical melting data was fit as previously reported. ${ }^{1}$ Before fitting, the raw data was normalized and the $T_{m}$ $\left({ }^{\circ} \mathrm{C}\right)$ was converted to Kelvin $(\mathrm{K})$. The data was fit to the following equations:

$$
\begin{gathered}
\mathrm{A}(\mathrm{T})=\left(1-f_{\mathrm{F}}\right)^{*} \mathrm{~A}_{\mathrm{U}}+\left(f_{\mathrm{F}}{ }^{*} \mathrm{~A}_{\mathrm{F}}\right) \\
f_{\mathrm{F}}=\mathrm{K} /(1+\mathrm{K}) \\
\mathrm{A}_{U}(\mathrm{~T})=\left(\mathrm{m}_{\mathrm{U}}{ }^{*} \mathrm{~T}\right)+\mathrm{b}_{U} \\
\mathrm{~A}_{\mathrm{F}}(\mathrm{T})=\left(\mathrm{m}_{\mathrm{F}}{ }^{*} \mathrm{~T}\right)+\mathrm{b}_{\mathrm{F}} \\
\mathrm{K}=\exp \left((\Delta \mathrm{H} / \mathrm{R})^{*}\left(1 / \mathrm{T}_{\mathrm{M}}-1 / \mathrm{T}\right)\right)
\end{gathered}
$$

Wherein $\mathrm{A}(\mathrm{T})$ is the absorbance of the solution at temperature $\mathrm{T}, f_{\mathrm{F}}$ is the fraction of species in the folded state, $A_{U}(T)$ and $A_{F}(T)$ are the unfolded and folded states (duplex), respectively, which are assumed to be linear 
functions of temperature, $\mathrm{K}$ is the equilibrium constant, $\Delta \mathrm{H}$ is the change in enthalpy, $T_{M}$ is the melting temperature in Kelvin, $T$ is the temperature in Kelvin, and $R$ is the gas constant. To calculate an accurate $T_{M}$, the upper and lower baselines were individually fit then these parameters $\left(m_{U}, b_{U}, m_{F}, b_{F}\right)$ were held constant in the above equations (Figure S3.1).


Figure S3.1. (Left) Example of melt and 1st derivative to calculate $T_{m}$. (Right): Example of direct fit of melt to calculate ${ }^{\mathrm{TM}}$, compensating for pre and post baseline differences that can emerge at low concentration or high scan rate. Sample is $2 \mu \mathrm{M}$ $\mathrm{K}^{2 \mathrm{M}}$ AlaK ${ }^{2 \mathrm{M}}$ tripeptide with $2 \mu \mathrm{M} \mathrm{d}\left(\mathrm{T}_{4} \mathrm{C}_{4} \mathrm{~T}_{4}\right)$ in $1 \mathrm{X}$ PBS. For both images, the black line is the normalized melting curve and the red lines are the calculated first derivative and direct fit, respectively.

\section{S1.3. van't Hoff analysis}

The $T_{m}\left({ }^{\circ} \mathrm{C}\right)$ for each thermal melt was plotted against In $\left(\mathrm{C}_{\mathrm{T}} / 4\right)$ for van't Hoff analysis to calculate the $\Delta \mathrm{H}, \Delta \mathrm{S}$, and $\Delta G$ thermodynamic parameters. The van't Hoff equation (below) was applied where $T_{M}$ is the melting temperature in Kelvin (K), $\mathrm{R}$ is the gas constant at $1.987 \mathrm{cal} \mathrm{K}^{-1} \mathrm{~mol}^{-1}, \Delta \mathrm{H}$ is enthalpy, $\mathrm{C}_{\mathrm{T}}$ is total strand concentration, $a=4$ for non self complementary duplexes, ${ }^{1}$ and $\Delta S$ is entropy. The two state assumption (completely paired or unpaired) applied to all bPNA hybrids under typical melt conditions with the exception of the $(\mathrm{D}, \mathrm{L})$ diketopiperazine, $c-\left[\mathrm{k}^{2 \mathrm{M}} \mathrm{K}^{2 \mathrm{M}}\right]$ which had clearly multimodal melting throughout all concentrations; van't Hoff analysis was not considered reliable for this hybrid.

$$
\begin{gathered}
1 / \mathrm{T}_{\mathrm{M}}=\mathrm{R} / \Delta \mathrm{H} \ln \left(\mathrm{C}_{\mathrm{T}} / a\right)+\Delta \mathrm{S} / \Delta \mathrm{H}, \text { where } a=4 \\
\Delta \mathrm{G}=\Delta \mathrm{H}-\mathrm{T} \Delta \mathrm{S}, \mathrm{K}=\mathrm{e}^{-\Delta \mathrm{G} / \mathrm{RT}}
\end{gathered}
$$

Enthalpy change was calculated from the slope of the van't Hoff plot and entropy change was calculated from the $y$-intercept. The direct fit method was found to give more consistent results for the $T_{m}$, especially for lower melting complexes with RNA, where the data had a less defined first derivative peak. ${ }^{2}$ Analysis by van't Hoff fit assumes a two-state model, which was generally applicable to the hybrids studied. Some higher concentration transitions exhibited smaller transitions. In this case, only the major transition was considered. 


\section{S2. Tabulated thermodynamic data from van't Hoff analysis of bPNA hybrids}

Table S2.1. Thermodynamic parameters of the $\mathrm{K}^{2 \mathrm{M}} \mathrm{XK}^{2 \mathrm{M}}$ hybrids with DNA d $\left(\mathrm{T}_{4} \mathrm{C}_{4} \mathrm{~T}_{4}\right)^{a}$

\begin{tabular}{lllll}
\hline $\mathrm{K}^{2 \mathrm{M}} \mathrm{XK}^{2 \mathrm{M}}$ & $-\Delta \mathrm{H}(\mathrm{kcal} / \mathrm{mol})$ & $-\Delta \mathrm{S}(\mathrm{cal} / \mathrm{mol} \mathrm{K})$ & $-\Delta \mathrm{G}(\mathrm{kcal} / \mathrm{mol})$ & $\mathrm{T}_{\mathrm{m}}\left({ }^{\circ} \mathrm{C}\right)^{b}$ \\
\hline Lys & $64.1 \pm 2.1$ & $181.6 \pm 2.5$ & $11.70 \pm 0.6$ & $41.4 \pm 0.2$ \\
Trp & $64.8 \pm 1.2$ & $179.1 \pm 3.9$ & $11.37 \pm 0.08$ & $40.7 \pm 0.1$ \\
${ }_{\mathrm{t} \text { Bu Gly }}$ & $65.3 \pm 1.0$ & $180.7 \pm 3.1$ & $11.37 \pm 0.04$ & $40.4 \pm 0.2$ \\
Tyr & $66.9 \pm 0.9$ & $186.0 \pm 2.7$ & $11.44 \pm 0.07$ & $40.3 \pm 0.2$ \\
Leu & $67.6 \pm 1.1$ & $188.4 \pm 3.4$ & $11.43 \pm 0.02$ & $40.0 \pm 0.3$ \\
Ser & $66.8 \pm 2.8$ & $186.1 \pm 9.0$ & $11.3 \pm 0.2$ & $40.0 \pm 0.3$ \\
Val & $66.6 \pm 0.3$ & $185.1 \pm 1.0$ & $11.39 \pm 0.02$ & $40.0 \pm 0.2$ \\
Ala & $69.1 \pm 2.6$ & $193.5 \pm 8.2$ & $11.5 \pm 0.2$ & $39.9 \pm 0.3$ \\
Phe & $64.2 \pm 0.4$ & $177.7 \pm 1.4$ & $11.26 \pm 0.02$ & $39.7 \pm 0.1$ \\
Ile & $60.3 \pm 2.3$ & $165.1 \pm 7.1$ & $11.1 \pm 0.1$ & $39.62 \pm 0.04$ \\
Pro & $65.3 \pm 4.7$ & $181 \pm 15$ & $11.2 \pm 0.3$ & $39.5 \pm 0.6$ \\
Thr & $67.0 \pm 4.1$ & $187 \pm 13$ & $11.3 \pm 0.3$ & $39.4 \pm 0.2$ \\
Gly & $61.6 \pm 0.7$ & $170.7 \pm 2.4$ & $10.68 \pm 0.03$ & $37.512 \pm 0.008$ \\
BAla & $64.3 \pm 2.1$ & $180.2 \pm 6.6$ & $10.6 \pm 0.1$ & $36.7 \pm 0.2$ \\
\hline
\end{tabular}

${ }^{a}$ The thermodynamic parameters were calculated from the $T_{m}$ found by using the first derivative fit method. The bolded $X$ represents the three letter code of the amino acid in the center of each tripeptide. ${ }^{b}$ Conditions: $2 \mu \mathrm{M}$ hybrid (1:1 bPNA:DNA), $100 \mathrm{mM}$ NaCl, 10 $\mathrm{mM}$ phosphate $\mathrm{pH} 7.5$.

Table S2.2. Thermodynamic parameters of the $\mathrm{K}^{2 \mathrm{M}} \mathrm{XK}^{2 \mathrm{M}}$ hybrids with RNA r $\left(\mathrm{U}_{4} \mathrm{GUGAU} \mathrm{U}_{4}\right)^{\mathrm{a}}$

\begin{tabular}{lllll}
\hline $\mathrm{K}^{2 \mathrm{M} X K^{2 \mathrm{M}}}$ & $-\Delta \mathrm{H}(\mathrm{kcal} / \mathrm{mol})$ & $-\Delta \mathrm{S}(\mathrm{cal} / \mathrm{mol} \mathrm{K})$ & $-\Delta \mathrm{G}(\mathrm{kcal} / \mathrm{mol})$ & $\mathrm{T}_{\mathrm{m}}\left({ }^{\circ} \mathrm{C}\right)^{b}$ \\
\hline Trp & $58.5 \pm 3.6$ & $168 \pm 12$ & $8.30 \pm 0.07$ & $25.7 \pm 0.1$ \\
Ser & $68.7 \pm 4.7$ & $203 \pm 16$ & $7.98 \pm 0.05$ & $24.7 \pm 0.6$ \\
Gly & $63.00 \pm 0.08$ & $184.3 \pm 0.3$ & $8.06 \pm 0.02$ & $24.68 \pm 0.09$ \\
Tyr & $61.3 \pm 2.5$ & $178.0 \pm 8.9$ & $8.2 \pm 0.1$ & $24.1 \pm 0.2$ \\
BAla & $59.4 \pm 3.6$ & $172 \pm 12$ & $8.09 \pm 0.04$ & $24.1 \pm 0.2$ \\
Phe & $58.0 \pm 1.5$ & $167.6 \pm 4.8$ & $8.00 \pm 0.02$ & $23.9 \pm 0.3$ \\
Lys & $54.0 \pm 0.4$ & $154.3 \pm 1.3$ & $7.983 \pm 0.001$ & $23.8 \pm 0.1$ \\
Thr & $57.1 \pm 1.6$ & $164.9 \pm 5.3$ & $7.98 \pm 0.03$ & $23.8 \pm 0.1$ \\
Leu & $64.7 \pm 2.5$ & $190.1 \pm 8.4$ & $8.00 \pm 0.05$ & $23.7 \pm 0.1$ \\
Ala & $59.2 \pm 0.3$ & $172.2 \pm 1.0$ & $7.87 \pm 0.02$ & $23.61 \pm 0.09$ \\
Val & $64.0 \pm 3.0$ & $188 \pm 10$ & $7.91 \pm 0.02$ & $23.4 \pm 0.2$ \\
Ile & $59.6 \pm 3.2$ & $173 \pm 11$ & $7.87 \pm 0.04$ & $23.1 \pm 0.2$ \\
tBuGly & $57.0 \pm 2.5$ & $164.8 \pm 8.1$ & $7.86 \pm 0.05$ & $22.7 \pm 0.5$ \\
Pro & $64.4 \pm 4.1$ & $190 \pm 14$ & $7.69 \pm 0.04$ & $22.1 \pm 0.4$ \\
\hline
\end{tabular}


the three letter code of the amino acid in the center of each tripeptide. ${ }^{b}$ Conditions: $2 \mu \mathrm{M}$ hybrid (1:1 bPNA:RNA), $100 \mathrm{mM}$ NaCl, 10 $\mathrm{mM}$ phosphate $\mathrm{pH} 7.5$. 
Table S2.3. Thermodynamic parameters of dipeptide bPNA hybrids with DNA d $\left(\mathrm{T}_{4} \mathrm{C}_{4} \mathrm{~T}_{4}\right)^{a}$

\begin{tabular}{ccccc}
\hline $\mathrm{bPNA}$ & $\mathrm{T}_{\mathrm{m}}\left({ }^{\circ} \mathrm{C}\right)^{b}$ & $-\Delta \mathrm{G}(\mathrm{kcal} / \mathrm{mol})$ & $-\Delta \mathrm{H}(\mathrm{kcal} / \mathrm{mol})$ & $-\Delta \mathrm{S}(\mathrm{cal} / \mathrm{mol} \mathrm{K})$ \\
\hline $\mathrm{c}\left[\mathrm{K}^{2 \mathrm{M}}\right]_{2}$ & $47.2 \pm 0.5$ & $12.5 \pm 0.1$ & $61.5 \pm 1.5$ & $164.4 \pm 4.7$ \\
$\mathrm{k}^{2 \mathrm{M}} \mathrm{K}^{2 \mathrm{M}}$ & $46.0 \pm 0.3$ & $12.9 \pm 0.3$ & $72.7 \pm 3.9$ & $200.6 \pm 12$ \\
$\mathrm{~K}^{2 \mathrm{M}} \mathrm{k}^{2 \mathrm{M}}$ & $43.0 \pm 0.3$ & $11.7 \pm 0.2$ & $61.8 \pm 2.9$ & $167 \pm 16$ \\
$\mathrm{k}^{2 \mathrm{M} \mathrm{k}^{2 \mathrm{M}}}$ & $40.2 \pm 0.4$ & $11.1 \pm 0.1$ & $59.1 \pm 2.5$ & $160.8 \pm 7.8$ \\
$\mathrm{~K}^{2 \mathrm{M}} \mathrm{K}^{2 \mathrm{M}}$ & $39.7 \pm 0.2$ & $10.9 \pm 0.1$ & $57.8 \pm 1.7$ & $157.4 \pm 5.4$ \\
$\mathrm{c}\left[\mathrm{K}^{2 \mathrm{M}} \mathrm{k}^{2 \mathrm{M}}\right]$ & $\mathrm{N} / \mathrm{A}$ & $\mathrm{N} / \mathrm{A}$ & $\mathrm{N} / \mathrm{A}$ & $\mathrm{N} / \mathrm{A}$ \\
$\mathrm{K}^{2 \mathrm{M}} \mathrm{AlaK}^{2 \mathrm{M}}$ & $39.4 \pm 0.3$ & $11.0 \pm 0.1$ & $62.2 \pm 2.3$ & $171 \pm 7.3$ \\
$\mathrm{~K}^{2 \mathrm{M}} \mathrm{GlyK}^{2 \mathrm{M}}$ & $37.78 \pm 0.09$ & $10.9 \pm 0.1$ & $66.6 \pm 1.4$ & $186.7 \pm 4.4$ \\
$\mathrm{~K}^{2 \mathrm{M}} \mathrm{BAlaK}^{2 \mathrm{M}}$ & $35.85 \pm 0.06$ & $10.5 \pm 0.1$ & $63.8 \pm 0.5$ & $178.8 \pm 1.8$ \\
\hline
\end{tabular}

${ }^{a}$ Direct fitting of melts was used to determine $T_{m}$. Tripeptides in grey shown were treated identically and shown here for reference. ${ }^{b}$ Conditions: $2 \mu \mathrm{M}$ hybrid (1:1 bPNA:DNA), $100 \mathrm{mM} \mathrm{NaCl}, 10 \mathrm{mM}$ phosphate pH 7.5. N/A (Not applicable) indicates multimodal transitions observed throughout.

Table S2.4. Thermodynamic parameters of dipeptide bPNA hybrids with RNA r $\left(\mathrm{U}_{4} \mathrm{GUGAU}_{4}\right)^{a}$

\begin{tabular}{ccccc}
\hline $\mathrm{bPNA}$ & $\mathrm{T}_{\mathrm{m}}\left({ }^{\circ} \mathrm{C}\right)^{b}$ & $-\Delta \mathrm{G}(\mathrm{kcal} / \mathrm{mol})$ & $-\Delta \mathrm{H}(\mathrm{kcal} / \mathrm{mol})$ & $-\Delta \mathrm{S}(\mathrm{cal} / \mathrm{mol} \mathrm{K})$ \\
\hline $\mathrm{c}\left[\mathrm{K}^{2 \mathrm{M}}\right]_{2}$ & $28.1 \pm 0.2$ & $8.71 \pm 0.06$ & $55.0 \pm 2.6$ & $155.3 \pm 8.4$ \\
$\mathrm{~K}^{2 \mathrm{M}} \mathrm{k}^{2 \mathrm{M}}$ & $26.2 \pm 0.1$ & $8.4 \pm 0.1$ & $52.3 \pm 0.6$ & $147.3 \pm 2.1$ \\
$\mathrm{~K}^{2 \mathrm{M}} \mathrm{GlyK}^{2 \mathrm{M}}$ & $25.6 \pm 0.4$ & $8.3 \pm 0.1$ & $64.7 \pm 1.7$ & $188.9 \pm 0.3$ \\
$\mathrm{~K}^{2 \mathrm{M}} \beta \mathrm{BlaK}^{2 \mathrm{M}}$ & $25.4 \pm 0.5$ & $8.3 \pm 0.1$ & $55.0 \pm 1.4$ & $156.7 \pm 4.6$ \\
$\mathrm{~K}^{2 \mathrm{M} \mathrm{K}^{2 \mathrm{M}}}$ & $25.3 \pm 0.6$ & $8.3 \pm 0.1$ & $55.8 \pm 3.8$ & $159 \pm 12$ \\
$\mathrm{k}^{2 \mathrm{M}} \mathrm{K}^{2 \mathrm{M}}$ & $24.8 \pm 0.5$ & $8.1 \pm 0.1$ & $50.9 \pm 3.1$ & $143 \pm 10$ \\
$\mathrm{k}^{2 \mathrm{M}} \mathrm{k}^{2 \mathrm{M}}$ & $24.0 \pm 0.1$ & $8.0 \pm 0.1$ & $52.9 \pm 0.4$ & $150.5 \pm 1.4$ \\
$\mathrm{~K}^{2 \mathrm{M}} \mathrm{AlaK}^{2 \mathrm{M}}$ & $23.8 \pm 0.4$ & $8.1 \pm 0.1$ & $53.4 \pm 1.4$ & $151.9 \pm 4.7$ \\
$\mathrm{c}\left[\mathrm{K}^{2 \mathrm{M}} \mathrm{k}^{2 \mathrm{M}}\right]$ & $\mathrm{N} / \mathrm{A}$ & $\mathrm{N} / \mathrm{A}$ & $\mathrm{N} / \mathrm{A}$ & $\mathrm{N} / \mathrm{A}$ \\
\hline
\end{tabular}

${ }^{a}$ Direct fitting of melts was used to determine $\mathrm{T}_{\mathrm{m}}$. Tripeptides in grey shown were treated identically and shown here for reference. ${ }^{b}$ Conditions: $2 \mu \mathrm{M}$ hybrid (1:1 bPNA:RNA), $100 \mathrm{mM} \mathrm{NaCl}, 10 \mathrm{mM}$ phosphate $\mathrm{pH}$ 7.5. N/A

(Not applicable) indicates multimodal transitions observed throughout.

Table S2.5. bPNA hybridization with RNA, DNA and $(T \rightarrow U)$ DNA $^{a}$

\begin{tabular}{|c|c|c|c|c|c|c|}
\hline \multirow[b]{2}{*}{ Nucleic acid strand } & \multicolumn{3}{|c|}{$K^{2 M} A^{\prime a K} K^{2 M}$} & \multicolumn{3}{|c|}{$c\left[K^{2 M}\right]_{2}$} \\
\hline & $\mathrm{T}_{\mathrm{m}}\left({ }^{\circ} \mathrm{C}\right)$ & $\begin{array}{c}-\Delta G_{25} \\
(\mathrm{kcal} / \mathrm{mol})^{b}\end{array}$ & $\begin{array}{c}-\Delta \mathrm{G}_{37} \\
(\mathrm{kcal} / \mathrm{mol})\end{array}$ & $\mathrm{T}_{\mathrm{m}}\left({ }^{\circ} \mathrm{C}\right)$ & $\begin{array}{c}-\Delta \mathrm{G}_{25} \\
(\mathrm{kcal} / \mathrm{mol})\end{array}$ & $\begin{array}{c}-\Delta \mathrm{G}_{37} \\
(\mathrm{kcal} / \mathrm{mol})\end{array}$ \\
\hline 5'-r(UUUUCCCCUUUU)-3' & $14.8 \pm 0.6$ & $6.5 \pm 0.1$ & $5.0 \pm 0.2$ & $19.6 \pm 0.6$ & $7.2 \pm 0.1$ & $5.6 \pm 0.1$ \\
\hline 5'-d(UUUUCCCCUUUU)-3' & $21.4 \pm 0.9$ & $7.8 \pm 0.1$ & $6.2 \pm 0.1$ & $34.1 \pm 0.8$ & $10.3 \pm 0.2$ & $8.0 \pm 0.1$ \\
\hline 5'-d(UUUUCCCCTTTT)-3' & $30.1 \pm 0.4$ & $9.2 \pm 0.1$ & $7.2 \pm 0.1$ & $41.5 \pm 0.2$ & $11.6 \pm 0.1$ & $9.4 \pm 0.1$ \\
\hline 5'-d(UUTTCCCCTTUU)-3' & $31.2 \pm 0.5$ & $9.5 \pm 0.1$ & $7.4 \pm 0.1$ & $40.7 \pm 0.7$ & $11.3 \pm 0.4$ & $9.3 \pm 0.2$ \\
\hline 5'-d(TTTTCCССТTTT)-3' & $39.4 \pm 0.3$ & $11.0 \pm 0.1$ & $8.9 \pm 0.1$ & $47.3 \pm 0.5$ & $12.5 \pm 0.1$ & $10.5 \pm 0.1$ \\
\hline
\end{tabular}

${ }^{a}$ Direct fitting of melts was used to determine $\mathrm{T}_{\mathrm{m}}$. Conditions: $2 \mu \mathrm{M}$ hybrid (1:1 bPNA:RNA or DNA), $100 \mathrm{mM} \mathrm{NaCl,} 10 \mathrm{mM}$ phosphate $\mathrm{pH}$ 7.5. N/A. $\Delta \mathrm{G}$ calculated at $25^{\circ} \mathrm{C}$ and $37^{\circ} \mathrm{C}$. 


\section{S3. Raw melt data}

For all graphs, increasing concentrations $(2,3.5,5,7.5,10,15,20$ and $25 \mu \mathrm{M})$ of 1:1 bPNA hybrids are shown overlaid, with $2 \mu \mathrm{M}$ sample trace shown in bold for reference.

Table S3.1. Melts and first derivative plots of tripeptide bPNA hybrids with DNA d $\left(T_{4} C_{4} T_{4}\right)^{a}$

bPNA tripeptides

$\mathrm{K}^{2 \mathrm{M}} \mathrm{AlaK}^{2 \mathrm{M}}$

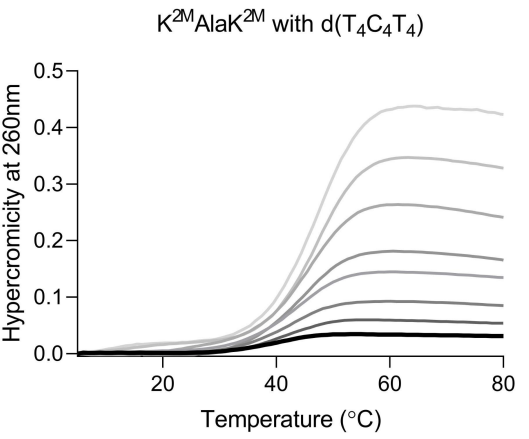

$\mathrm{K}^{2 \mathrm{M}} \mathrm{BAlaK}^{2 \mathrm{M}}$

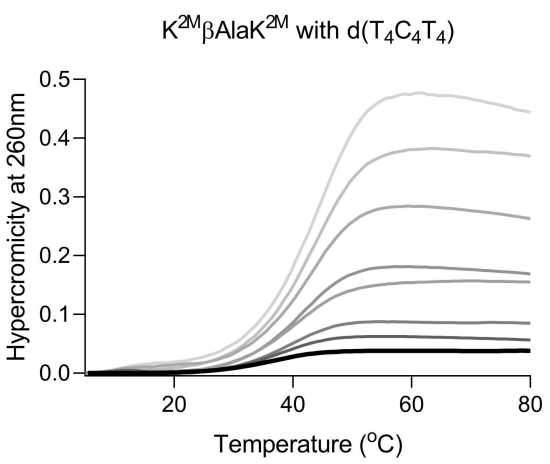

$\mathrm{K}^{2 \mathrm{M}} \mathrm{GlyK}^{2 \mathrm{M}}$

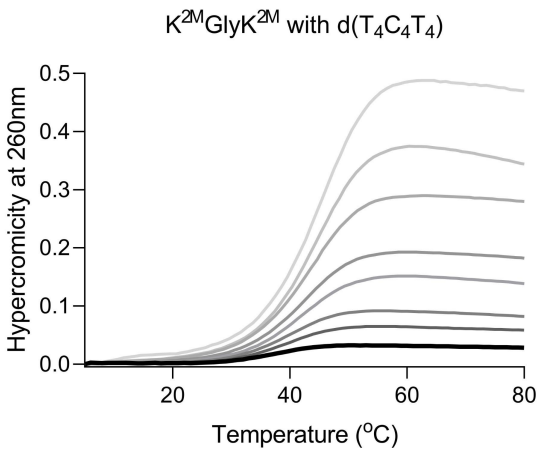

$\mathrm{K}^{2 \mathrm{M}} \| \mathrm{leK} \mathrm{K}^{2 \mathrm{M}}$

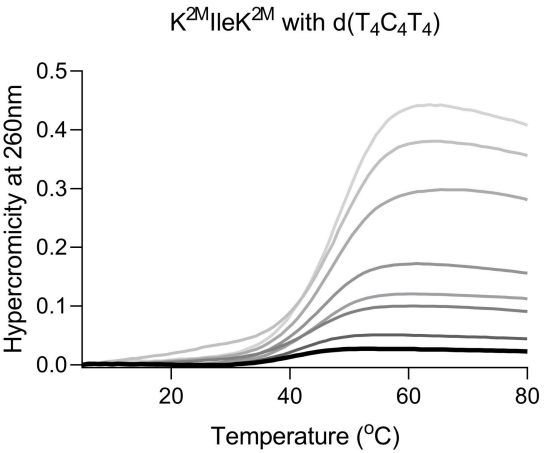

\section{1st derivative}

Table S3.1 cont'd

$\mathrm{K}^{2 \mathrm{M}}$ LeuK $^{2 \mathrm{M}}$

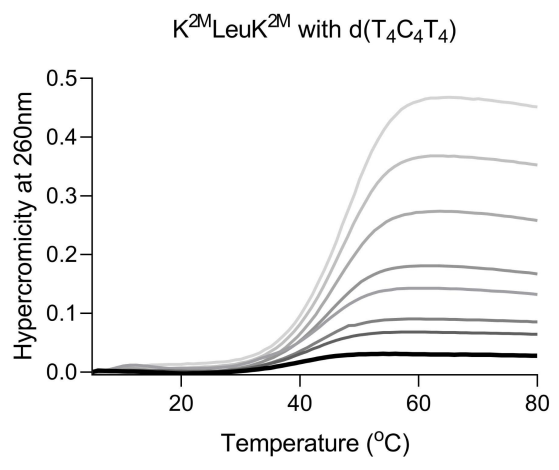

$\mathrm{K}^{2 \mathrm{M}}$ LysK $^{2 \mathrm{M}}$



$\mathrm{K}^{2 \mathrm{M}} \mathrm{PheK}^{2 \mathrm{M}}$

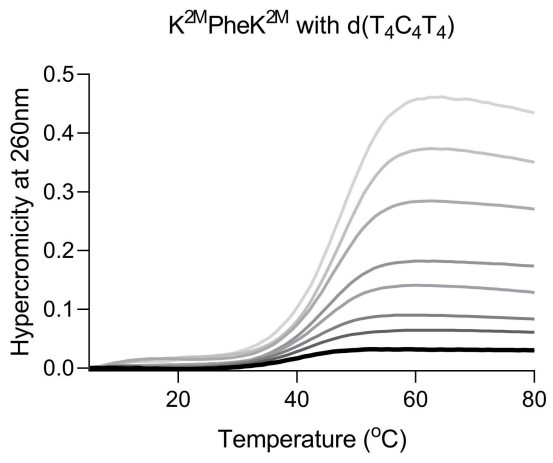

$\mathrm{K}^{2 \mathrm{M}} \operatorname{ProK}^{2 \mathrm{M}}$

$\mathrm{K}^{2 \mathrm{M}} \mathrm{ProK}^{2 \mathrm{M}}$ with $\mathrm{d}\left(\mathrm{T}_{4} \mathrm{C}_{4} \mathrm{~T}_{4}\right)$

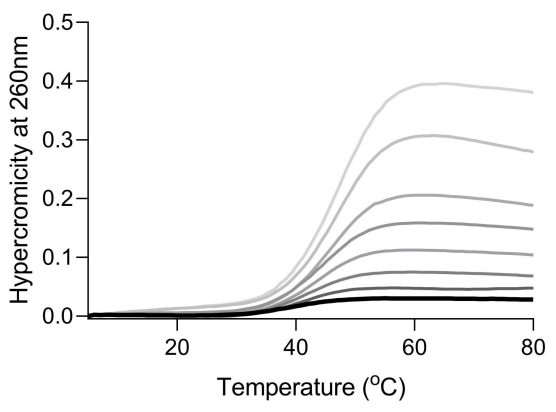

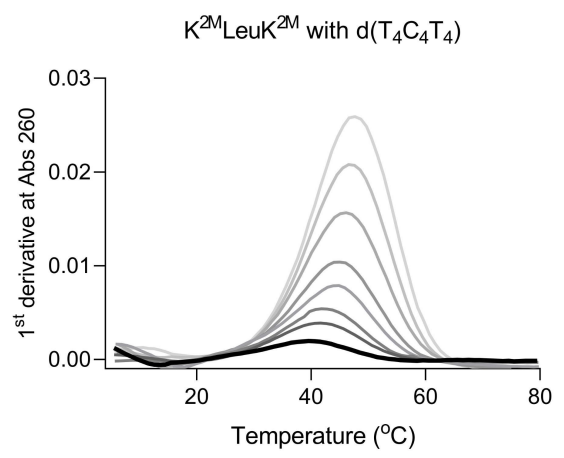
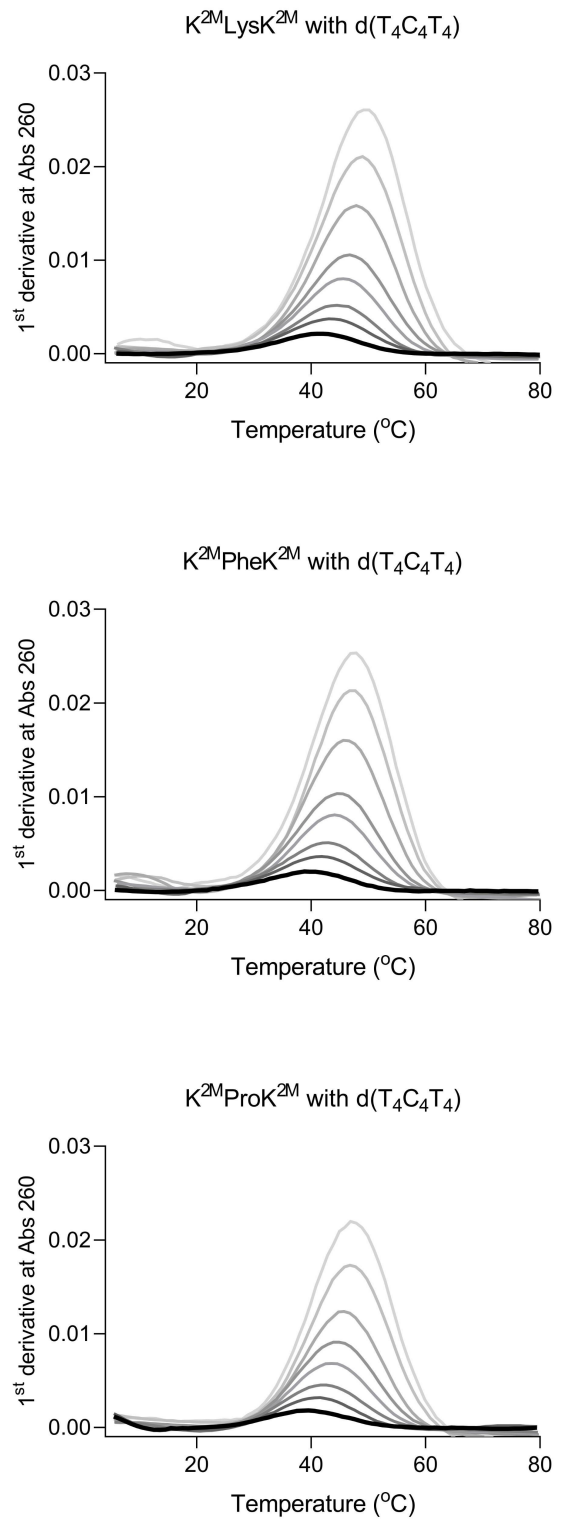
Table S3.1 cont'd

$\mathrm{K}^{2 \mathrm{M}} \operatorname{SerK}^{2 \mathrm{M}}$

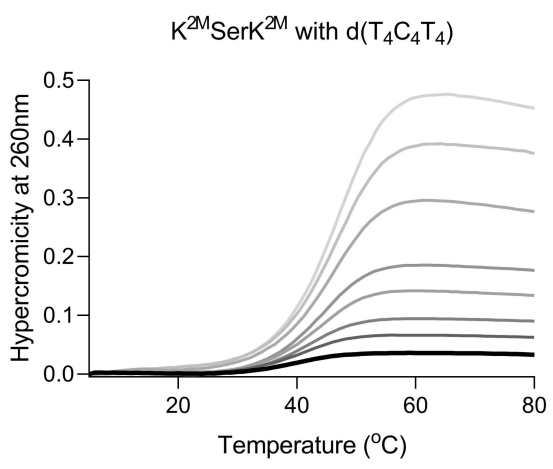

$\mathrm{K}^{2 \mathrm{M}} \mathrm{tBuGlyK} \mathrm{K}^{2 \mathrm{M}}$

$\mathrm{K}^{2 \mathrm{M}} \mathrm{ThrK}^{2 \mathrm{M}}$

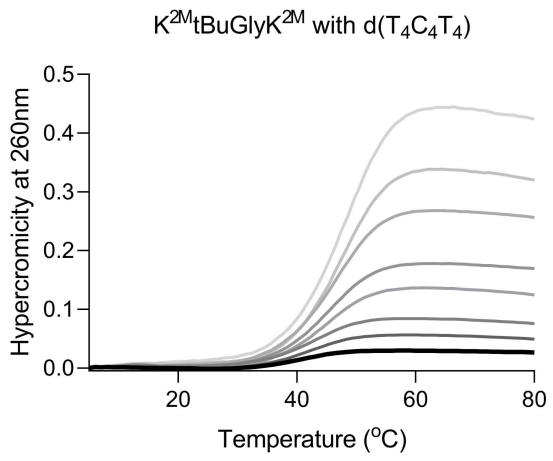

$\mathrm{K}^{2 \mathrm{M}} \mathrm{ThrK}^{2 \mathrm{M}}$ with $\mathrm{d}\left(\mathrm{T}_{4} \mathrm{C}_{4} \mathrm{~T}_{4}\right)$

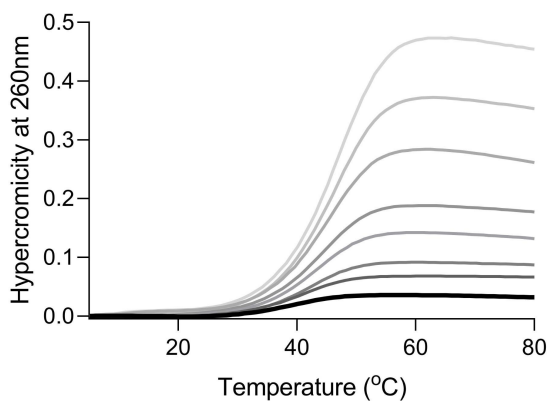

$\mathrm{K}^{2 \mathrm{M}} \operatorname{TrpK}^{2 \mathrm{M}}$

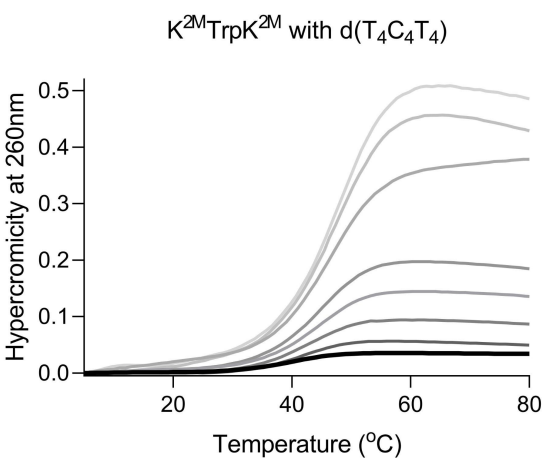



Table S3.1 cont'd $\mathrm{K}^{2 \mathrm{M}} \mathrm{TyrK}^{2 \mathrm{M}}$



$\mathrm{K}^{2 \mathrm{M}} \operatorname{ValK}^{2 \mathrm{M}}$



$\mathrm{K}^{2 \mathrm{M}} \mathrm{TyrK}^{2 \mathrm{M}}$ with $\mathrm{d}\left(\mathrm{T}_{4} \mathrm{C}_{4} \mathrm{~T}_{4}\right)$
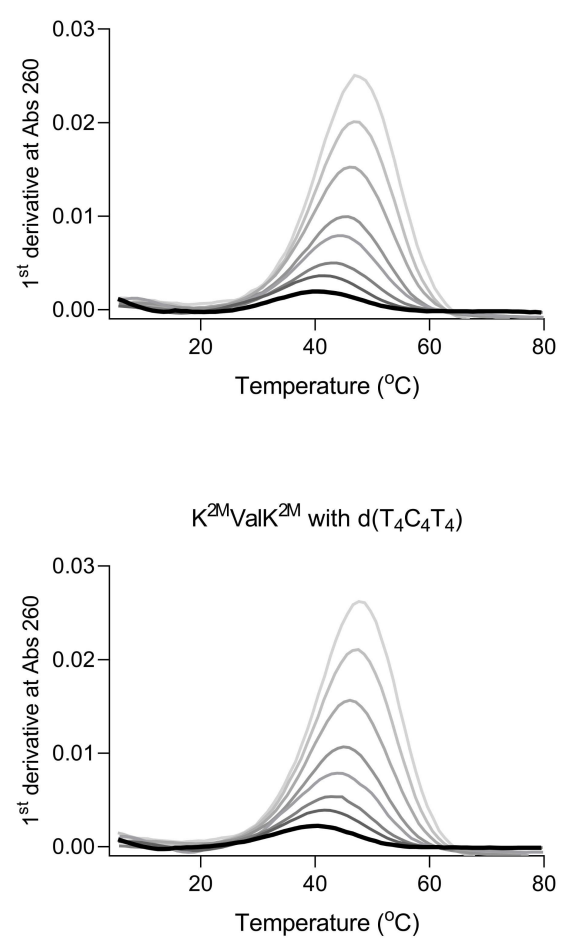

${ }^{a}$ Increasing concentrations $(2,3.5,5,7.5,10,15,20$ and $25 \mu \mathrm{M})$ of $1: 1 \mathrm{bPNA}$ hybrids shown overlaid, with $2 \mu \mathrm{M}$ sample trace shown in bold for reference 
Table S3.2. Melts and first derivative plots of tripeptide bPNA hybrids with $\mathrm{rU}_{4} \mathrm{GUGAU}_{4}{ }^{a}$

bPNA

\section{$\mathrm{K}^{2 \mathrm{M}} \mathrm{AlaK}^{2 \mathrm{M}}$}



$\mathrm{K}^{2 \mathrm{M}} \mathrm{BAlaK}^{2 \mathrm{M}}$

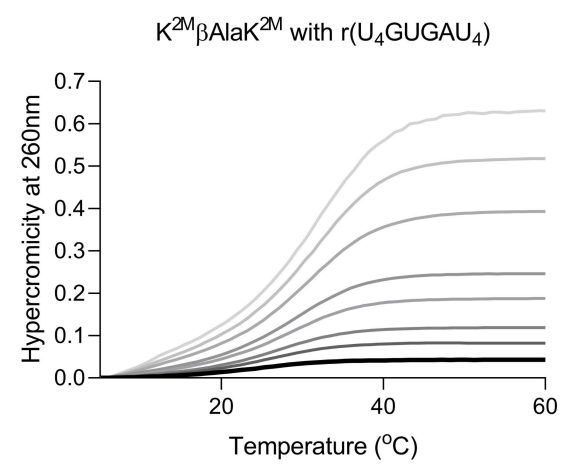

$\mathrm{K}^{2 \mathrm{M}} \mathrm{GlyK}^{2 \mathrm{M}}$

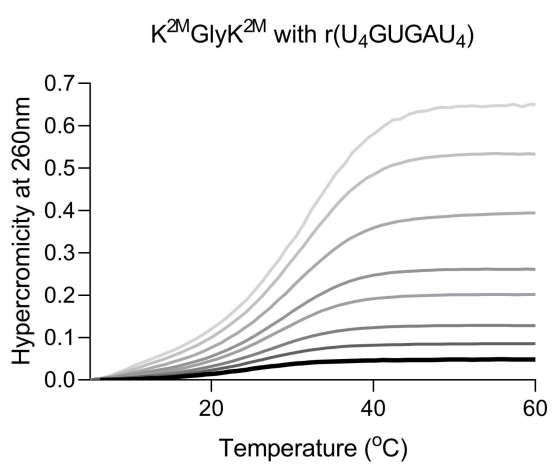

$\mathrm{K}^{2 \mathrm{M}} \mathrm{IleK} \mathrm{K}^{2 \mathrm{M}}$

$\mathrm{K}^{2 \mathrm{M}} \mathrm{IleK}^{2 \mathrm{M}}$ with $\mathrm{r}\left(\mathrm{U}_{4} \mathrm{GUGAU}_{4}\right)$



1st derivative

$\mathrm{K}^{2 \mathrm{M}} \mathrm{AlaK}^{2 \mathrm{M}}$ with $\mathrm{r}\left(\mathrm{U}_{4} \mathrm{GUGAU}_{4}\right)$

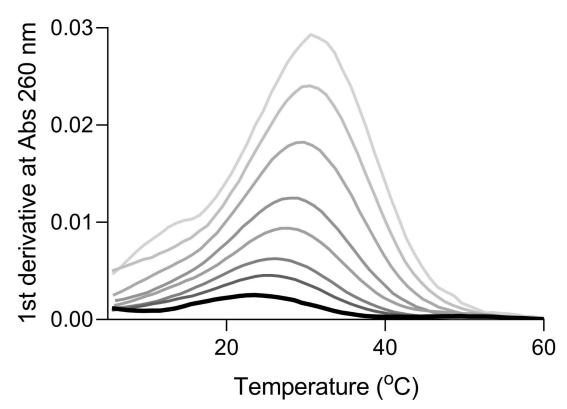

$\mathrm{K}^{2 \mathrm{M}} \mathrm{BAlaK}^{2 \mathrm{M}}$ with $\mathrm{r}\left(\mathrm{U}_{4} \mathrm{GUGAU}_{4}\right)$
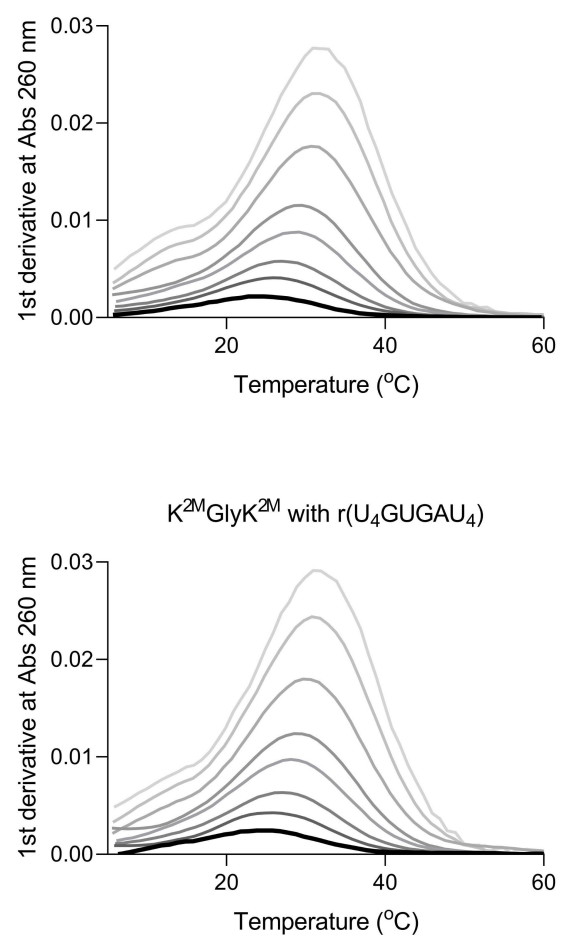

$\mathrm{K}^{2 \mathrm{M}} \mathrm{IleK}^{2 \mathrm{M}}$ with $\mathrm{r}\left(\mathrm{U}_{4} \mathrm{GUGAU}_{4}\right)$




Table S3.2.cont'd

bPNA

$\mathrm{K}^{2 \mathrm{M}}$ LysK $^{2 \mathrm{M}}$

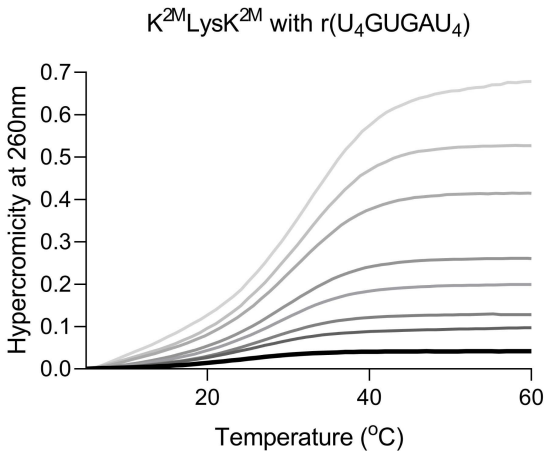

$\mathrm{K}^{2 \mathrm{M}} \mathrm{PheK}^{2 \mathrm{M}}$

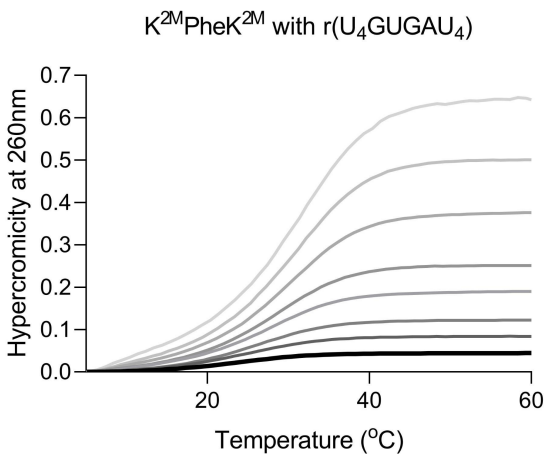

$\mathrm{K}^{2 \mathrm{M}} \operatorname{ProK}^{2 \mathrm{M}}$

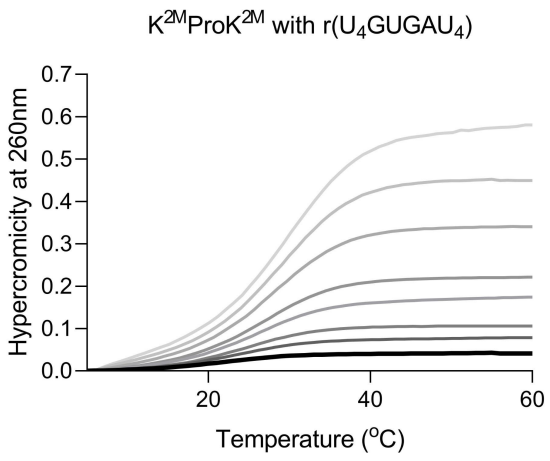

$\mathrm{K}^{2 \mathrm{M}} \operatorname{SerK}^{2 \mathrm{M}}$

$\mathrm{K}^{2 \mathrm{M}} \mathrm{SerK}^{2 \mathrm{M}}$ with $\mathrm{r}\left(\mathrm{U}_{4} \mathrm{GUGAU}_{4}\right)$

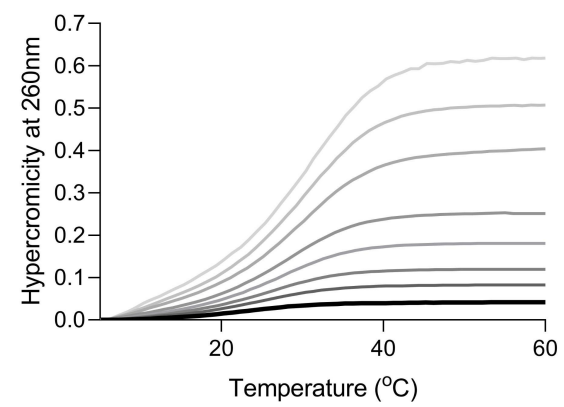

1st derivative

$\mathrm{K}^{2 \mathrm{M}} \mathrm{LysK}^{2 \mathrm{M}}$ with $\mathrm{r}\left(\mathrm{U}_{4} \mathrm{GUGAU}_{4}\right)$
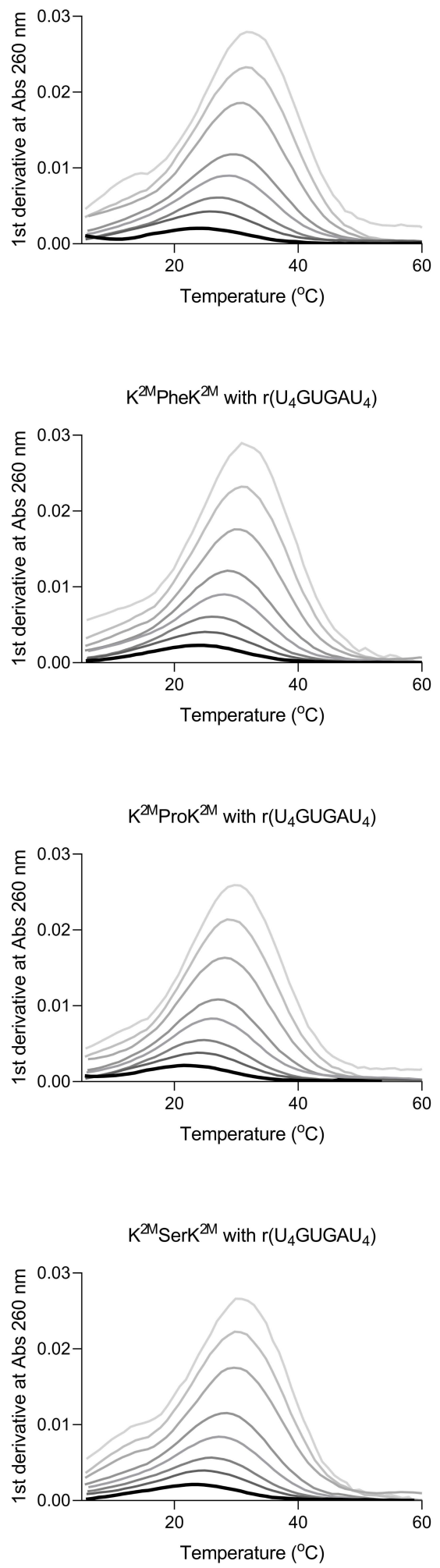
Table S3.2.cont'd

$\mathrm{K}^{2 \mathrm{M}} \mathrm{tBuGlyK}^{2 \mathrm{M}}$

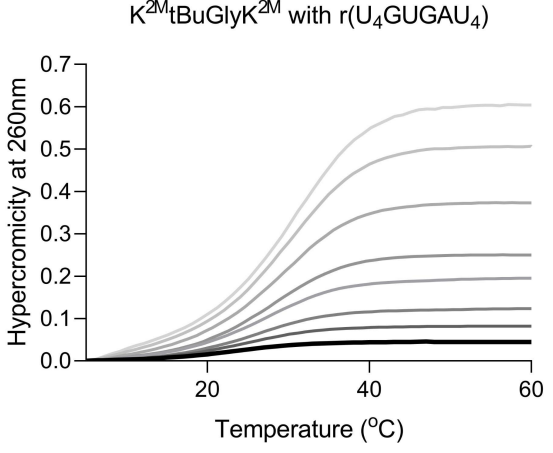

$\mathrm{K}^{2 \mathrm{M}} \mathrm{ThrK}^{2 \mathrm{M}}$

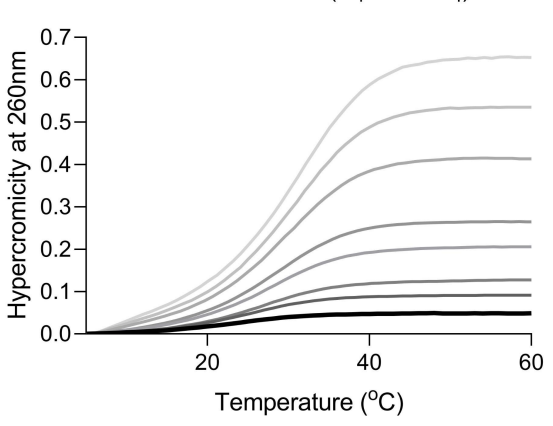

$\mathrm{K}^{2 \mathrm{M}} \operatorname{TrpK}^{2 \mathrm{M}}$

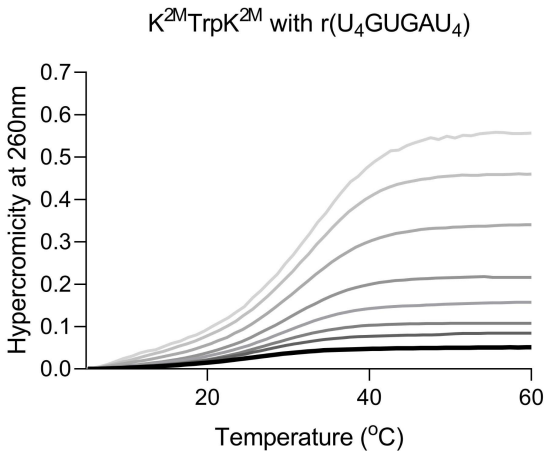

$\mathrm{K}^{2 \mathrm{M}} \mathrm{TyrK}^{2 \mathrm{M}}$

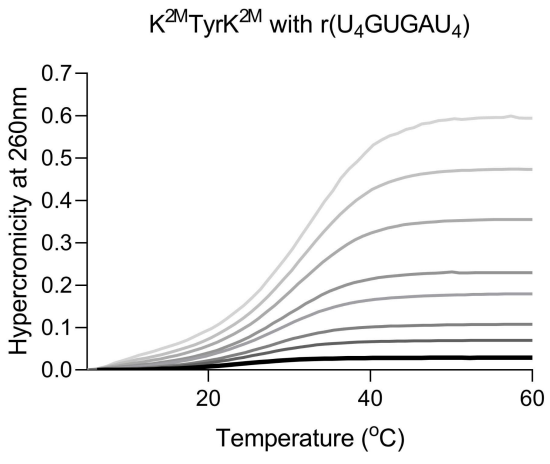

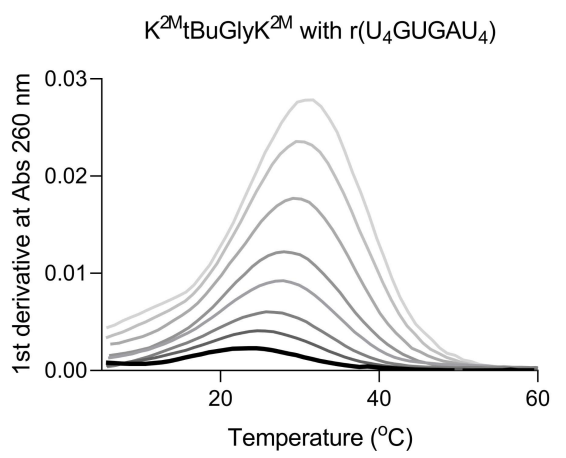
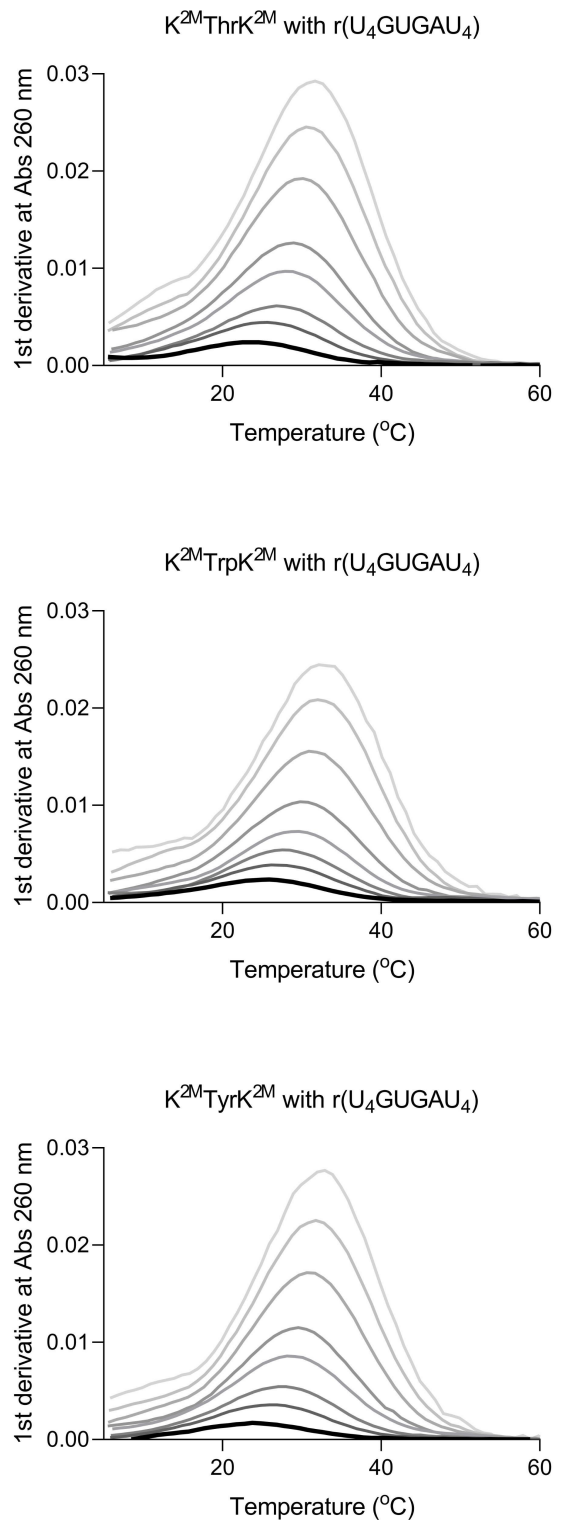
Table S3.2. cont'd

$$
\mathrm{K}^{2 \mathrm{M}} \mathrm{ValK}^{2 \mathrm{M}} \text { with } \mathrm{r}\left(\mathrm{U}_{4} \mathrm{GUGAU}_{4}\right)
$$

$\mathrm{K}^{2 \mathrm{M}}$ ValK $^{2 \mathrm{M}}$



$\mathrm{K}^{2 \mathrm{M}}$ ValK $^{2 \mathrm{M}}$ with $\mathrm{r}\left(\mathrm{U}_{4} \mathrm{GUGAU}_{4}\right)$

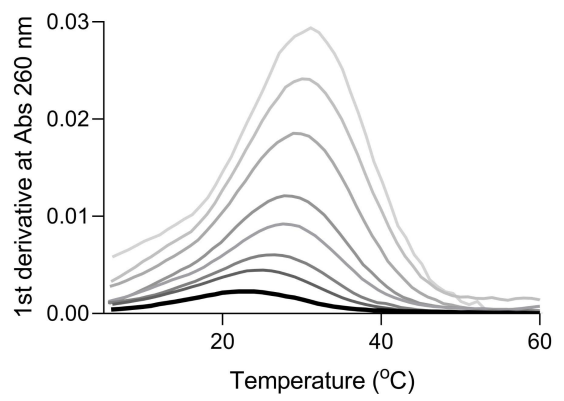

ancreasing concentrations $(2,3.5,5,7.5,10,15,20$ and $25 \mu \mathrm{M})$ of 1:1 bPNA hybrids shown overlaid, with $2 \mu \mathrm{M}$ sample trace shown in bold for reference 
Table S3.3 Melts and first derivative plots of dipeptide bPNA hybrids with DNA d $\left(\mathrm{T}_{4} \mathrm{C}_{4} \mathrm{~T}_{4}\right)^{a}$

$\mathrm{K}^{2 \mathrm{M}} \mathrm{K}^{2 \mathrm{M}}$

$\mathrm{K}^{2 \mathrm{M}} \mathrm{K}^{2 \mathrm{M}}$ with $\mathrm{d}\left(\mathrm{T}_{4} \mathrm{C}_{4} \mathrm{~T}_{4}\right)$

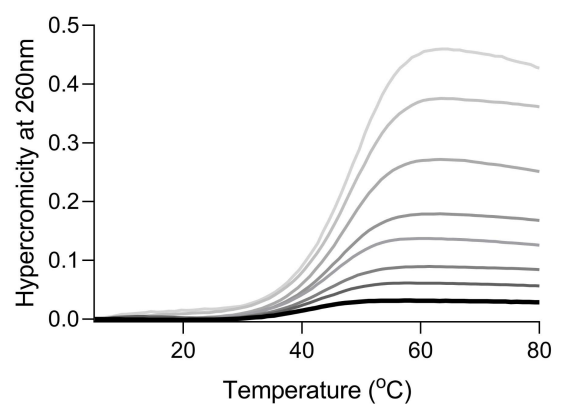

$c\left[\mathrm{~K}^{2 \mathrm{M}}\right]_{2}$

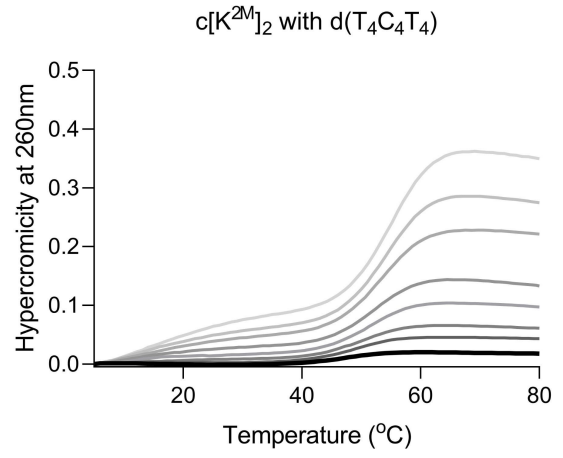

$\mathrm{K}^{2 \mathrm{M}} \mathrm{k}^{2 \mathrm{M}}$

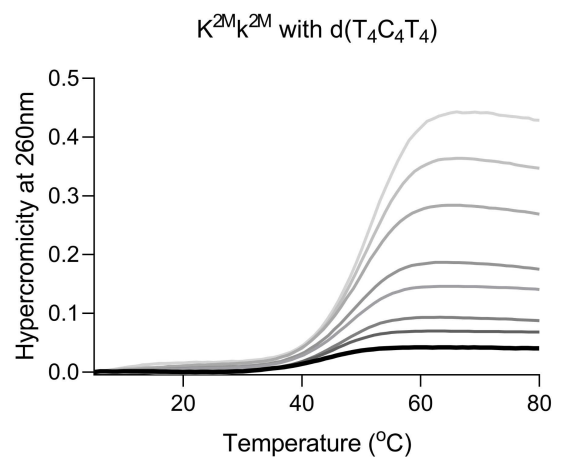

$\mathrm{k}^{2 \mathrm{M}} \mathrm{K}^{2 \mathrm{M}}$

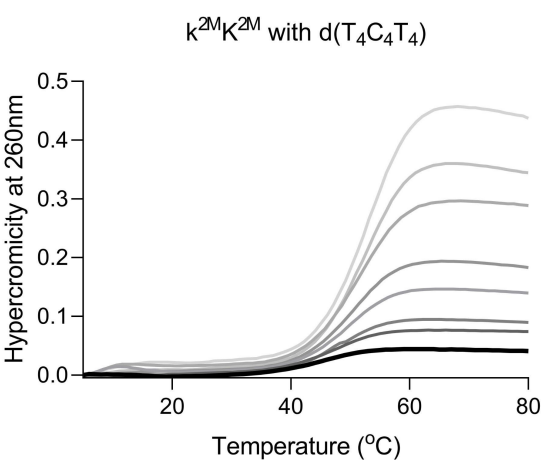

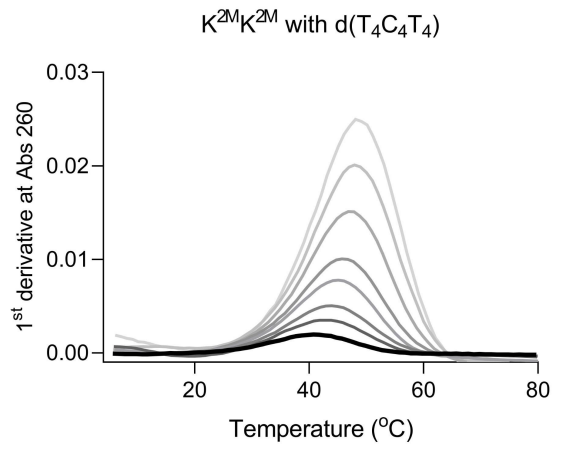
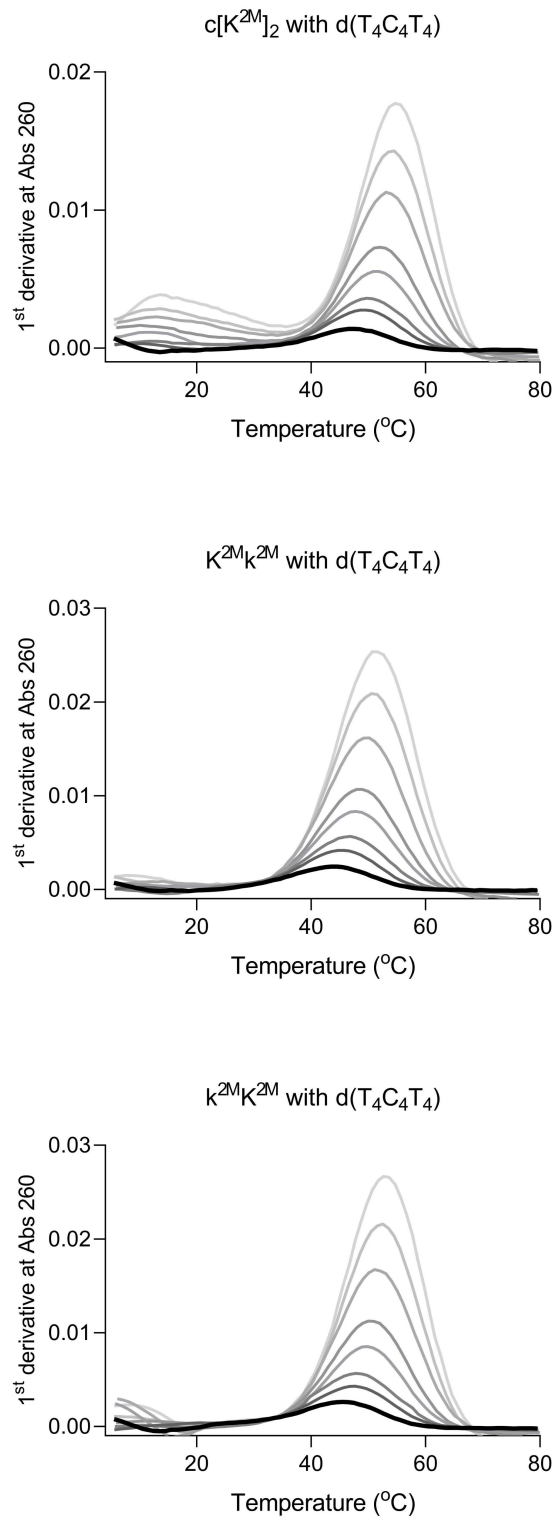

ancreasing concentrations $(2,3.5,5,7.5,10,15,20$ and $25 \mu \mathrm{M})$ of 1:1 bPNA hybrids shown overlaid, with $2 \mu \mathrm{M}$ sample trace shown in bold for reference 
Table S3.3 cont'd

$$
k^{2 M} k^{2 M}
$$

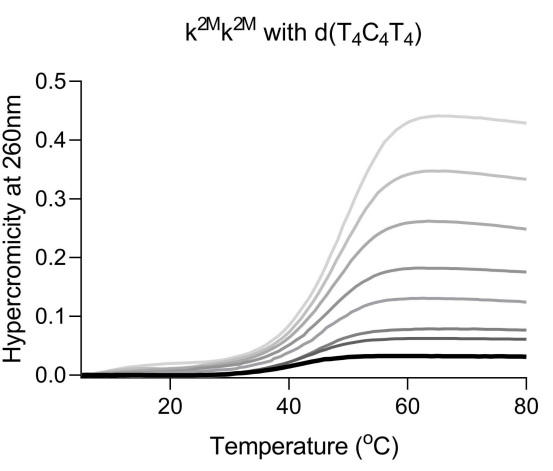

$c\left[\mathrm{~K}^{2 \mathrm{M}} \mathrm{k}^{2 \mathrm{M}}\right]$

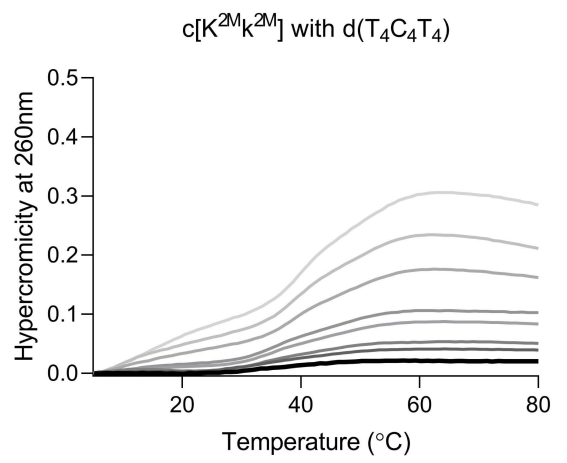

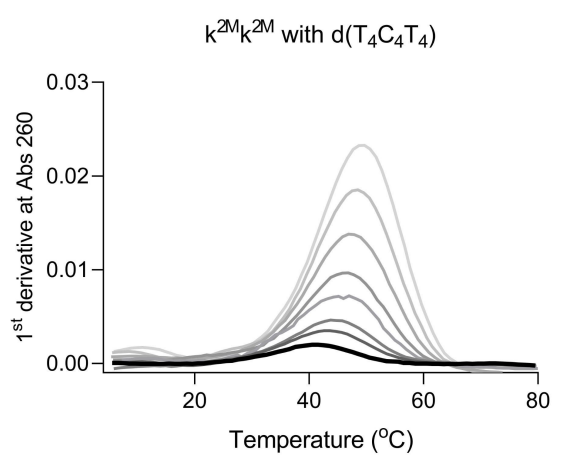

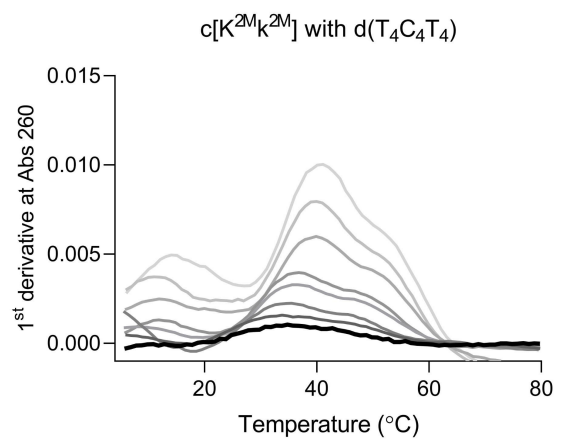

Increasing concentrations $(2,3.5,5,7.5,10,15,20$ and $25 \mu \mathrm{M})$ of $1: 1 \mathrm{bPNA}$ hybrids shown overlaid, with $2 \mu \mathrm{M}$ sample trace shown in bold for reference. $\mathrm{D}, \mathrm{L}$ diketopiperazine $c\left[\mathrm{~K}^{2 \mathrm{M}} \mathrm{k}^{2 \mathrm{M}}\right]$ exhibits multimodal transitions and was not used in van't Hoff analysis. 
Table S3.4. Melts and first derivative plots of dipeptide bPNA hybrids with RNA rU $\mathrm{GUGAU}_{4}{ }^{a}$

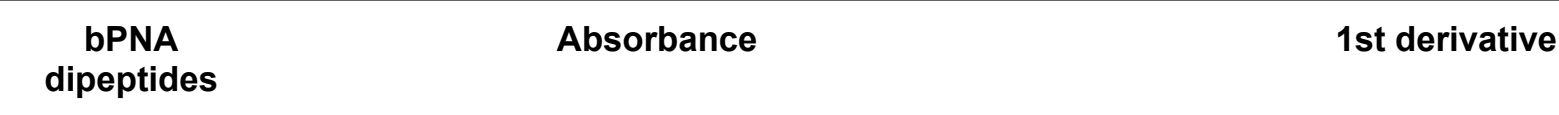

$\mathrm{K}^{2 \mathrm{M}} \mathrm{K}^{2 \mathrm{M}}$

$\mathrm{K}^{2 \mathrm{M}} \mathrm{K}^{2 \mathrm{M}}$ with $\mathrm{r}\left(\mathrm{U}_{4} \mathrm{GUGAU}_{4}\right)$

$\mathrm{K}^{2 \mathrm{M}} \mathrm{K}^{2 \mathrm{M}}$ with $\mathrm{r}\left(\mathrm{U}_{4} \mathrm{GUGAU}_{4}\right)$
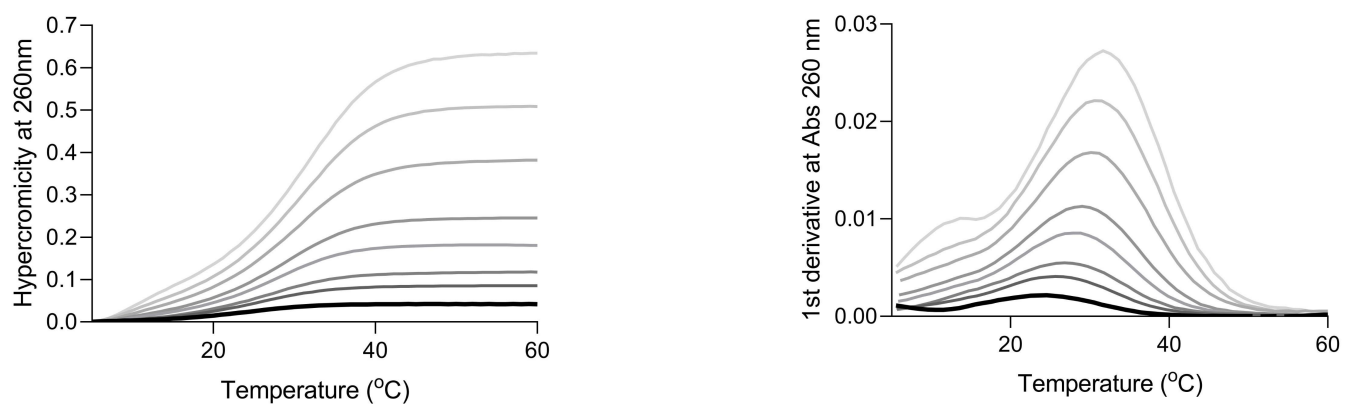

$c\left[\mathrm{~K}^{2 \mathrm{M}}\right]_{2}$

$c\left[\mathrm{~K}^{2 \mathrm{M}}\right]_{2}$ with $\mathrm{r}\left(\mathrm{U}_{4} \mathrm{GUGAU} \mathrm{U}_{4}\right)$
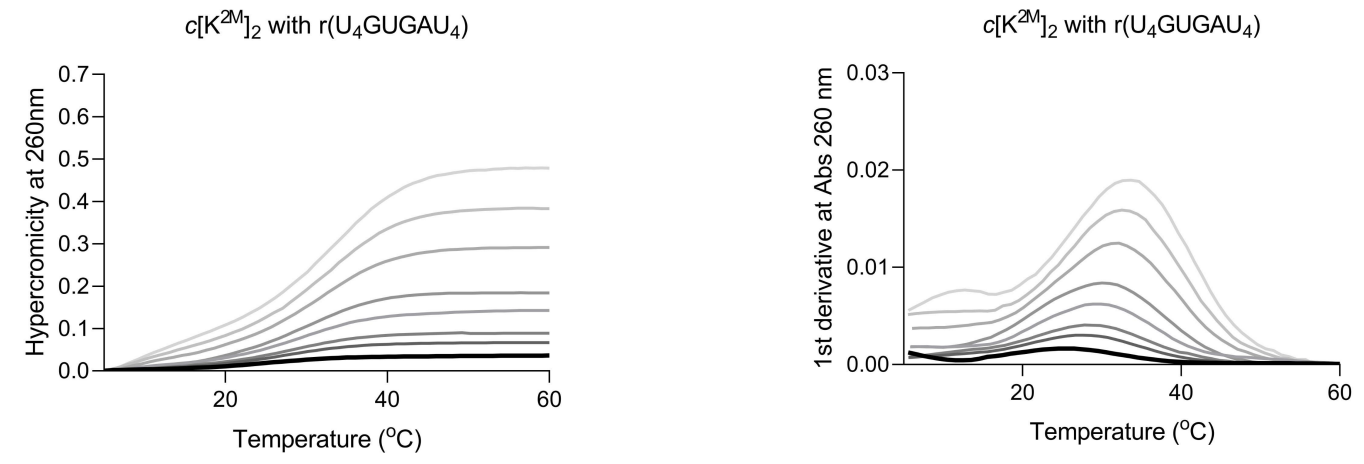

$\mathrm{K}^{2 \mathrm{M}} \mathrm{K}^{2 \mathrm{M}}$

$\mathrm{K}^{2 \mathrm{M}} \mathrm{k}^{2 \mathrm{M}}$ with $\mathrm{r}\left(\mathrm{U}_{4} \mathrm{GUGAU}_{4}\right)$
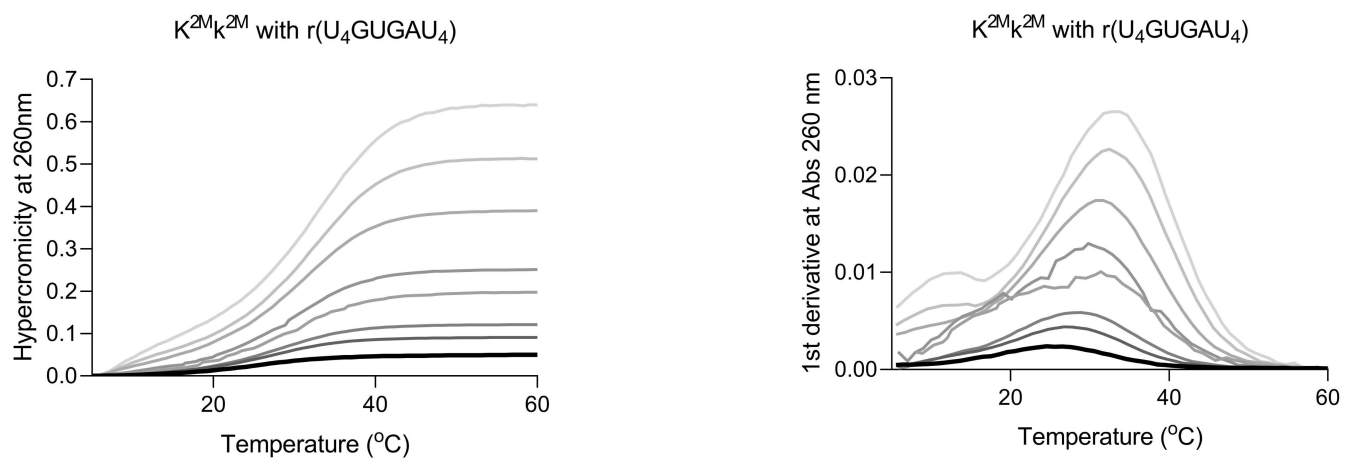

$\mathrm{k}^{2 \mathrm{M}} \mathrm{K}^{2 \mathrm{M}}$
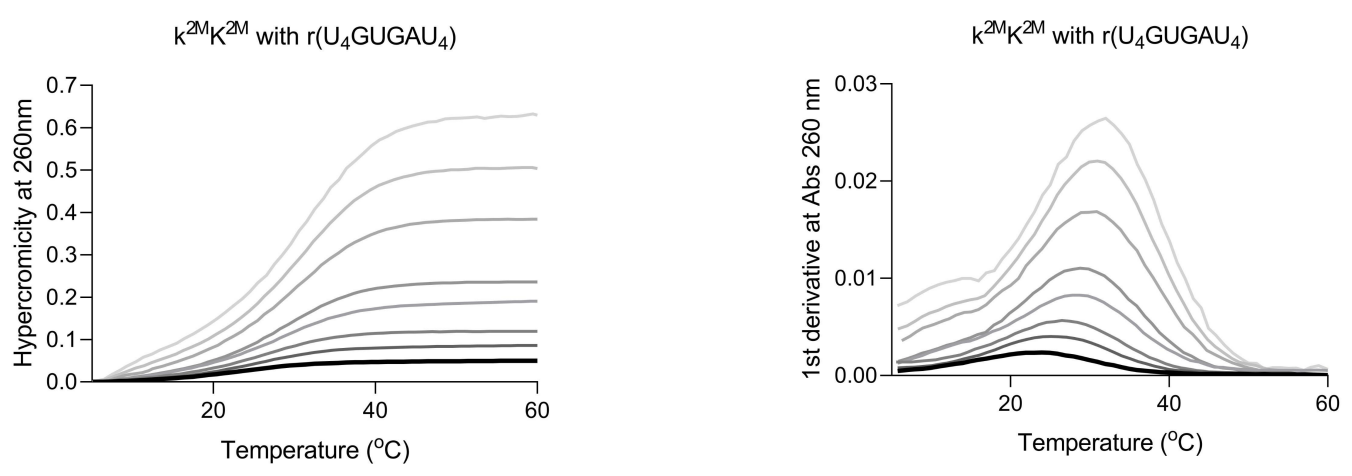
Table 3.4 cont'd

$\mathrm{k}^{2 \mathrm{M}} \mathrm{k}^{2 \mathrm{M}}$ with $\mathrm{r}\left(\mathrm{U}_{4} \mathrm{GUGAU}_{4}\right)$

$\mathrm{k}^{2 \mathrm{M}} \mathrm{k}^{2 \mathrm{M}}$
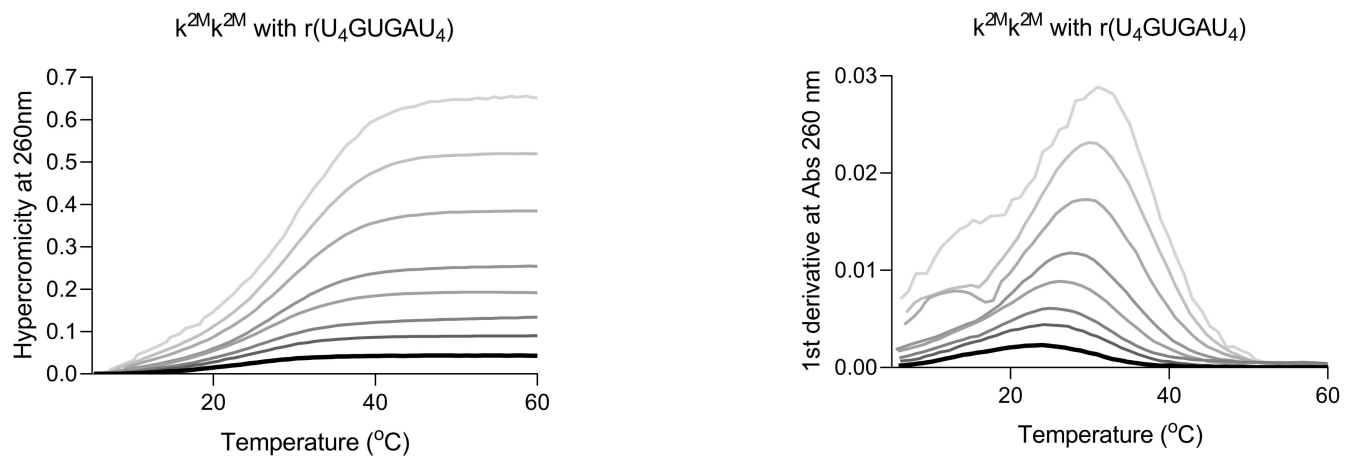

ancreasing concentrations $(2,3.5,5,7.5,10,15,20$ and $25 \mu \mathrm{M})$ of 1:1 bPNA hybrids shown overlaid, with $2 \mu \mathrm{M}$ sample trace shown in bold for reference. 
Table S3.5. Melts and 1st derivatives of $\mathrm{K}^{2 \mathrm{M}} \mathrm{AlaK}^{2 \mathrm{M}}$ hybrid with $\mathrm{r}\left(\mathrm{U}_{4} \mathrm{C}_{4} \mathrm{U}_{4}\right)$ and $\mathrm{T} \rightarrow \mathrm{U}$ DNAs

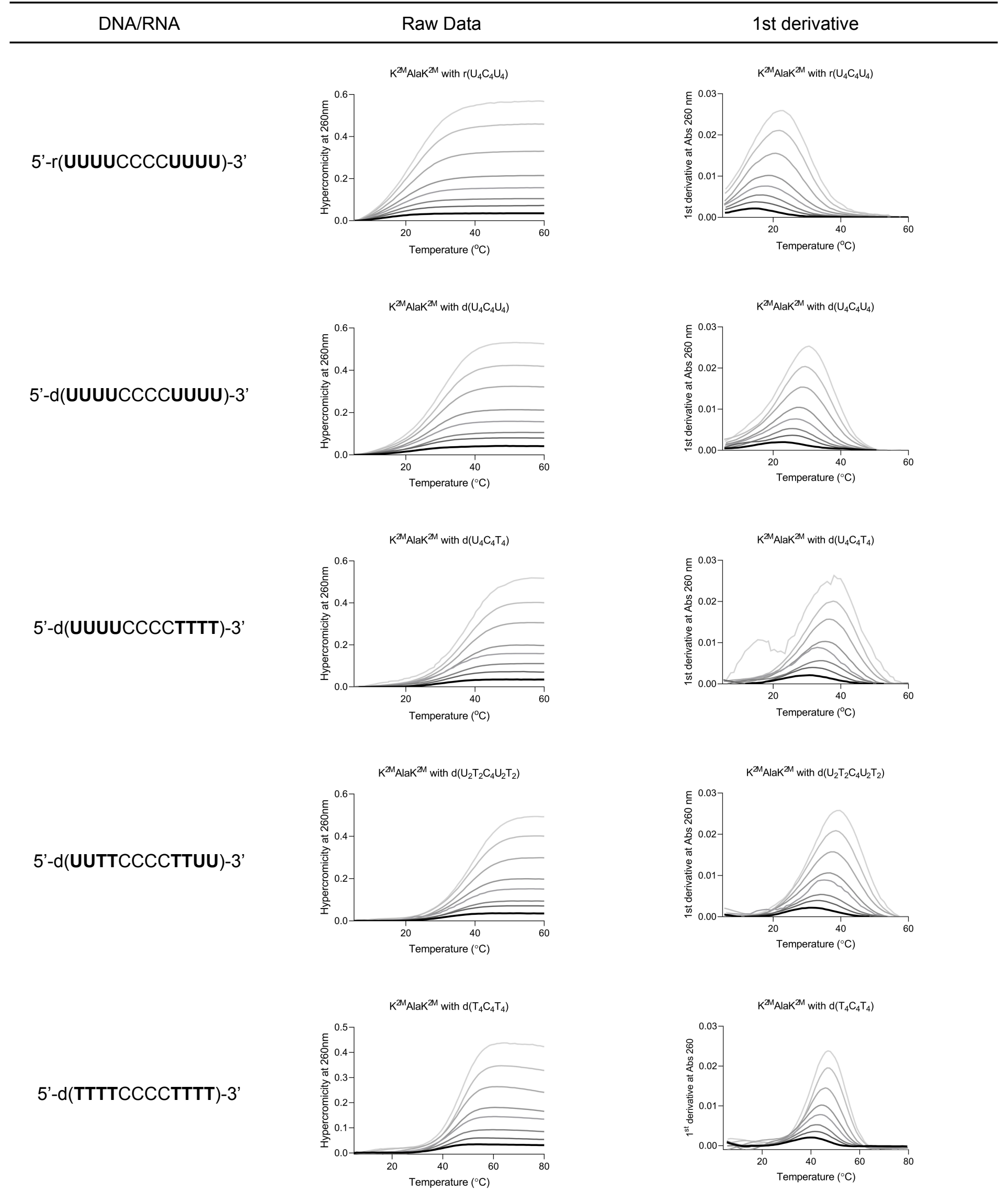


$\underline{\text { Table S3.6. Melts and 1st derivatives of } c\left[\mathrm{~K}^{2 \mathrm{M}}\right]_{2} \text { hybrid with } r\left(\mathrm{U}_{4} \mathrm{C}_{4} \mathrm{U}_{4}\right) \text { and } \mathrm{T} \rightarrow \mathrm{U} \text { DNAs }}$

\section{5'-r(UUUUCCCCUUUU)-3'}

5'-d(UUUUCCCCUUUU)-3'
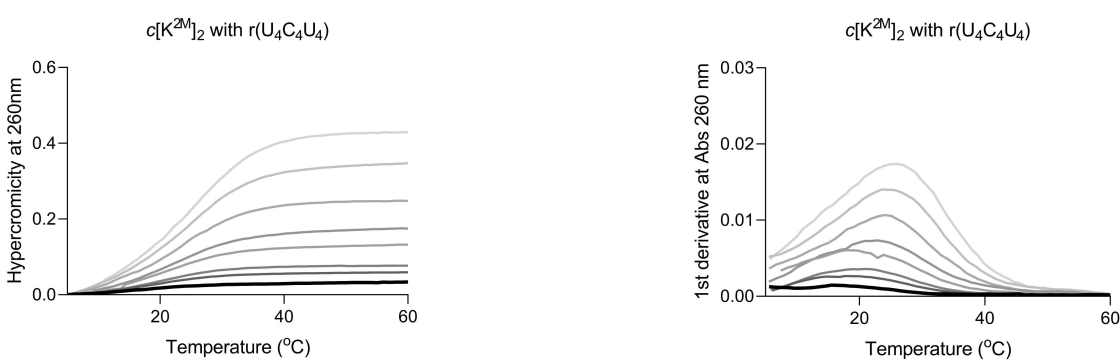

$c\left[\mathrm{~K}^{2 \mathrm{M}}\right]_{2}$ with $\mathrm{d}\left(\mathrm{U}_{4} \mathrm{C}_{4} \mathrm{U}_{4}\right)$

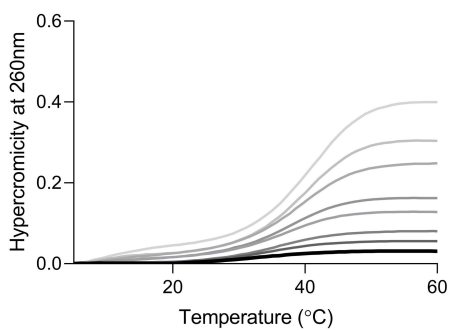

$c\left[\mathrm{~K}^{2 \mathrm{M}}\right]_{2}$ with $\mathrm{d}\left(\mathrm{U}_{4} \mathrm{C}_{4} \mathrm{~T}_{4}\right)$

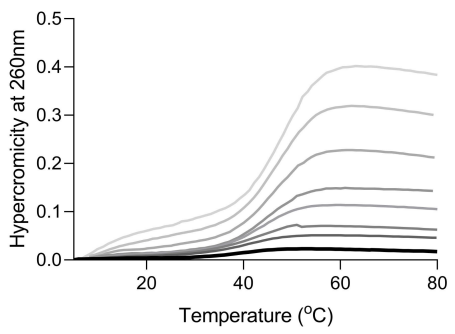

$c\left[\mathrm{~K}^{2 \mathrm{M}}\right]_{2}$ with $\mathrm{d}\left(\mathrm{U}_{2} \mathrm{~T}_{2} \mathrm{C}_{4} \mathrm{U}_{2} \mathrm{~T}_{2}\right)$

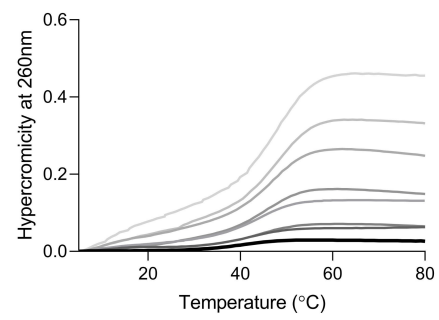

$\mathrm{c}\left[\mathrm{K}^{2 \mathrm{M}}\right]_{2}$ with $\mathrm{d}\left(\mathrm{T}_{4} \mathrm{C}_{4} \mathrm{~T}_{4}\right)$

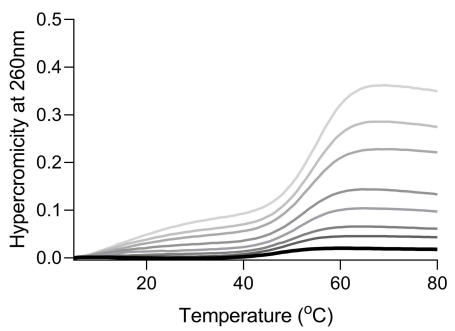

$c\left[\mathrm{~K}^{2 \mathrm{M}}\right]_{2}$ with $\mathrm{d}\left(\mathrm{U}_{4} \mathrm{C}_{4} \mathrm{U}_{4}\right)$

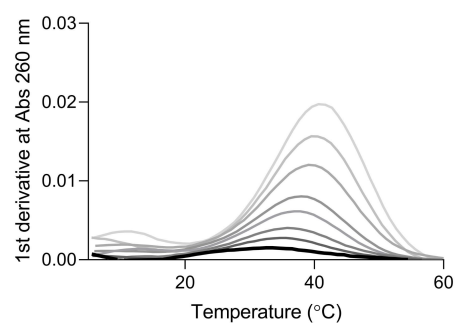

$c\left[\mathrm{~K}^{2 \mathrm{M}}\right]_{2}$ with $\mathrm{d}\left(\mathrm{U}_{4} \mathrm{C}_{4} \mathrm{~T}_{4}\right)$

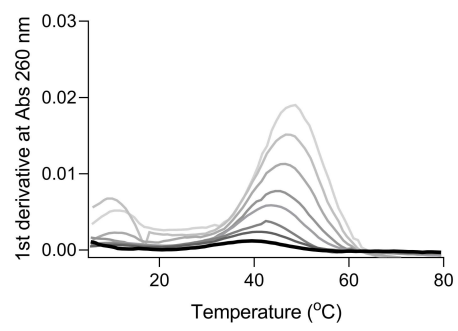

$c\left[\mathrm{~K}^{2 \mathrm{M}}\right]_{2}$ with $\mathrm{d}\left(\mathrm{U}_{2} \mathrm{~T}_{2} \mathrm{C}_{4} \mathrm{U}_{2} \mathrm{~T}_{2}\right)$

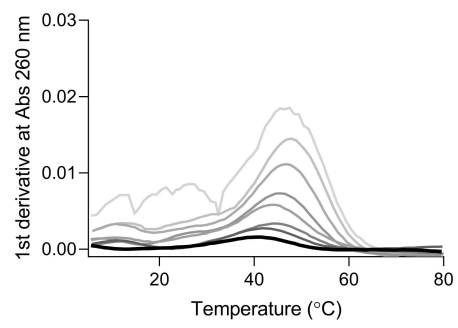

$c\left[\mathrm{~K}^{2 \mathrm{M}}\right]_{2}$ with $\mathrm{d}\left(\mathrm{T}_{4} \mathrm{C}_{4} \mathrm{~T}_{4}\right)$

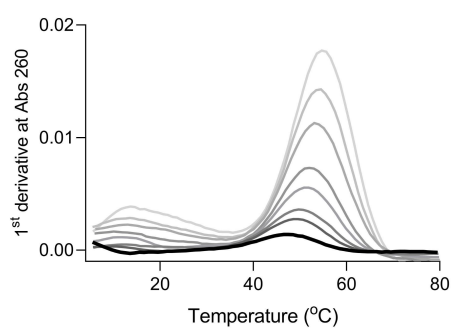

* $2 \mu \mathrm{M}$ sample trace shown in bold for reference 


\section{S4. Synthetic protocols for bPNA monomers and SPPS}

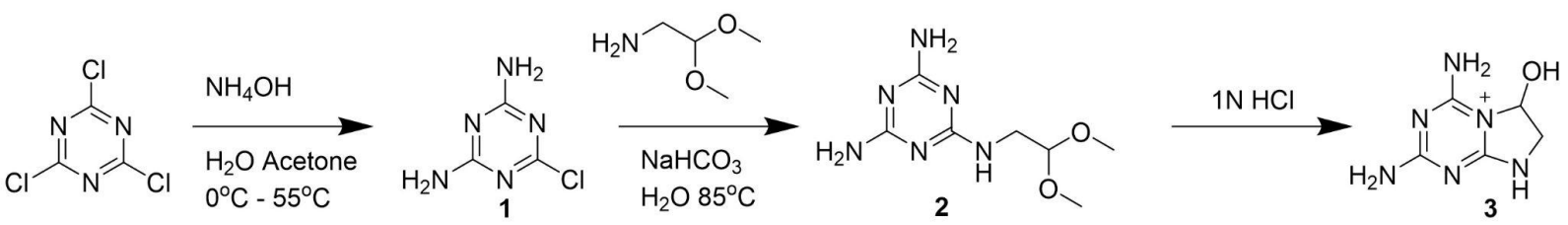

Figure S4.1. Synthetic scheme for melamine acetaldehyde.

Melamine chloride (6-chloro-1,3,5-triazine-2,4-diamine) (1) Water (385 mL) was added to a $1000 \mathrm{~mL}$ round bottom flask and chilled to $0^{\circ} \mathrm{C}$ before adding cyanuric chloride $(44 \mathrm{~g}, 239 \mathrm{mmol}, 1 \mathrm{eq})$ dissolved in acetone $(275 \mathrm{~mL})$. The mixture chilled over ice for 20 minutes followed by the dropwise addition of ammonium hydroxide $28 \%(115.5 \mathrm{~mL}, 812.6 \mathrm{mmol}, 3.4 \mathrm{eq})$. After, the reaction warmed to room temperature before reacting at $55^{\circ} \mathrm{C}$ in a sand bath overnight. Upon completion, the reaction was chilled with ice-water, filtered, washed with cold water three times, and dried via vacuum overnight. A chalky white solid was obtained yielding $31.75 \mathrm{~g}(91.8 \%)$. ${ }^{1} \mathrm{H}$ NMR: 7.14 (d, 4H). ${ }^{13} \mathrm{C}$ NMR: 168.65, 167.07. ESI-MS: Mass calculated: $[\mathrm{M}+\mathrm{H}]{ }^{+}=$ 146.0155, mass found: $[\mathrm{M}+\mathrm{H}]^{+}=146.0230$.

Melamine acetal ( $\mathrm{N}^{2}$-(2,2-dimethoxyethyl)-1,3,5-triazine-2,4,6-triamine) (2) To a $500 \mathrm{~mL}$ round bottom flask, 6-chloro-1,3,5-triazine-2,4-diamine (15 g, $103 \mathrm{mmol}, 1 \mathrm{eq})$ and $\mathrm{H}_{2} \mathrm{O}(200 \mathrm{~mL})$ were added. This was followed by $\mathrm{NaHCO}_{3}(11.3 \mathrm{~g}, 134 \mathrm{mmol}, 1.3 \mathrm{eq})$ and 2,2-dimethoxyethylamine (14.6 mL, $\left.134 \mathrm{mmol}, 1.3 \mathrm{eq}\right)$ then heating the reaction to $85^{\circ} \mathrm{C}$ overnight in a sand bath. The following day the reaction was cooled over ice, filtered, washed with ice-cold $\mathrm{H} 2 \mathrm{O}$, and dried by vacuum overnight. A white solid was collected giving $16.3 \mathrm{~g}(73.5 \%)$. ${ }^{1} \mathrm{H}$ NMR:6.40 (t, 1H), $6.06(\mathrm{~d}, 4 \mathrm{H}) 4.46(\mathrm{t}, 1 \mathrm{H}) 3.28(\mathrm{~m}, 9 \mathrm{H}){ }^{13} \mathrm{C}$ NMR: 167.48, 166.84, 102.56, 53.46, 41.97. ESI-MS: Mass calculated: $[\mathrm{M}+\mathrm{H}]^{+}=215.2290$, mass found: $[\mathrm{M}+\mathrm{H}]^{+}=215.1262$.

Melamine acetaldehyde (2-((4,6-diamino-1,3,5-triazin-2-yl)amino)acetaldehyde) (3)

$\mathrm{N}^{2}$-(2,2-dimethoxyethyl)-1,3,5-triazine-2,4,6-triamine (16.3 g, $\left.76.1 \mathrm{mmol}\right)$ was placed in a $250 \mathrm{~mL}$ round bottom flask followed by $1 \mathrm{M} \mathrm{HCl}(150 \mathrm{~mL})$. The reaction stirred at room temperature overnight. A white solid precipitated from the solution and recovered by vacuum filtration rinsing with cold water three times. The recovered white solid yielded $9.85 \mathrm{~g}(63.5 \%) .{ }^{1} \mathrm{H}$ NMR: $9.33(\mathrm{~s}, 1 \mathrm{H}), 8.39(\mathrm{~d}, 2 \mathrm{H}), 7.96(\mathrm{~d}, 1 \mathrm{H}), 7.76(\mathrm{~d}, 2 \mathrm{H})$, $6.06(\mathrm{t}, 1 \mathrm{H}), 3.87(\mathrm{q}, 1 \mathrm{H}), 3.39$ (m, 2H). ${ }^{13} \mathrm{C}$ NMR: 165.86, 157.62, 154.12, 79.00, 48.20. ESI-MS:Mass calculated: $[\mathrm{M}+\mathrm{H}]^{+}=169.1600$, mass found: $[\mathrm{M}+\mathrm{H}]^{+}=169.0856$ and Hydrate form - Mass calculated: $[\mathrm{M}+\mathrm{H}]^{+}=$ 187.1750, mass found: $[\mathrm{M}+\mathrm{H}]^{+}=187.0964$.
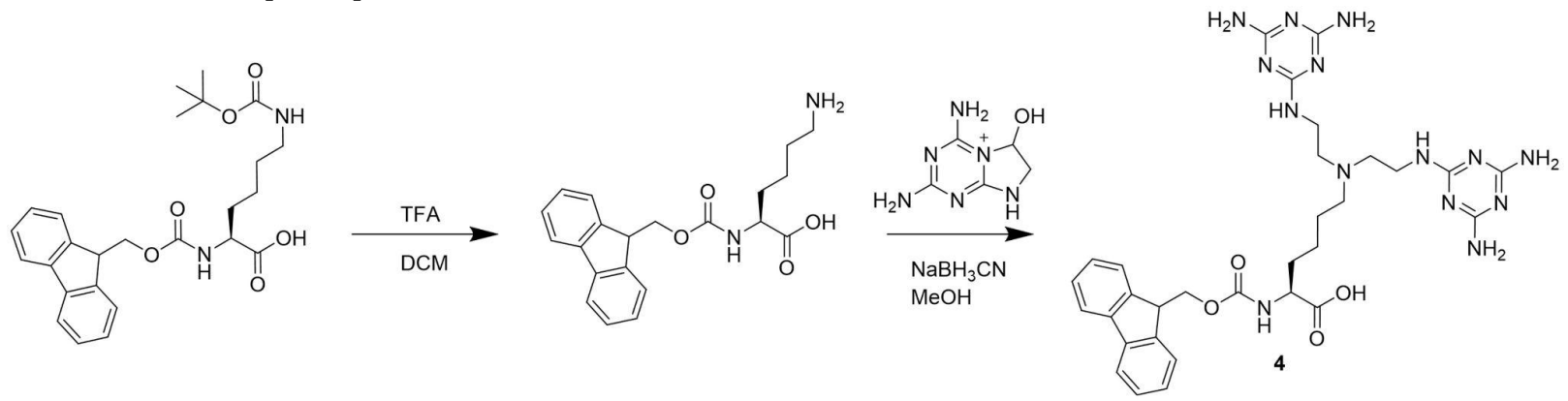

Figure S4.2. Synthetic scheme for Fmoc- $\mathrm{K}^{2 \mathrm{M}}-\mathrm{OH}$. 
Fmoc- $K^{2 M}-\mathrm{OH}$ (4) To a $250 \mathrm{~mL}$ round bottom flask, $5 \mathrm{~g}$ of Fmoc-Lys(Boc)-OH was added followed by $20 \mathrm{~mL}$ of $\mathrm{DCM}$ and $20 \mathrm{~mL}$ of trifluoroacetic acid (TFA). The reaction stirred at room temperature for $2 \mathrm{hrs}$. After, the DCM/TFA mixture was removed by a stream of $\mathrm{N}_{2}$, dissolved in DCM, and concentrated by the $\mathrm{N}_{2}$ stream again. Water was added to the compound, froze, and lyophilized to dryness giving $5.3 \mathrm{~g}$ of an off-white solid. Once dry, the material was immediately transferred to a $1000 \mathrm{~mL}$ round bottom flask and dissolved in $550 \mathrm{~mL}$ of $\mathrm{MeOH} . \mathrm{NaHCO}_{3}(1.85 \mathrm{~g}, 22 \mathrm{mmol}, 2 \mathrm{eq})$ was added and the reaction stirred for 15 min to bring the $\mathrm{pH} \sim 5$. Next, $\mathrm{MCHO}(2.24 \mathrm{~g}, 11 \mathrm{mmol}, 1 \mathrm{eq})$ was added and the reaction was heated to $50-55^{\circ} \mathrm{C}$ for $2 \mathrm{hrs}$. After, the reaction cooled to room temperature before adding $\mathrm{NaBH}_{3} \mathrm{CN}(1.6 \mathrm{~g}, 25.3 \mathrm{mmol}, 2.3 \mathrm{eq})$ dissolved in $\sim 10 \mathrm{~mL}$ of $\mathrm{MeOH}$. The reaction was tracked by analytical HPLC. The process of heating with aldehyde (0.5-1 eq) and cooling with $\mathrm{NaBH}_{3} \mathrm{CN}(1.15-2.3 \mathrm{eq})$ was repeated until completion of the reaction. Upon completion, the reaction was cooled over ice before vacuum filtration. The product was washed with small amounts of $\mathrm{MeOH}$ and remained on the filter until dry. The final product was a white powder giving $6.3 \mathrm{~g} \mathrm{(85.2 \% ).} \mathrm{Monomer} \mathrm{purity}$ was checked by the analytical run at $1 \mathrm{~mL} / \mathrm{min}$ using the following gradient: $0 \%$ solvent $\mathrm{B}$ in $0-5 \mathrm{~min}, 0-60 \%$ solvent $B$ in $5-15 \mathrm{~min}, 60 \%$ solvent $B$ in $15-20 \mathrm{~min}, 60-100 \%$ solvent $B$ in $20-20.5 \mathrm{~min}, 100 \%$ solvent $B$ in 20.5-22.5 min, $100-0 \%$ solvent $B$ in $22.5-23 \mathrm{~min}, 0 \%$ solvent $B$ in $23-25$ min (solvent $A=0.1 \%$ TFA in $1 \%$ acetonitrile, $99 \%$ water, solvent $B=0.07 \%$ TFA in $90 \%$ acetonitrile, $10 \%$ water).

${ }^{1} \mathrm{H}$ NMR: $7.88(\mathrm{~d}, 2 \mathrm{H}), 7.71(\mathrm{~d}, 2 \mathrm{H}), 7.59(\mathrm{~d}, 1 \mathrm{H}), 7.41(\mathrm{t}, 3 \mathrm{H}), 7.32(\mathrm{t}, 2 \mathrm{H}), 6.47(\mathrm{t}, 2 \mathrm{H}), 6.21(\mathrm{~d}, 8 \mathrm{H}), 4.27(\mathrm{~d}$, $2 \mathrm{H}), 4.22(\mathrm{q}, 1 \mathrm{H}), 3.96-3.91(\mathrm{~m}, 1 \mathrm{H}), 3.38-3.27(\mathrm{~m}, 4 \mathrm{H}), 2.75-2.63(\mathrm{~m}, 4 \mathrm{H}), 2.63-2.53(\mathrm{~m}, 2 \mathrm{H}), 1.78-1.61(\mathrm{~m}$, $2 \mathrm{H}), 1.51-1.22(\mathrm{~m}, 4 \mathrm{H}) .{ }^{13} \mathrm{C}$ NMR: $174.74,165.52,156.25,143.92,143.87,140.80,127.75,127.17,125.36$, $120.18,65.67,54.18,53.58,52.88,46.77,36.73,30.85,24.45,23.14$. MALDI: Mass calculated: $[\mathrm{M}+\mathrm{H}]^{+}=$ 673.7550, mass found: $[\mathrm{M}+\mathrm{H}]^{+}=673.6216$.

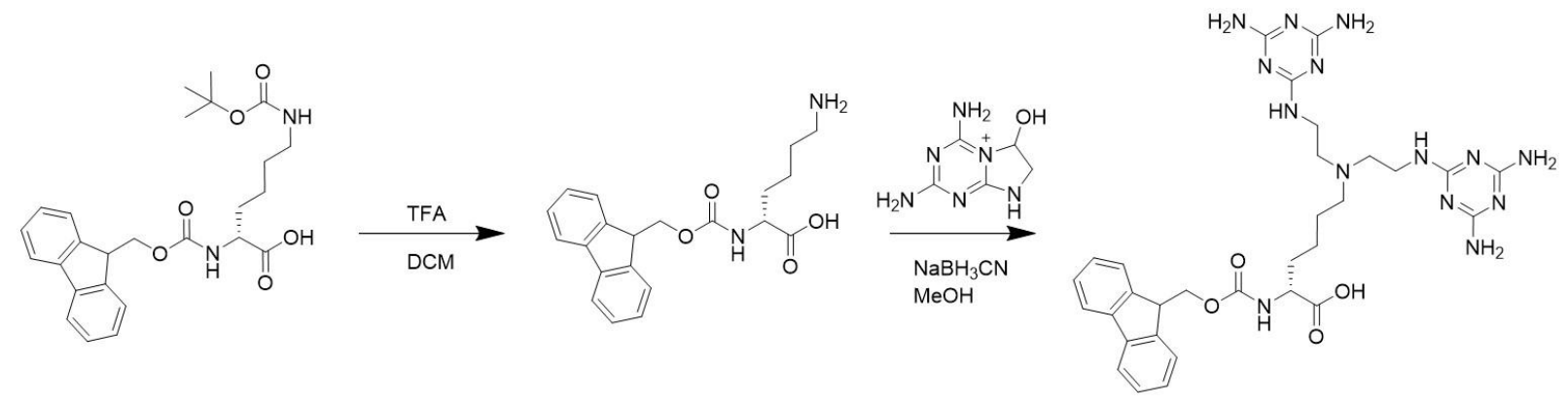

Figure S4.3. Synthetic scheme for Fmoc- $\mathrm{k}^{2 \mathrm{M}}-\mathrm{OH}$.

Fmoc-k ${ }^{2 M}$-OH. $5 \mathrm{~g}$ of Fmoc-D-Lys(Boc)-OH Boc-deprotected with $40 \mathrm{~mL}$ TFA (50\% v/v in DCM) over 2 hrs then concentrated by $\mathrm{N}_{2}$ stream (2X DCM treatment). Residue was diluted in water and lyophilized to yield $5.15 \mathrm{~g}$ of an off-white solid. Once dry, the material was immediately transferred to a $1000 \mathrm{~mL}$ round bottom flask and dissolved in $550 \mathrm{~mL}$ of $\mathrm{MeOH}$. $\mathrm{NaHCO}_{3}(1.8 \mathrm{~g}, 21.4 \mathrm{mmol}, 2 \mathrm{eq})$ was added and the reactions stirred for 15 min to bring the $\mathrm{pH} \sim 5$. Next, $\mathrm{MCHO}(2.18 \mathrm{~g}, 10.7 \mathrm{mmol}, 1 \mathrm{eq})$ was added and the reaction was heated to $50-55^{\circ} \mathrm{C}$ for $2 \mathrm{hrs}$. After, the reaction cooled to room temperature before adding $\mathrm{NaBH}_{3} \mathrm{CN}(1.55 \mathrm{~g}, 24.6 \mathrm{mmol}$, $2.3 \mathrm{eq}$ ) dissolved in $\sim 10 \mathrm{~mL}$ of $\mathrm{MeOH}$. The reaction was tracked by analytical HPLC. The process of heating with aldehyde (0.5-1 eq) and cooling with $\mathrm{NaBH} 3 \mathrm{CN}(1.15-2.3 \mathrm{eq})$ was repeated until completion of the reaction. Upon completion, the reaction was cooled over ice before vacuum filtration. The product was washed with small amounts of $\mathrm{MeOH}$ and remained on the filter until dry. The final product was a light-yellow powder giving $5.12 \mathrm{~g}(71.3 \%)$. Monomer purity was checked by the analytical run at $1 \mathrm{~mL} / \mathrm{min}$ using the following gradient: $0 \%$ solvent B in $0-5 \mathrm{~min}, 0-60 \%$ solvent B in $5-15 \mathrm{~min}, 60 \%$ solvent B in $15-20 \mathrm{~min}, 60-100 \%$ solvent $B$ in $20-20.5 \mathrm{~min}, 100 \%$ solvent $B$ in $20.5-22.5 \mathrm{~min}, 100-0 \%$ solvent $B$ in $22.5-23 \mathrm{~min}, 0 \%$ solvent $B$ in $23-25$ min (solvent $A=0.1 \%$ TFA in $1 \%$ acetonitrile, $99 \%$ water, solvent $B=0.07 \%$ TFA in $90 \%$ acetonitrile, $10 \%$ water). ${ }^{1} \mathrm{H}$ NMR: $7.88(\mathrm{~d}, 2 \mathrm{H}), 7.71(\mathrm{~d}, 2 \mathrm{H}), 7.62(\mathrm{~d}, 1 \mathrm{H}), 7.41(\mathrm{t}, 3 \mathrm{H}), 7.32(\mathrm{t}, 2 \mathrm{H}), 6.54(\mathrm{t}, 2 \mathrm{H}), 6.24(\mathrm{~d}, 8 \mathrm{H}), 4.27(\mathrm{~d}$, $2 \mathrm{H}), 4.22(\mathrm{q}, 1 \mathrm{H}), 3.96-3.91(\mathrm{~m}, 1 \mathrm{H}), 3.38-3.27(\mathrm{~m}, 4 \mathrm{H}), 2.84-2.57(\mathrm{~m}, 4 \mathrm{H}), 1.78-1.61(\mathrm{~m}, 2 \mathrm{H}), 1.51-1.22(\mathrm{~m}$, 4H). ${ }^{13} \mathrm{C}$ NMR: $174.74,165.52,156.25,143.92,143.87,140.80,127.75,127.17,125.36,120.18,65.67,54.18$, $53.58,52.88,46.77,36.73,30.85,24.45,23.14$. MALDI: Mass calculated: $[\mathrm{M}+\mathrm{H}]^{+}=673.7550$, mass found: $[\mathrm{M}+\mathrm{H}]^{+}=673.6216$. 


\section{S4.3. Synthesis of Diketopiperazine- $\mathrm{K}^{2 \mathrm{M}}\left(c\left[\mathrm{~K}^{2 \mathrm{M}}\right]_{2}\right)$}

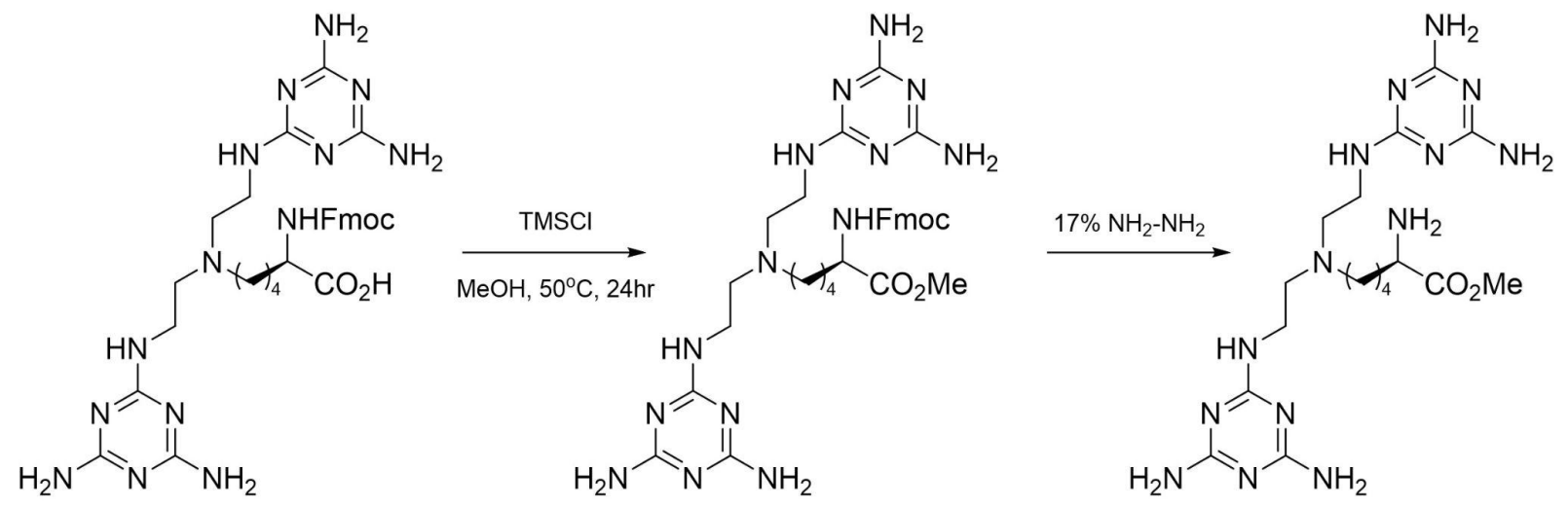

Figure S4.4. Synthetic scheme for $\mathrm{NH}_{2}-\mathrm{K}^{2 \mathrm{M}}-\mathrm{OMe}$.

Fmoc-K ${ }^{2 \mathrm{M}}$-OMe. A $50 \mathrm{~mL}$ round bottom flask was charged with Fmoc-K $\mathrm{K}^{2 \mathrm{M}}-\mathrm{OH}(1 \mathrm{~g}, 1.5 \mathrm{mmol}, 1 \mathrm{eq})$ followed by trimethylsilyl chloride $(0.945 \mathrm{~mL}, 7.44 \mathrm{mmol}, 5 \mathrm{eq})$. After, $10 \mathrm{~mL} \mathrm{MeOH}$ was added, and the reaction stirred at room temperature for $1 \mathrm{hr}$. The reaction was monitored by HPLC to determine completion. The reaction was concentrated giving $1.1 \mathrm{~g}$ of a light brown solid and was continued to the next step without purification.

$\mathrm{NH}_{2}-\mathrm{K}^{2 \mathrm{M}}$-OMe. Fmoc-K $\mathrm{K}^{2 \mathrm{M}}$-OMe $(1.1 \mathrm{~g}, 1.6 \mathrm{mmol}$, $1 \mathrm{eq})$ was reacted with $17 \%$ hydrazine hydrate $(3.3 \mathrm{~mL})$ at room temperature for $1 \mathrm{hr}$. Reaction monitored by HPLC and upon completion, cold diethyl ether was added, sonicated, and decanted. This process was repeated three times and the remaining product was dried with an $\mathrm{N}_{2}$ stream to remove the excess diethyl ether. Then, the product was dissolved in $\sim 5 \mathrm{~mL} \mathrm{H}_{2} \mathrm{O}$ and lyophilized.
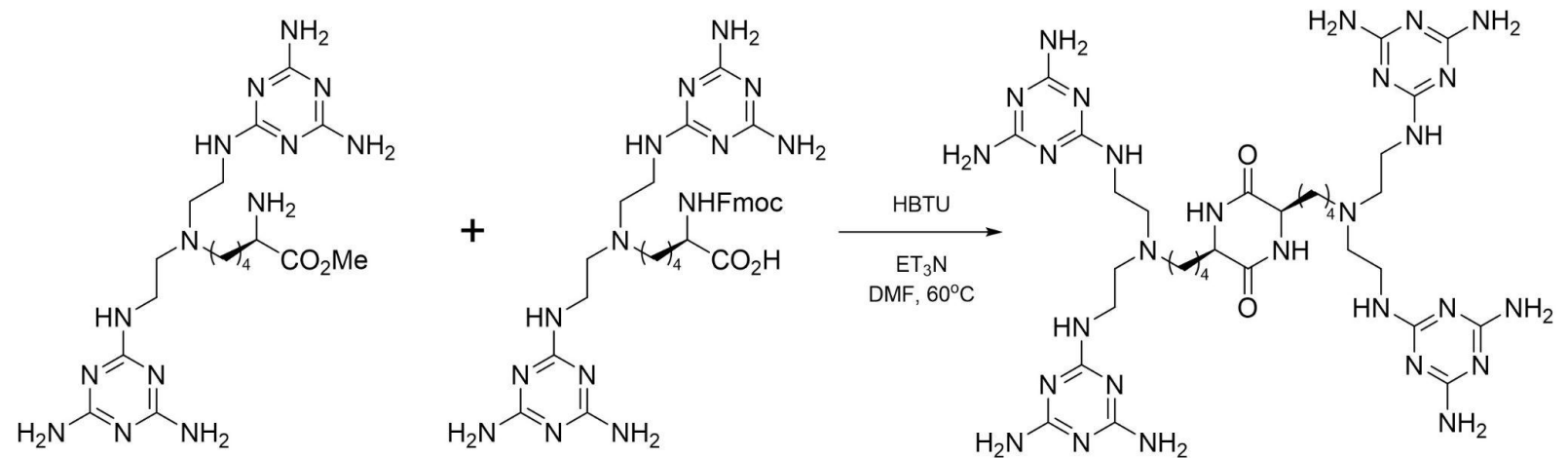

Figure S4.5. Synthetic scheme for $\mathrm{c}\left[\mathrm{K}^{2 \mathrm{M}}\right]_{2}$.

Diketopiperazine $c\left[\mathrm{~K}^{2 \mathrm{M}}\right]_{2}$. To a $100 \mathrm{~mL}$ round bottom flask was added $\mathrm{Fmoc}-\mathrm{K}^{2 \mathrm{M}}-\mathrm{OH}(500 \mathrm{mg}, 0.744 \mathrm{mmol}, 1$ eq) and NMP (20 mL). Next, HBTU (282 mg, $0.744 \mathrm{mmol}, 1 \mathrm{eq})$ and triethylamine (520 $\mu \mathrm{L}, 3.7 \mathrm{mmol}, 5 \mathrm{eq})$ were added and the reaction stirred at room temperature for 10 minutes. This was followed by the addition of $\mathrm{NH}_{2}-\mathrm{K}^{2 \mathrm{M}}$-OMe $(346 \mathrm{mg}, 0.744 \mathrm{mmol}, 1 \mathrm{eq})$ and the reaction was heated to $60^{\circ} \mathrm{C}$ for 2 days. The reaction did not go to completion and was purified via HPLC. The crude DKP-K ${ }^{2 \mathrm{M}}$ was dissolved in HPLC solvent A and purified on a semi-prep $\mathrm{C} 18$ reverse phase column at $8 \mathrm{~mL} / \mathrm{min}$ using the following gradient: $0 \%$ solvent $\mathrm{B}$ in 0-5 min, 5-20\% solvent $B$ in 5-15 min, $20 \%$ solvent $B$ in $15-22$ min, $20-100 \%$ solvent $B$ in $22-24 \mathrm{~min}, 100 \%$ solvent $B$ in $24-29 \mathrm{~min}, 100-0 \%$ solvent $B$ in $29-31 \mathrm{~min}, 0 \%$ solvent $B$ in $31-35$ min (solvent $A=0.1 \%$ TFA in water, solvent $B=0.07 \%$ TFA in $90 \%$ acetonitrile, $10 \%$ water). The UV detector was set at $238 \mathrm{~nm}$. The identity of the peptide was checked by MALDI-TOF, its purity checked by analytical HPLC on a C18 column, and the purified peptides were lyophilized to dryness. Peptide purity was checked by the analytical run at $1 \mathrm{~mL} / \mathrm{min}$ using the following gradient: $0 \%$ solvent $B$ in $0-5 \mathrm{~min}, 0-20 \%$ solvent $B$ in $5-10$ min, $20 \%$ solvent $B$ in $10-16$ min, $20-100 \%$ solvent $B$ in $16-16.5 \mathrm{~min}, 100 \%$ solvent $B$ in $16.5-21.5 \mathrm{~min}, 100-0 \%$ solvent $B$ in $21.5-22$ min, $0 \%$ solvent $B$ in $22-30$ min (solvent $A=0.1 \%$ TFA in $1 \%$ acetonitrile, $99 \%$ water, solvent $B=0.07 \%$ TFA in $90 \%$ acetonitrile, $10 \%$ water). 

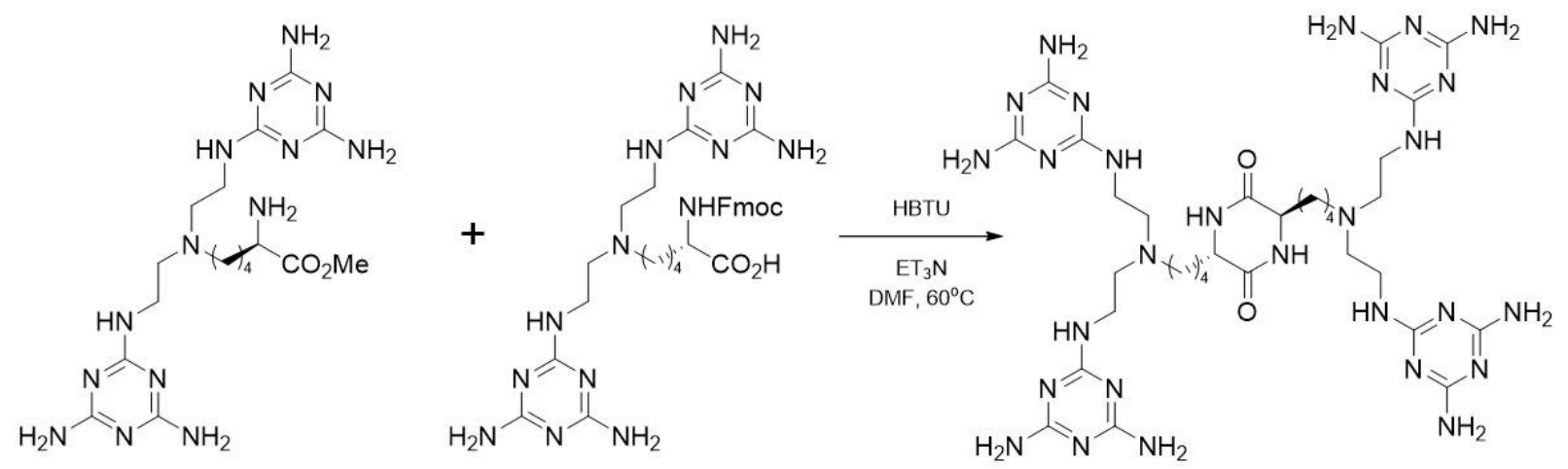

Figure S4.6. Synthetic scheme for $c\left[\mathrm{~K}^{2 \mathrm{M}} \mathrm{k}^{2 \mathrm{M}}\right]$.

$c\left[\mathrm{~K}^{2 \mathrm{M}} \mathbf{k}^{2 \mathrm{M}}\right]$. To a $100 \mathrm{~mL}$ round bottom flask was added $\mathrm{Fmoc}-\mathrm{K}^{2 \mathrm{M}}-\mathrm{OH}(100 \mathrm{mg}, 0.149 \mathrm{mmol}, 1 \mathrm{eq})$ and NMP (4 $\mathrm{mL})$. Next, HBTU (56.4 mg, $0.149 \mathrm{mmol}, 1 \mathrm{eq})$ and triethylamine $(104 \mu \mathrm{L}, 0.744 \mathrm{mmol}, 5 \mathrm{eq})$ were added and the reaction stirred at room temperature for 10 minutes. This was followed by the addition of $\mathrm{NH}_{2}-\mathrm{K}^{2 \mathrm{M}}-\mathrm{OMe}$ $(69.2 \mathrm{mg}, 0.149 \mathrm{mmol}, 1 \mathrm{eq})$ and the reaction was heated to $60^{\circ} \mathrm{C}$ for 3 days. The reaction did not go to completion and was purified via HPLC. The crude DL DKP-K ${ }^{2 \mathrm{M}}$ was dissolved in HPLC solvent $A$ and purified on a semi-prep C18 reverse phase column at $8 \mathrm{~mL} / \mathrm{min}$ using the following gradient: $0 \%$ solvent $\mathrm{B}$ in $0-5 \mathrm{~min}$, $5-20 \%$ solvent $B$ in $5-15$ min, $20 \%$ solvent $B$ in $15-22$ min, $20-100 \%$ solvent $B$ in $22-24$ min, $100 \%$ solvent $B$ in 24-29 min, $100-0 \%$ solvent $B$ in $29-31 \mathrm{~min}, 0 \%$ solvent $B$ in 31-35 min (solvent $A=0.1 \%$ TFA in water, solvent $\mathrm{B}=0.07 \%$ TFA in $90 \%$ acetonitrile, $10 \%$ water). The UV detector was set at $238 \mathrm{~nm}$. The identity of the peptide was checked by MALDI-TOF, its purity checked by analytical HPLC on a C18 column, and the purified peptides were lyophilized to dryness. Peptide purity was checked by the analytical run at $1 \mathrm{~mL} / \mathrm{min}$ using the following gradient: $0 \%$ solvent $B$ in $0-5 \mathrm{~min}, 0-20 \%$ solvent $B$ in $5-10 \mathrm{~min}, 20 \%$ solvent $B$ in $10-16 \mathrm{~min}, 20-100 \%$ solvent $B$ in $16-16.5 \mathrm{~min}, 100 \%$ solvent $B$ in $16.5-21.5 \mathrm{~min}, 100-0 \%$ solvent $B$ in $21.5-22 \mathrm{~min}, 0 \%$ solvent $B$ in $22-30$ min (solvent $A=0.1 \%$ TFA in $1 \%$ acetonitrile, $99 \%$ water, solvent $B=0.07 \%$ TFA in $90 \%$ acetonitrile, $10 \%$ water).

S4.6. SPPS of bPNA variants. Utilizing standard Fmoc chemistry, peptide synthesis was performed manually using Rink Amide resin (100-200 mesh, loading $0.3 \mathrm{mmol} / \mathrm{g}$ ). For $150 \mathrm{mg}$ of resin, $0.25 \mathrm{M}$ of standard amino acids were coupled with $0.25 \mathrm{M}$ of PyAOP and $0.25 \mathrm{M}$ of DIEA in $2 \mathrm{~mL}$ of neat NMP. As for coupling with Fmoc- $\mathrm{K}^{2 \mathrm{M}}-\mathrm{OH}$, it required $0.1 \mathrm{M}$ of $\mathrm{Fmoc}-\mathrm{K}^{2 \mathrm{M}}-\mathrm{OH}$ with $0.1 \mathrm{M}$ of PyAOP and $0.1 \mathrm{M}$ DIEA in $2 \mathrm{~mL}$ of NMP:DMSO (3:1). Fmoc cleavage was performed with $2 \mathrm{~mL}$ of piperidine:NMP (1:1). Acetyl capping was performed with 2 $\mathrm{mL}$ of acetic anhydride: pyridine (3:2) in neat NMP. Cleavage of the peptide from the solid support and the protective groups was performed using $95 \%$ trifluoroacetic acid (TFA) with $5 \% \mathrm{H}_{2} \mathrm{O}$ for $2 \mathrm{hrs}$. To precipitate the peptides, cold diethyl ether $\left(\mathrm{Et}_{2} \mathrm{O}\right)$ was added followed by $2 \mathrm{x}$ washing with cold $\mathrm{Et}_{2} \mathrm{O}$ and drying the crude pellet over an $\mathrm{N}_{2}$ stream. Crude peptides were dissolved in HPLC solvent A and purified on a semi-prep C18 reverse phase column at $8 \mathrm{~mL} / \mathrm{min}$ using the following gradient: $0 \%$ solvent $\mathrm{B}$ in $0-5 \mathrm{~min}, 0-20 \%$ solvent $\mathrm{B}$ in 5-15 min, $20 \%$ solvent $B$ in $15-22$ min, $20-100 \%$ solvent $B$ in $22-23 \mathrm{~min}, 100 \%$ solvent $B$ in $23-28 \mathrm{~min}, 100-0 \%$ solvent $B$ in $28-29 \mathrm{~min}, 0 \%$ solvent $B$ in $29-33$ min (solvent $A=0.1 \%$ TFA in water, solvent $B=0.07 \%$ TFA in $90 \%$ acetonitrile, $10 \%$ water). The bolded numbers represent where the gradient may change for each tripeptide and is indicated with each figure caption of the analytical run. The UV detector was set at $238 \mathrm{~nm}$. The identity of the peptide was checked by MALDI-TOF, its purity checked by analytical HPLC on a C18 reverse phase column, and the purified peptides were lyophilized to dryness. Peptide purity was checked by the analytical run at $1 \mathrm{~mL} / \mathrm{min}$ using the following gradient: $0 \%$ solvent $B$ in $0-5 \mathrm{~min}, 0-20 \%$ solvent $B$ in $5-15 \mathrm{~min}, \mathbf{2 0} \%$ solvent $B$ in $15-20 \mathrm{~min}, \mathbf{2 0}-100 \%$ solvent $B$ in $20-20.5 \mathrm{~min}, 100 \%$ solvent $B$ in $20.5-22.5 \mathrm{~min}, 100-0 \%$ solvent $B$ in 22.5-23 min, $0 \%$ solvent $B$ in $23-25$ min (solvent $A=0.1 \%$ TFA in $1 \%$ acetonitrile, $99 \%$ water, solvent $B=0.07 \%$ TFA in $90 \%$ acetonitrile, $10 \%$ water). Again, bolded numbers indicate where the gradient may change, but the percentage is the same as in the prep runs (see figure captions). 
S4.7. SPPS of dipeptide library. Utilizing standard Fmoc chemistry, peptide synthesis was performed manually using Rink Amide resin (100-200 mesh, loading $0.3 \mathrm{mmol} / \mathrm{g})$. For $150 \mathrm{mg}$ of resin, each $\mathrm{Fmoc}-\mathrm{k}^{2 \mathrm{M}}-\mathrm{OH}$ or Fmoc- $\mathrm{K}^{2 \mathrm{M}}-\mathrm{OH}$ addition requires $0.1 \mathrm{M}$ of monomer coupled with $0.1 \mathrm{M}$ of PyAOP and $0.1 \mathrm{M}$ DIEA in $2 \mathrm{~mL}$ of NMP:DMSO (3:1). Fmoc cleavage was performed with $2 \mathrm{~mL}$ of piperidine:NMP (1:1). Acetyl capping was performed with $2 \mathrm{~mL}$ of acetic anhydride: pyridine (3:2) in neat NMP. Cleavage of the peptide from the solid support was performed using $95 \%$ trifluoroacetic acid (TFA) with $5 \% \mathrm{H}_{2} \mathrm{O}$ for $2 \mathrm{hrs}$. To precipitate the peptides, cold diethyl ether $\left(\mathrm{Et}_{2} \mathrm{O}\right)$ was added followed by $2 \mathrm{x}$ washing with cold $\mathrm{Et}_{2} \mathrm{O}$ and drying the crude pellet over an $\mathrm{N}_{2}$ stream. Crude peptides were dissolved in HPLC solvent $A$ and purified on a semi-prep C18 reverse phase column at $8 \mathrm{~mL} / \mathrm{min}$ using the following gradient: $0 \%$ solvent $B$ in $0-5 \mathrm{~min}, 5-15 \%$ solvent $B$ in $5-15 \mathrm{~min}, 15 \%$ solvent $B$ in $15-22 \mathrm{~min}, 15-100 \%$ solvent $B$ in $22-23 \mathrm{~min}, 100 \%$ solvent $B$ in $23-28 \mathrm{~min}, 100-0 \%$ solvent $B$ in $28-29 \mathrm{~min}, 0 \%$ solvent $B$ in $29-33$ min (solvent $A=0.1 \%$ TFA in $1 \%$ acetonitrile, $99 \%$ water, solvent $B=0.07 \%$ TFA in $90 \%$ acetonitrile, $10 \%$ water). The UV detector was set at $238 \mathrm{~nm}$. The identity of the peptide was checked by MALDI-TOF, its purity checked by analytical HPLC on a C18 reverse phase column (using the same gradient at $1 \mathrm{~mL} / \mathrm{min}$ ), and the purified peptides were lyophilized to dryness.

\section{Additional characterization data for Fmoc-k ${ }^{2 \mathrm{M}}-\mathrm{OH}$}
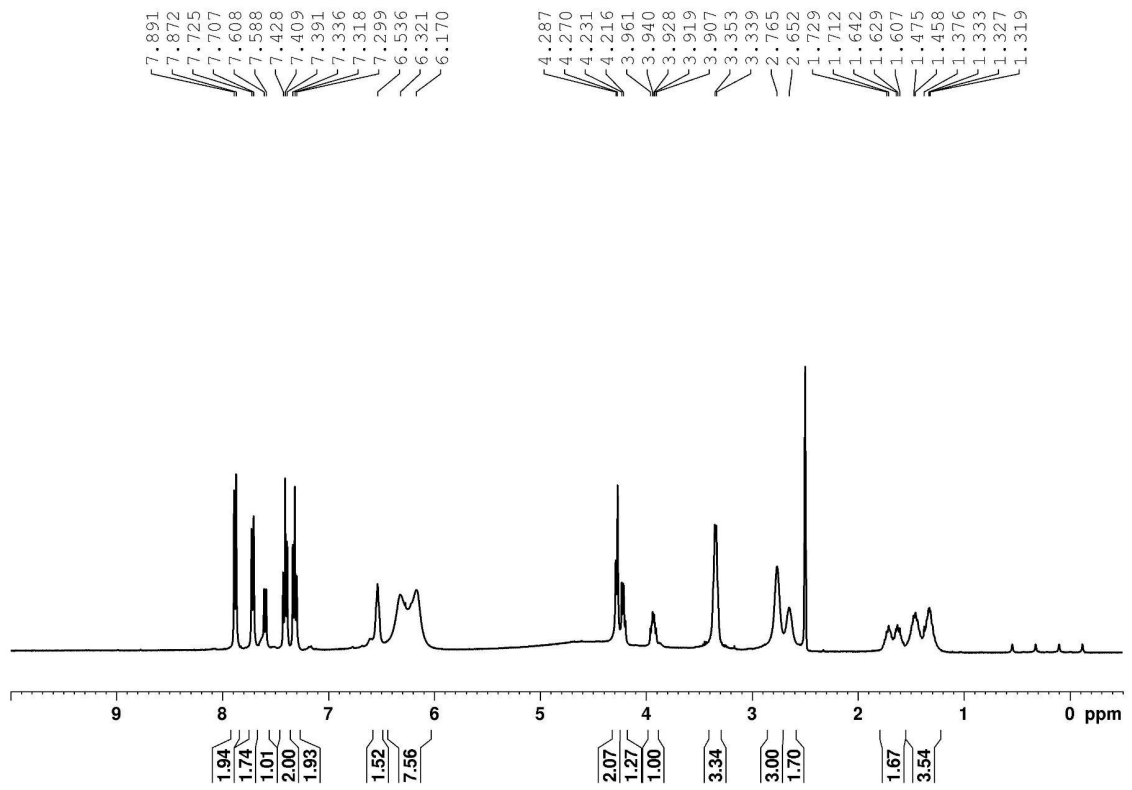

Figure S4.7. ${ }^{1} \mathrm{H}$ NMR (400 MHz, DMSO- $\left.\mathrm{d}_{6}\right)$ of Fmoc- $\mathrm{k}^{2 \mathrm{M}}-\mathrm{OH}$ 


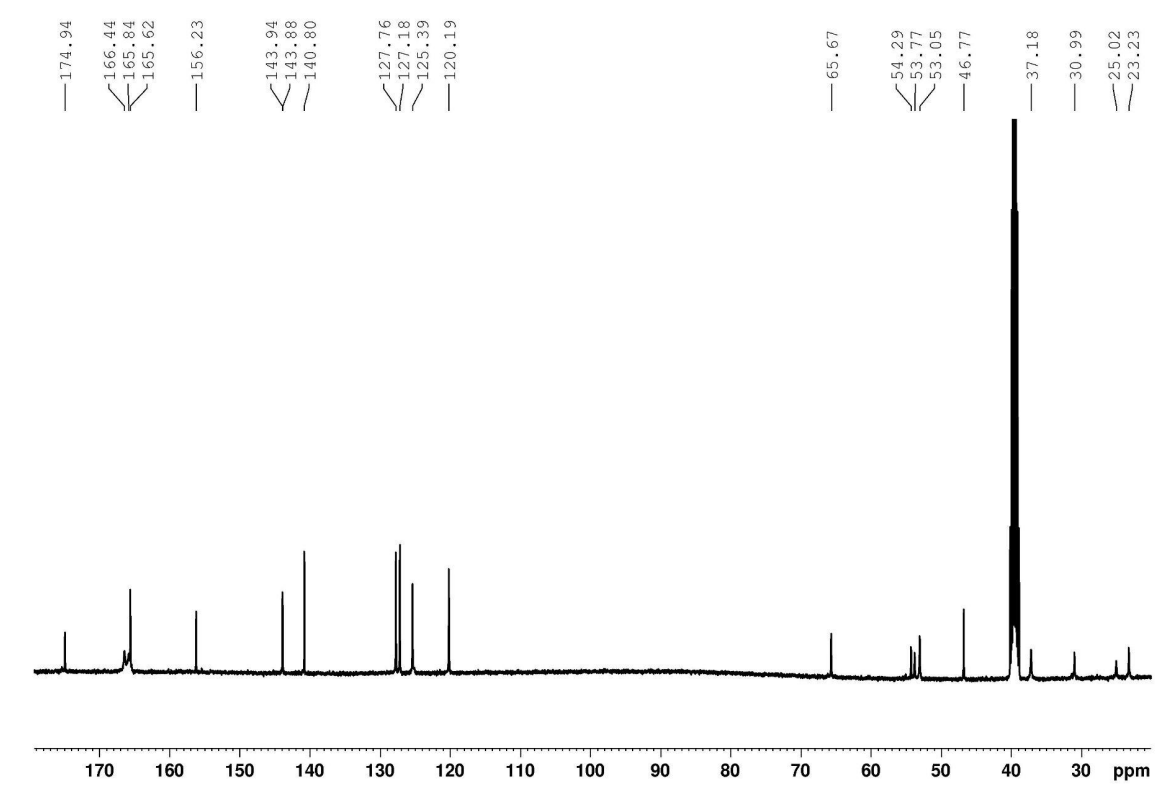

Figure S4.8. ${ }^{13} \mathrm{C}$ NMR $\left(100 \mathrm{MHz}\right.$, DMSO- $\left.\mathrm{d}_{6}\right)$ of Fmoc- $\mathrm{k}^{2 \mathrm{M}}-\mathrm{OH}$

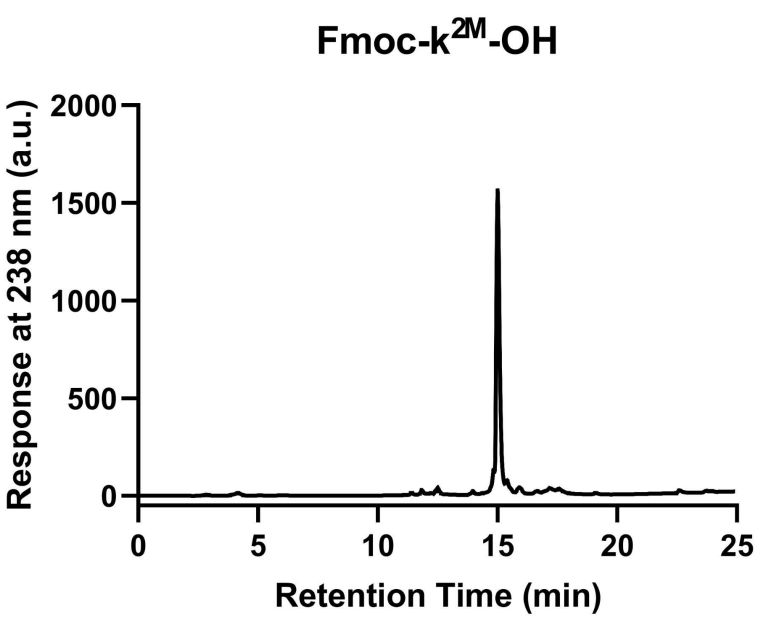

Figure S4.9. Analytical HPLC of Fmoc- $\mathrm{k}^{2 \mathrm{M}}-\mathrm{OH}$. gradient: $0 \%$ solvent $\mathrm{B}$ in $0-5 \mathrm{~min}, 0-60 \%$ solvent $\mathrm{B}$ in $5-15 \mathrm{~min}, 60 \%$ solvent $B$ in $15-20 \mathrm{~min}, 60-100 \%$ solvent $B$ in $20-20.5 \mathrm{~min}, 100 \%$ solvent $B$ in $20.5-22.5 \mathrm{~min}, 100-0 \%$ solvent $B$ in $22.5-23 \mathrm{~min}, 0 \%$ solvent $B$ in $23-25$ min (solvent $A=0.1 \%$ TFA in $1 \%$ acetonitrile, $99 \%$ water, solvent $B=0.07 \%$ TFA in $90 \%$ acetonitrile, $10 \%$ water). 


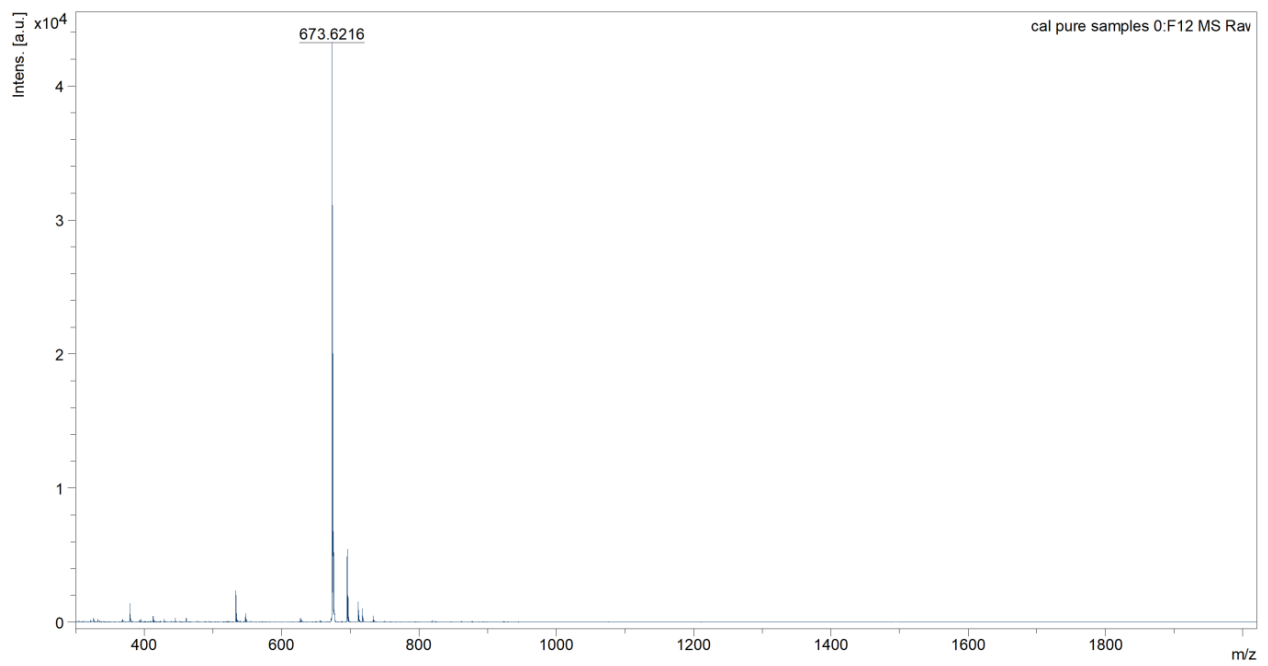

Figure S4.10. MALDI-TOF-MS of Fmoc- $\mathrm{k}^{2 \mathrm{M}} \mathrm{OH}$. Mass calculated: $[\mathrm{M}+\mathrm{H}]^{+}=673.7550$, mass found: $[\mathrm{M}+\mathrm{H}]^{+}=673.6216$, $[\mathrm{M}+\mathrm{Na}]^{+}=695.6124$. 
S5. Characterization of bPNA variants

HPLC and MALDI spectra
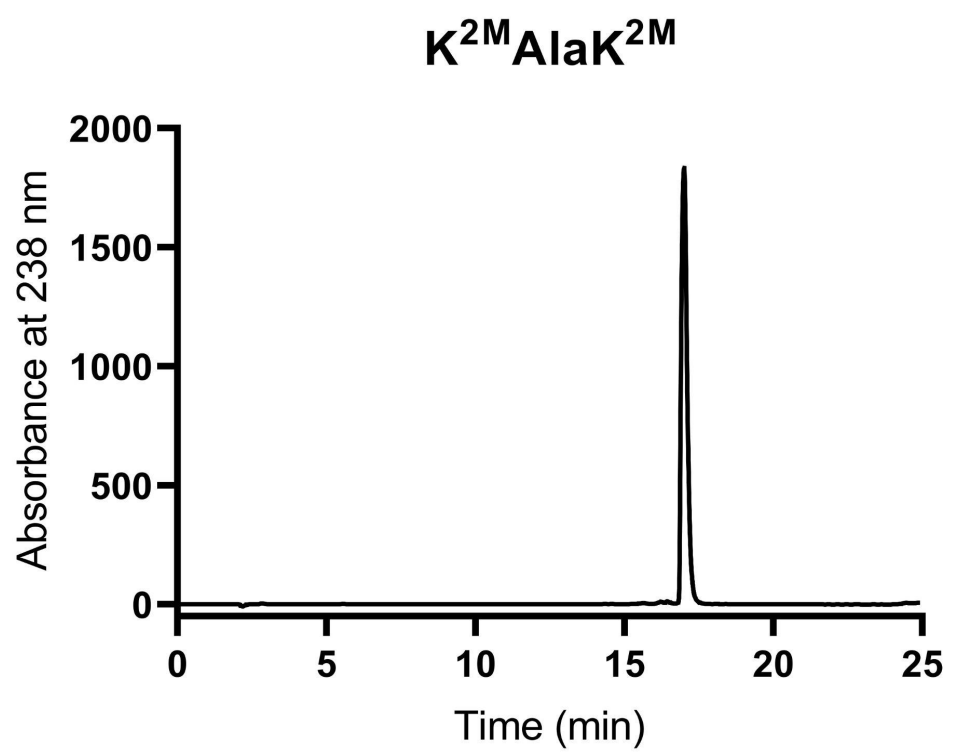

Figure S5.1. HPLC trace of $\mathrm{K}^{2 \mathrm{M}} \mathrm{AlaK}^{2 \mathrm{M}}$, using the gradient described at the beginning of this section. Requires $18 \%$ solvent B.

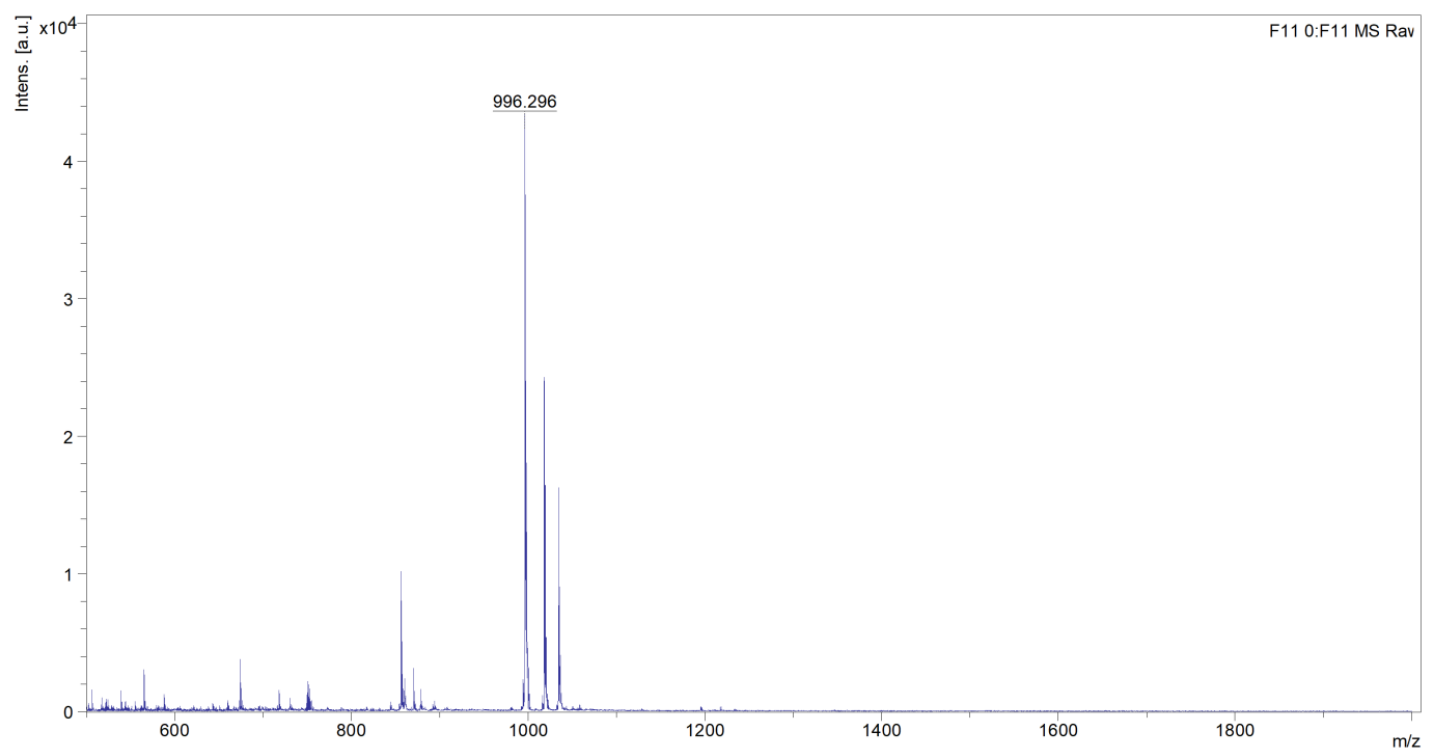

Figure S5.2 MALDI-TOF-MS of $\mathrm{K}^{2 \mathrm{M}} \mathrm{AlaK}{ }^{2 \mathrm{M}}$

Mass calculated: $[\mathrm{M}+\mathrm{H}]^{+}=996.1410$, mass found: $[\mathrm{M}+\mathrm{H}]^{+}=996.2961,[\mathrm{M}+\mathrm{Na}]^{+}=1018.2206,[\mathrm{M}+\mathrm{K}]^{+}=1034.2127$. 
$\mathrm{K}^{2 \mathrm{M}} \mathrm{BAlaK}^{2 \mathrm{M}}$

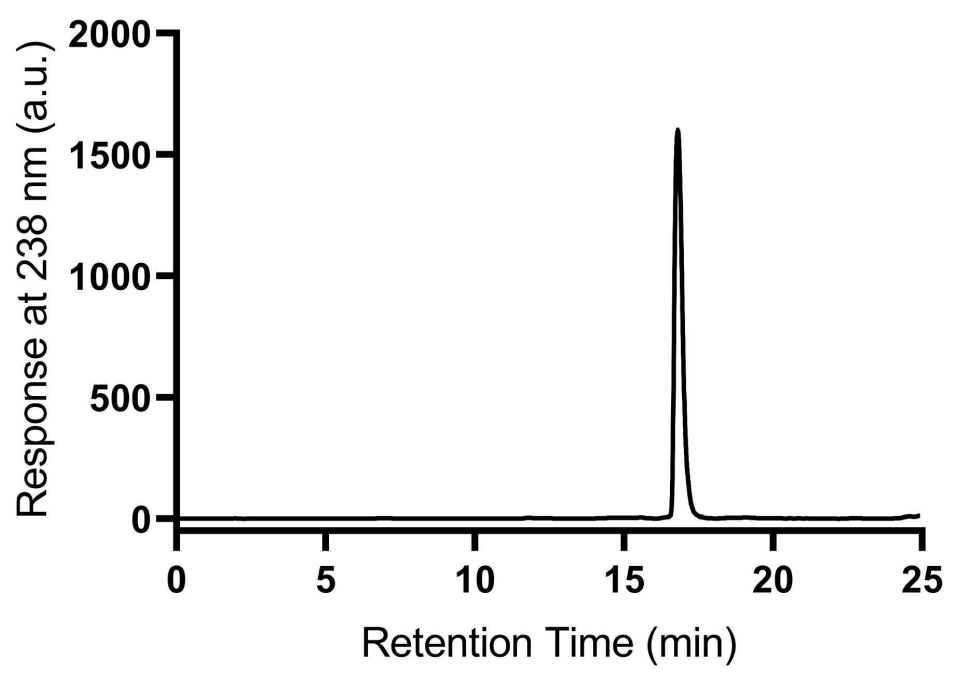

Figure S5.3. HPLC trace of $\mathrm{K}^{2 \mathrm{M}} \beta A \mathrm{AlK}^{2 \mathrm{M}}$, using the gradient described at the beginning of this section. Requires $15 \%$ solvent $\mathrm{B}$.

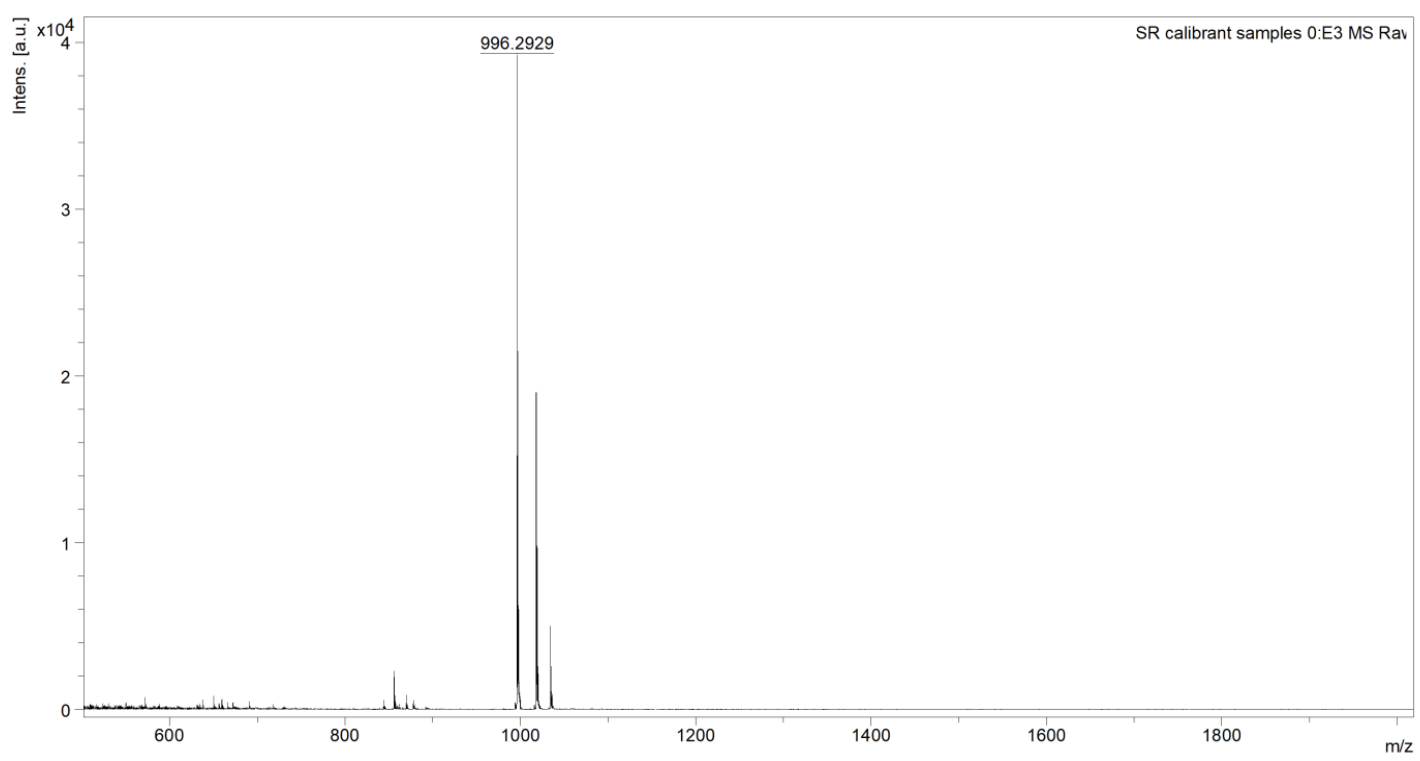

Figure S5.4. MALDI-TOF-MS of $\mathrm{K}^{2 \mathrm{M}}{ }_{\beta} \mathrm{AlaK}^{2 \mathrm{M}}$

Mass calculated: $[\mathrm{M}+\mathrm{H}]^{+}=996.1410$, mass found: $[\mathrm{M}+\mathrm{H}]^{+}=996.2929,[\mathrm{M}+\mathrm{Na}]^{+}=1018.2526,[\mathrm{M}+\mathrm{K}]^{+}=1034.2778$. 


\section{$\mathrm{K}^{2 \mathrm{M}} \mathrm{GlyK}^{2 \mathrm{M}}$}

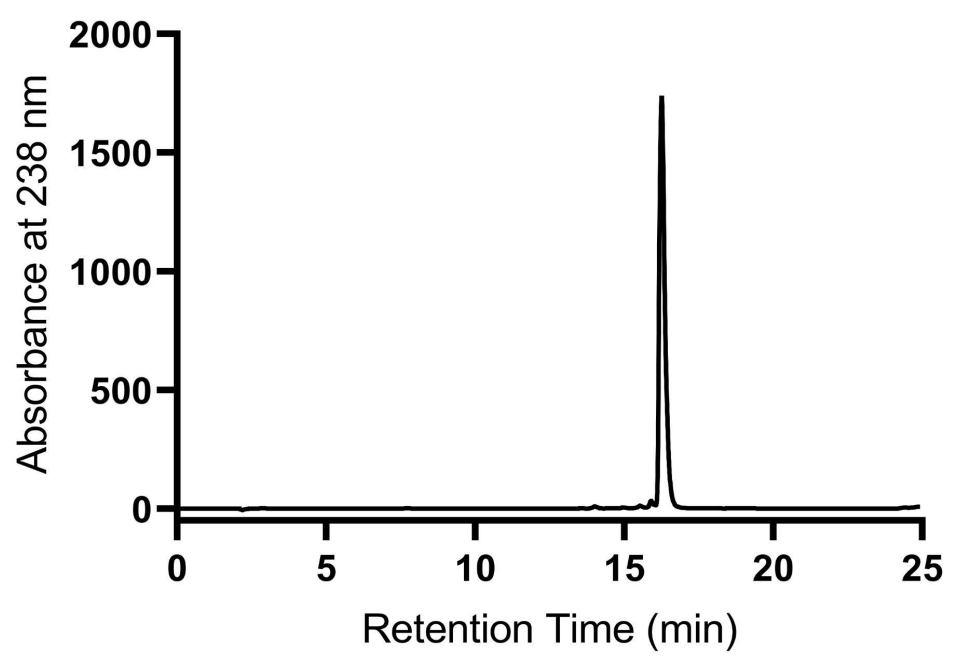

Figure S5.5. HPLC trace of $\mathrm{K}^{2 \mathrm{M}} \mathrm{GlyK}^{2 \mathrm{M}}$, using the gradient described at the beginning of this section. Requires $20 \%$ solvent $B$.

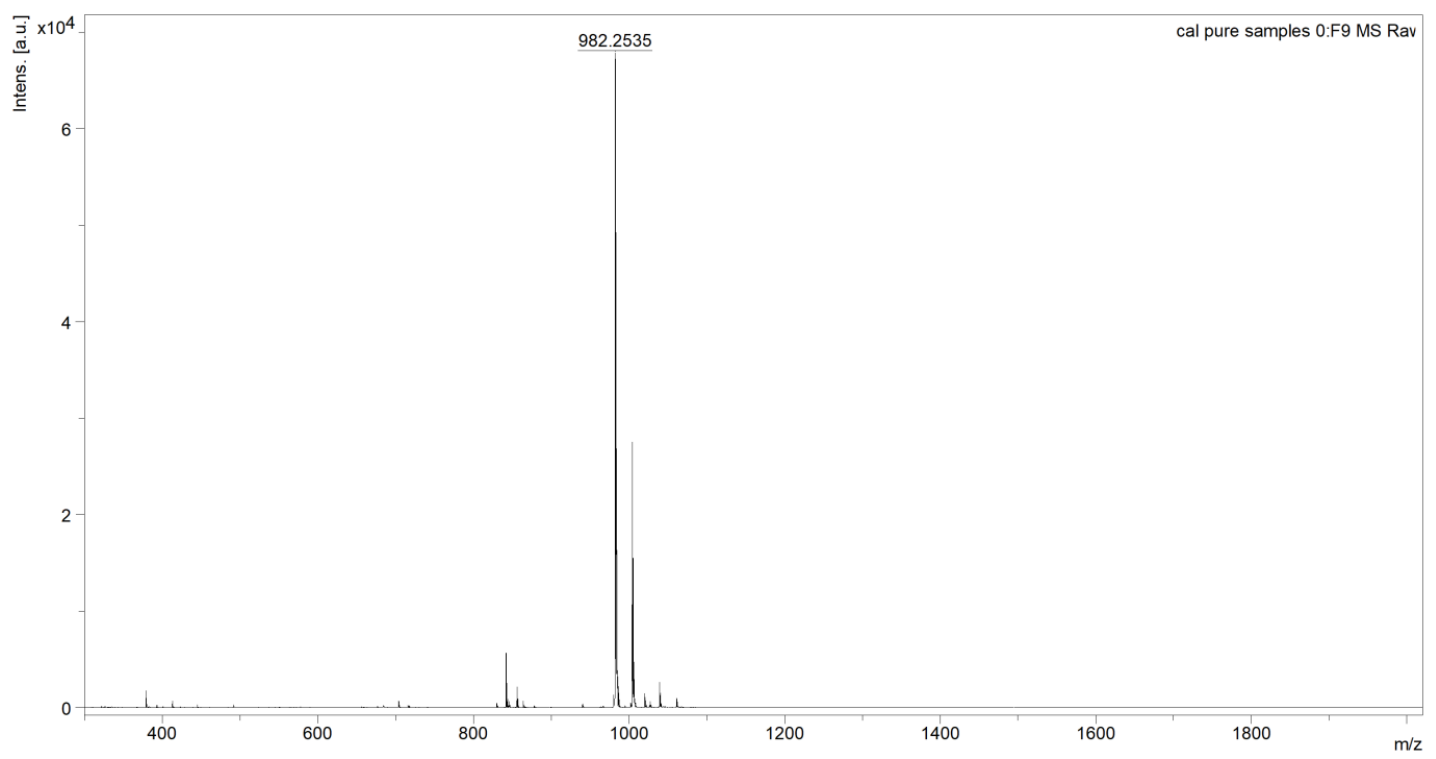

Figure S5.6. MALDI-TOF-MS of $\mathrm{K}^{2 \mathrm{M}} \mathrm{GlyK}^{2 \mathrm{M}}$

Mass calculated: $[\mathrm{M}+\mathrm{H}]^{+}=982.1140$, mass found: $[\mathrm{M}+\mathrm{H}]^{+}=982.2535,[\mathrm{M}+\mathrm{Na}]^{+}=1004.2610$. 
$\mathrm{K}^{2 \mathrm{M}} \mathrm{IleK}^{2 \mathrm{M}}$

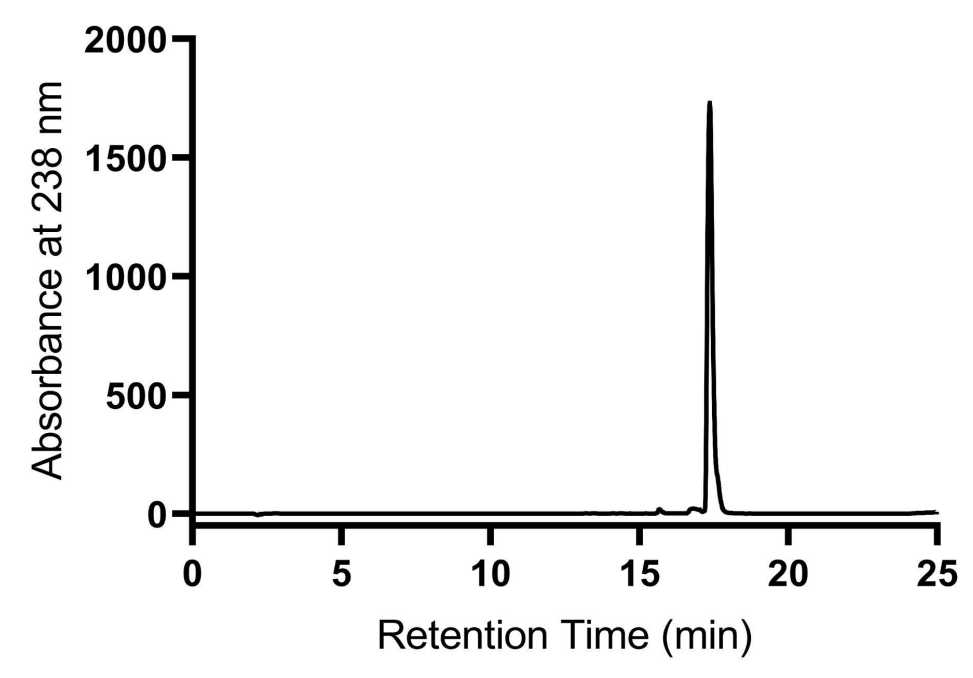

Figure S5.7. HPLC trace of $\mathrm{K}^{2 \mathrm{M}} \mathrm{IleK}^{2 \mathrm{M}}$, using the gradient described at the beginning of this section. Requires $25 \%$ solvent $B$.

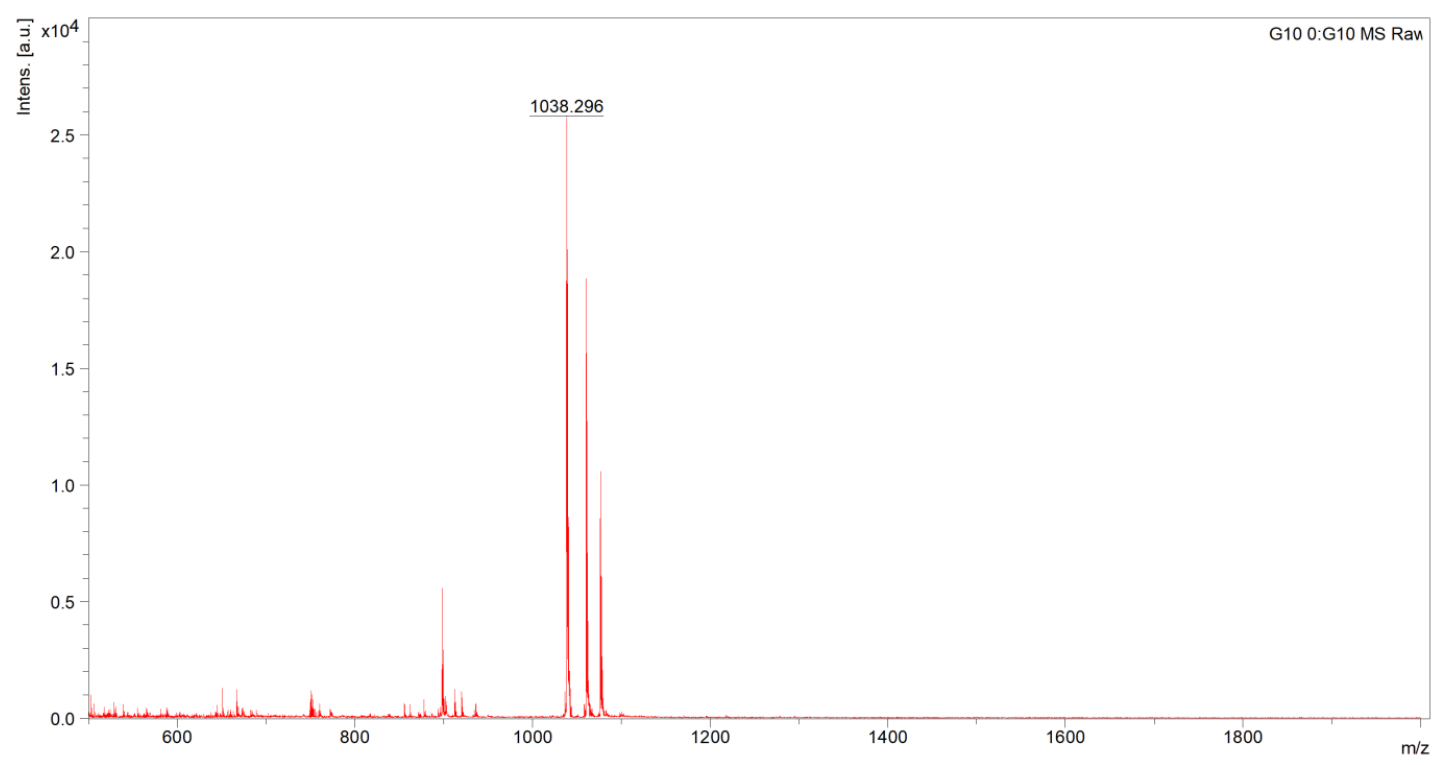

Figure S5.8. MALDI-TOF-MS of $\mathrm{K}^{2 \mathrm{M}} \mathrm{IleK}^{2 \mathrm{M}}$

Mass calculated: $[\mathrm{M}+\mathrm{H}]^{+}=1038.2220$, mass found: $[\mathrm{M}+\mathrm{H}]^{+}=1038.2965,[\mathrm{M}+\mathrm{Na}]^{+}=1060.2631,[\mathrm{M}+\mathrm{K}]^{+}=1076.2835$. 


\section{$\mathrm{K}^{2 \mathrm{M}}$ LeuK $^{2 \mathrm{M}}$}

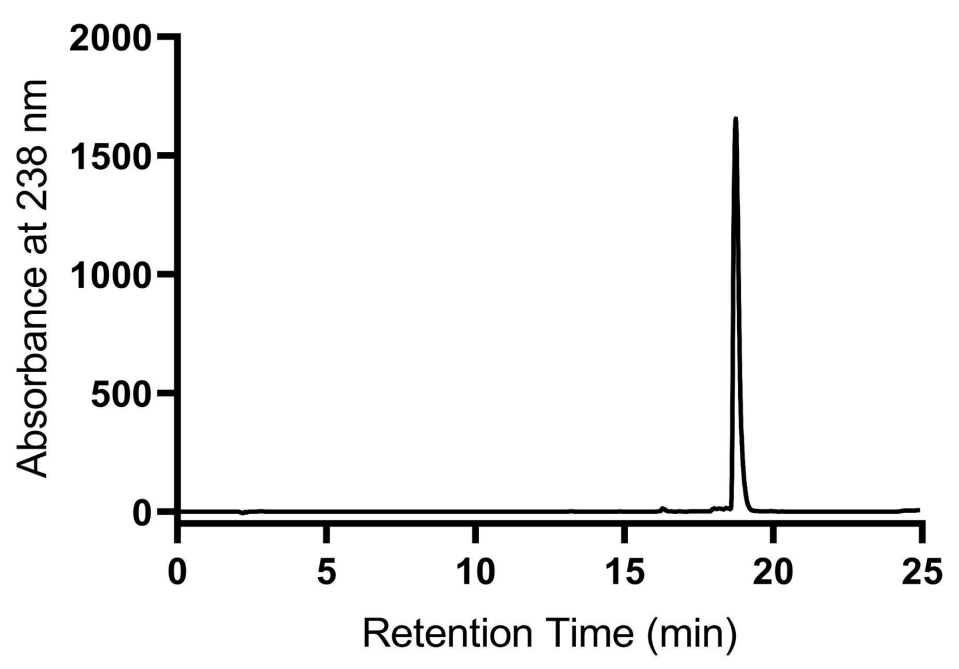

Figure S5.9. HPLC trace of $\mathrm{K}^{2 \mathrm{M}} \mathrm{LeuK}^{2 \mathrm{M}}$, using the gradient described at the beginning of this section. Requires $20 \%$ solvent B.

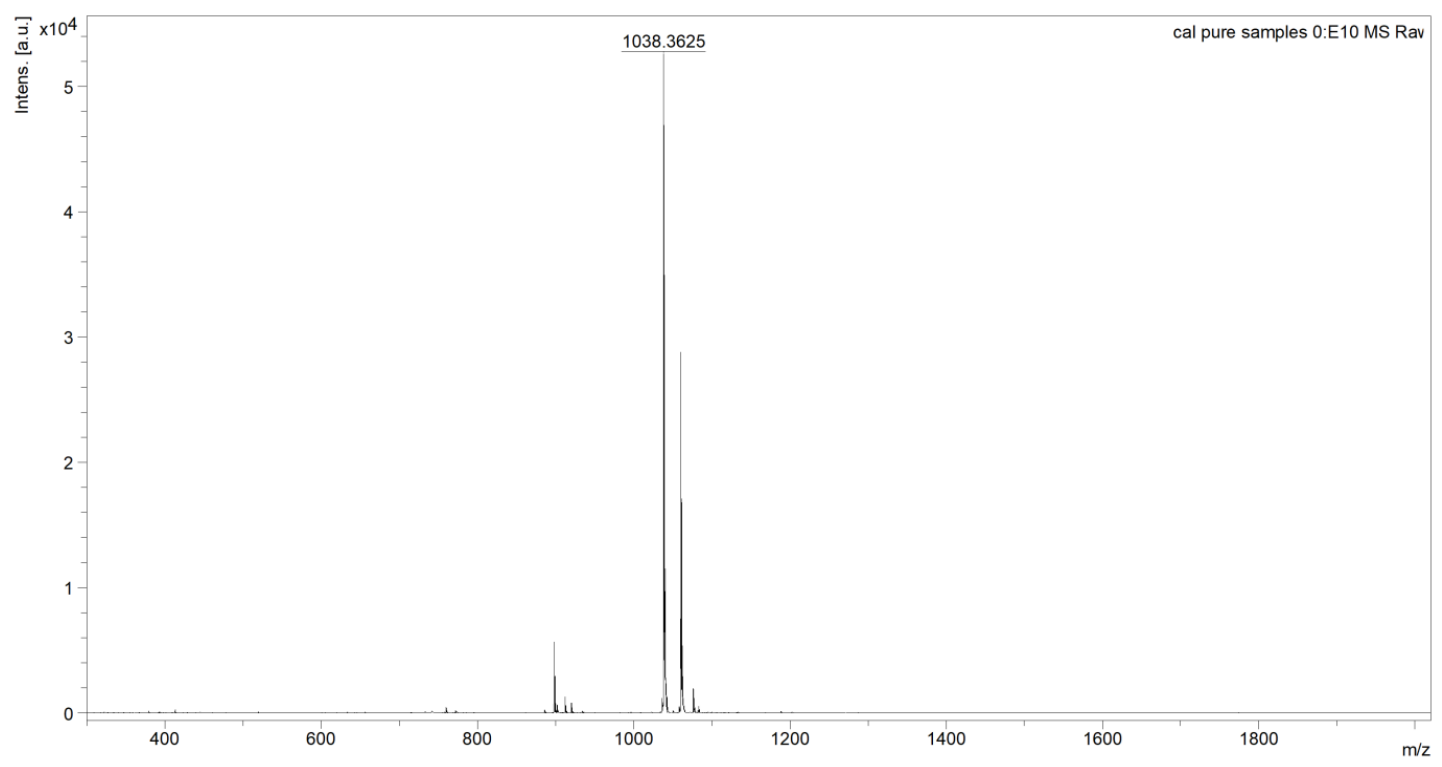

Figure S5.10. MALDI-TOF-MS of $\mathrm{K}^{2 \mathrm{M}}$ LeuK $^{2 \mathrm{M}}$

Mass calculated: $[\mathrm{M}+\mathrm{H}]^{+}=1038.2220$, mass found: $[\mathrm{M}+\mathrm{H}]^{+}=1038.3625,[\mathrm{M}+\mathrm{Na}]^{+}=1060.3631,[\mathrm{M}+\mathrm{K}]^{+}=1076.3262$. 


\section{$\mathrm{K}^{2 \mathrm{M}}$ LysK $^{2 \mathrm{M}}$}

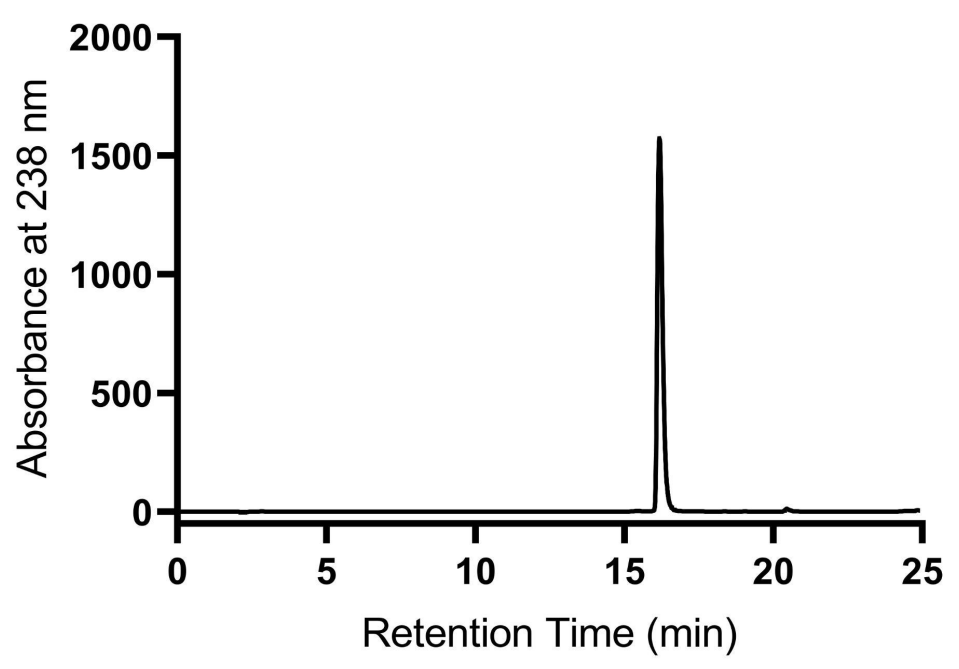

Figure S5.11. HPLC trace of $\mathrm{K}^{2 \mathrm{M}} \mathrm{LysK}^{2 \mathrm{M}}$, using the gradient described at the beginning of this section. Requires $20 \%$ solvent $B$.

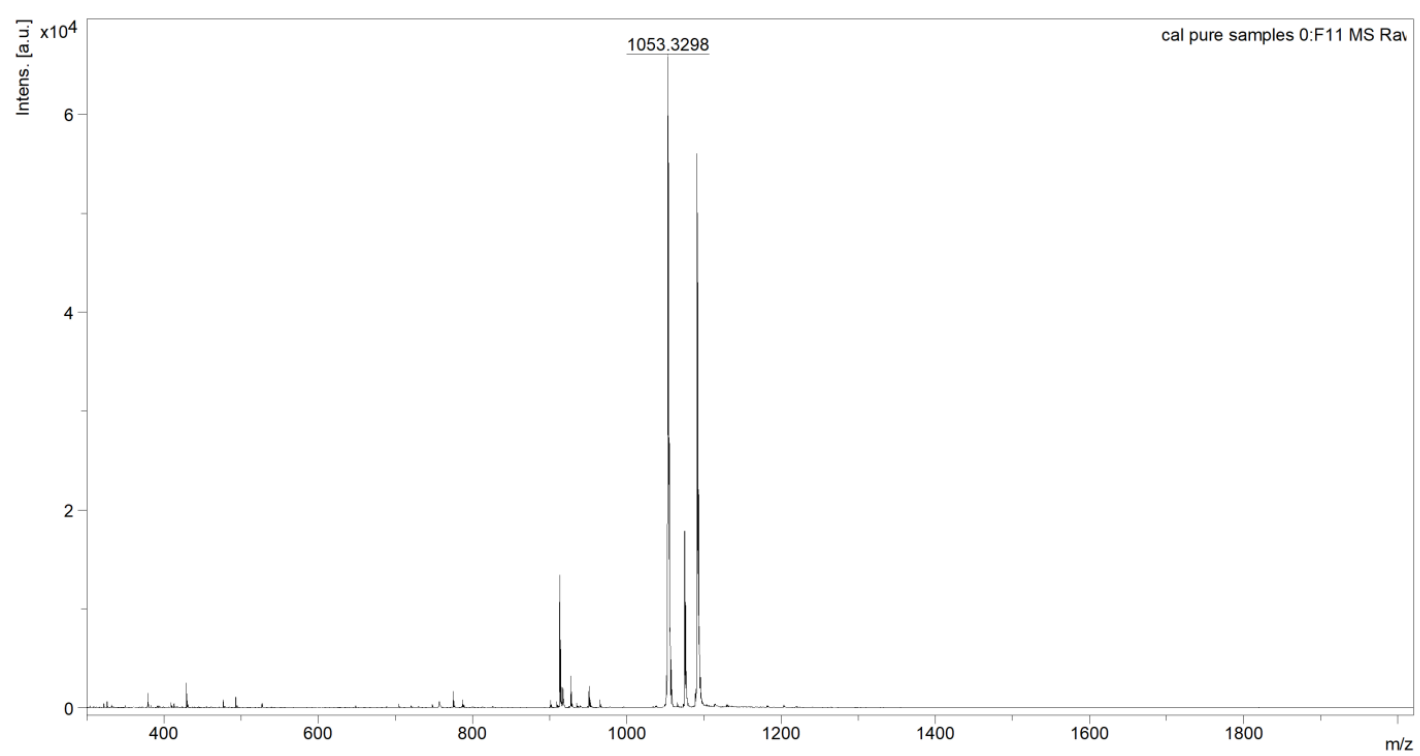

Figure S5.12. MALDI-TOF-MS of $\mathrm{K}^{2 \mathrm{M}}$ LysK $^{2 \mathrm{M}}$

Mass calculated: $[\mathrm{M}+\mathrm{H}]^{+}=1053.2370$, mass found: $[\mathrm{M}+\mathrm{H}]^{+}=1053.3298,[\mathrm{M}+\mathrm{Na}]^{+}=1075.3381,[\mathrm{M}+\mathrm{K}]^{+}=1091.3530$. 


\section{$\mathrm{K}^{2 \mathrm{M}} \mathrm{PheK}^{2 \mathrm{M}}$}

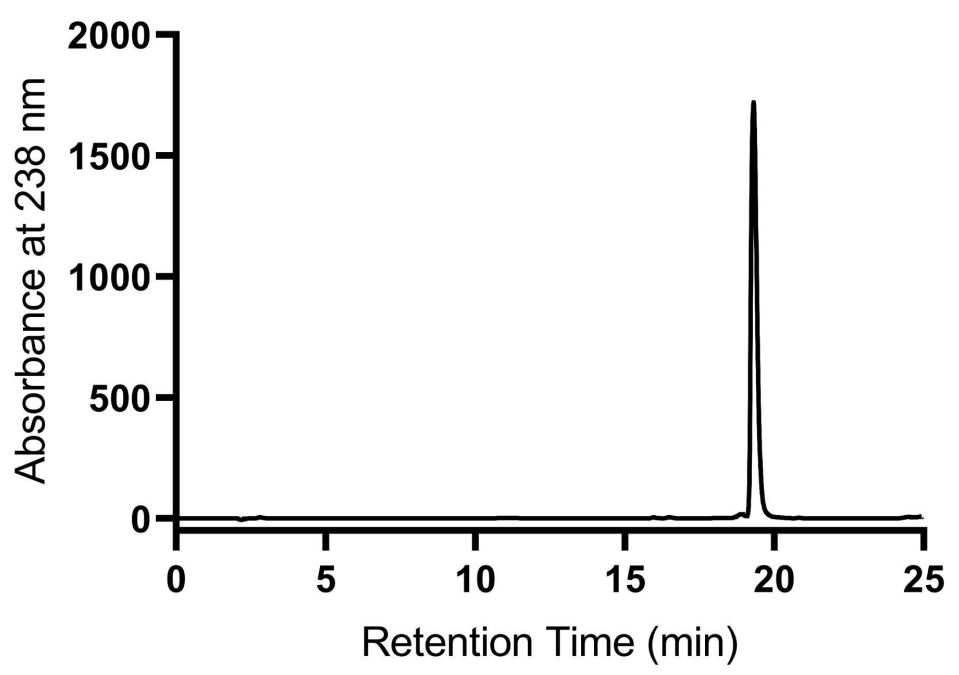

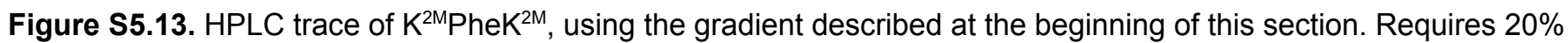
solvent $\mathrm{B}$.

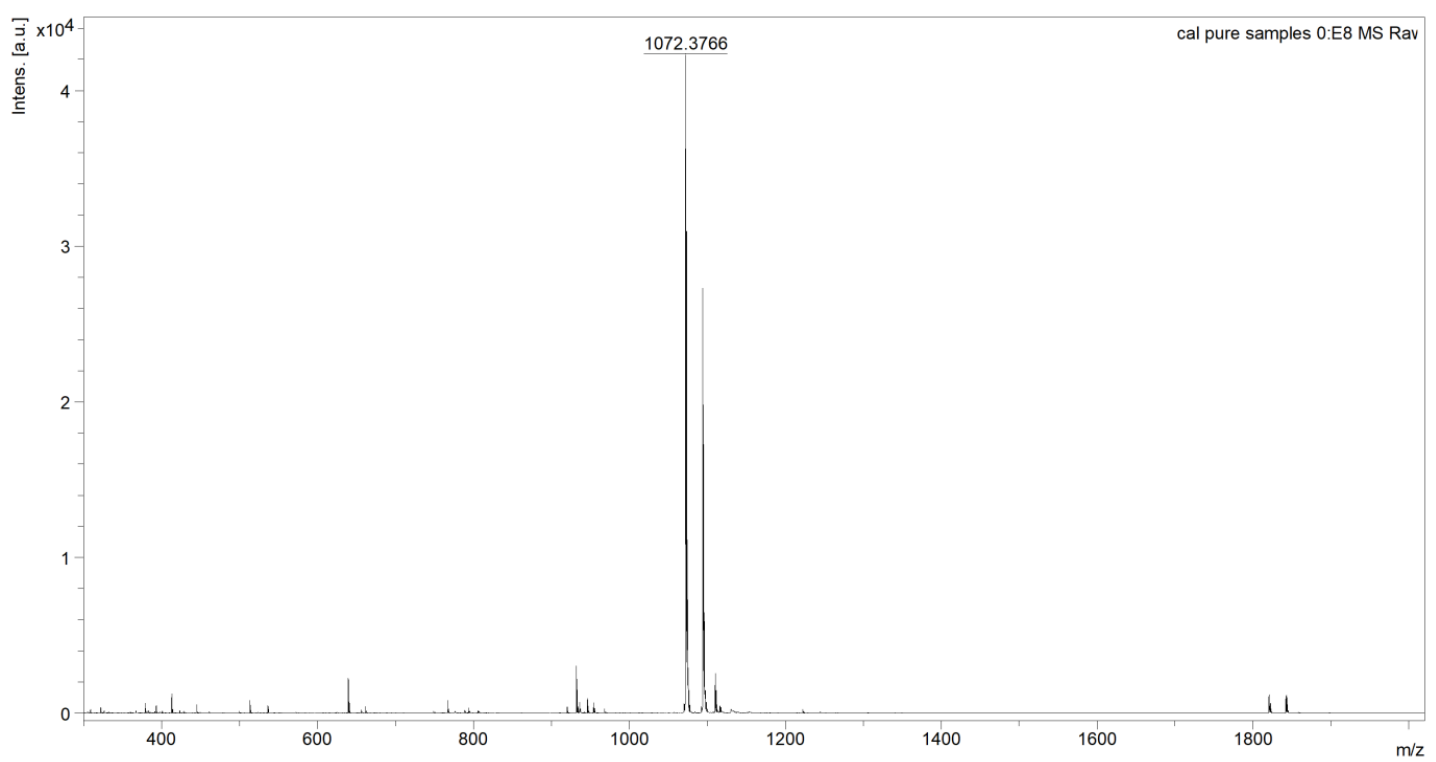

Figure S5.14. MALDI-TOF-MS of $\mathrm{K}^{2 \mathrm{M}} \mathrm{PheK}^{2 \mathrm{M}}$

Mass calculated: $[\mathrm{M}+\mathrm{H}]^{+}=1072.2390$, mass found: $[\mathrm{M}+\mathrm{H}]^{+}=1072.3766,[\mathrm{M}+\mathrm{Na}]^{+}=1094.4011,[\mathrm{M}+\mathrm{K}]^{+}=1110.3745$. 


\section{$\mathrm{K}^{2 \mathrm{M}} \operatorname{ProK}^{2 \mathrm{M}}$}

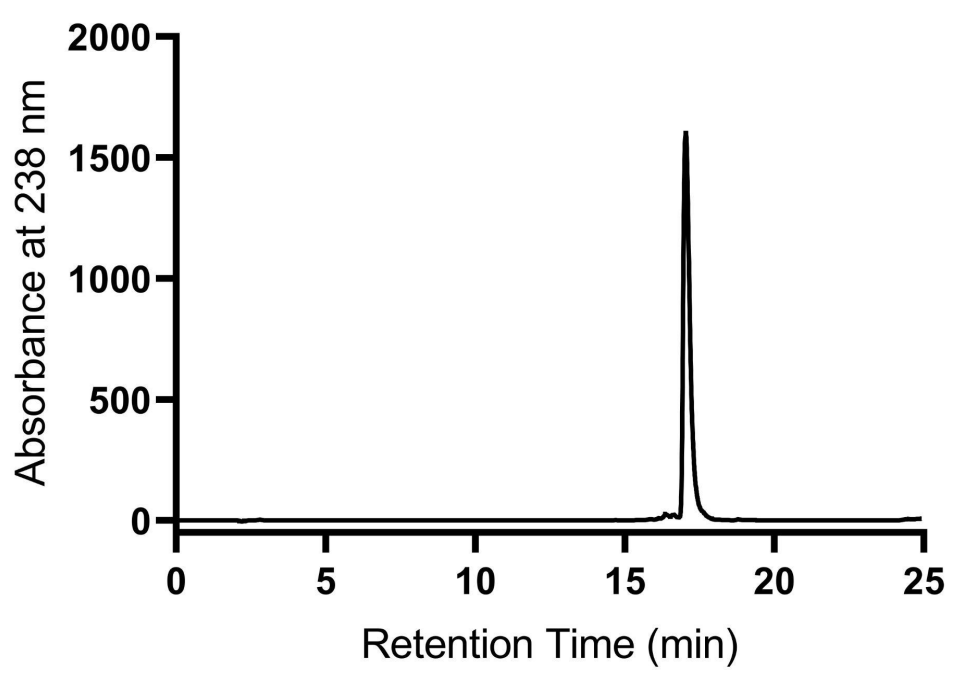

Figure S5.15. HPLC trace of $\mathrm{K}^{2 \mathrm{M}} \mathrm{ProK}^{2 \mathrm{M}}$, using the gradient described at the beginning of this section. Requires $18 \%$ solvent $\mathrm{B}$.

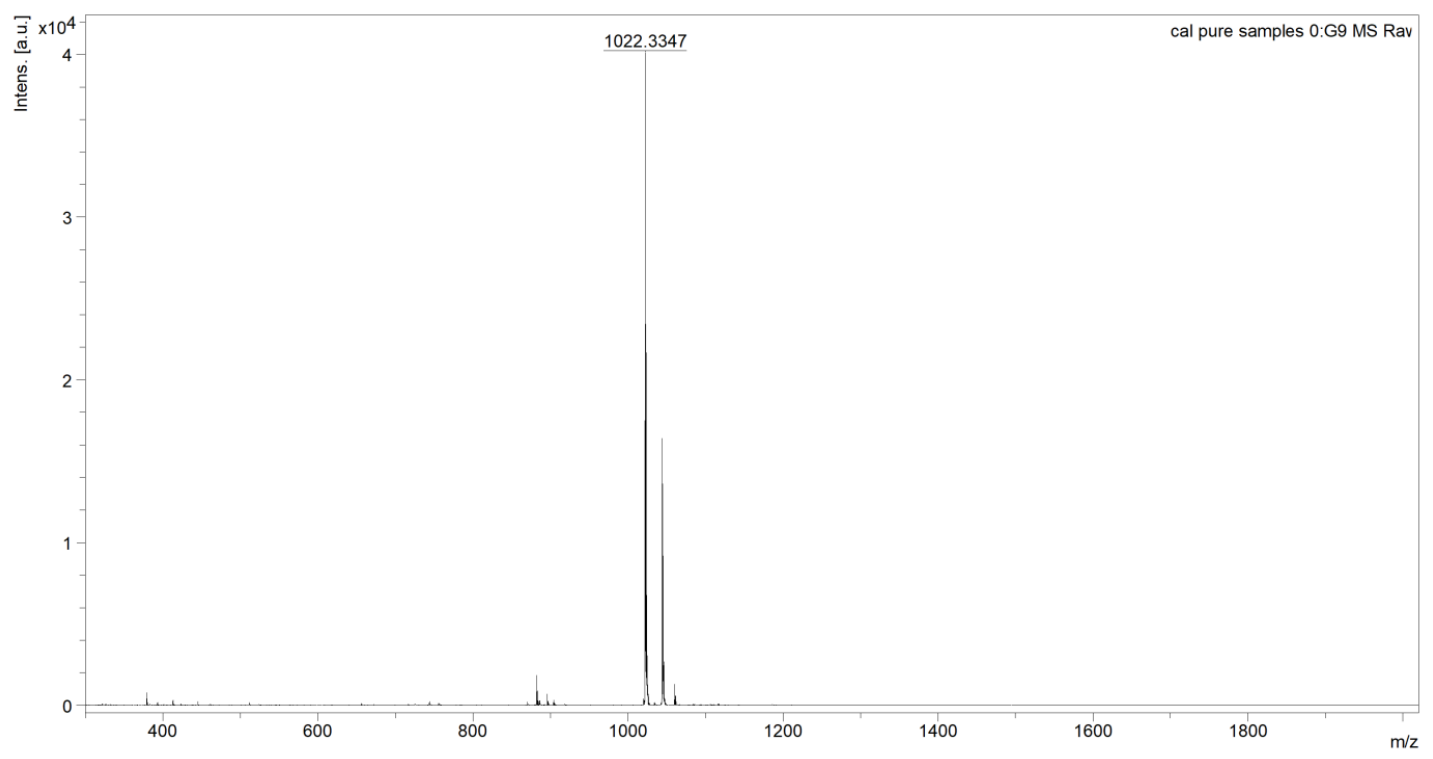

Figure S5.16. MALDI-TOF-MS of $\mathrm{K}^{2 \mathrm{M}} \mathrm{ProK}^{2 \mathrm{M}}$

Mass calculated: $[\mathrm{M}+\mathrm{H}]^{+}=1022.1790$, mass found: $[\mathrm{M}+\mathrm{H}]^{+}=1022.3347,[\mathrm{M}+\mathrm{Na}]^{+}=1044.3425$. 


\section{$\mathrm{K}^{2 \mathrm{M}} \operatorname{SerK}^{2 \mathrm{M}}$}

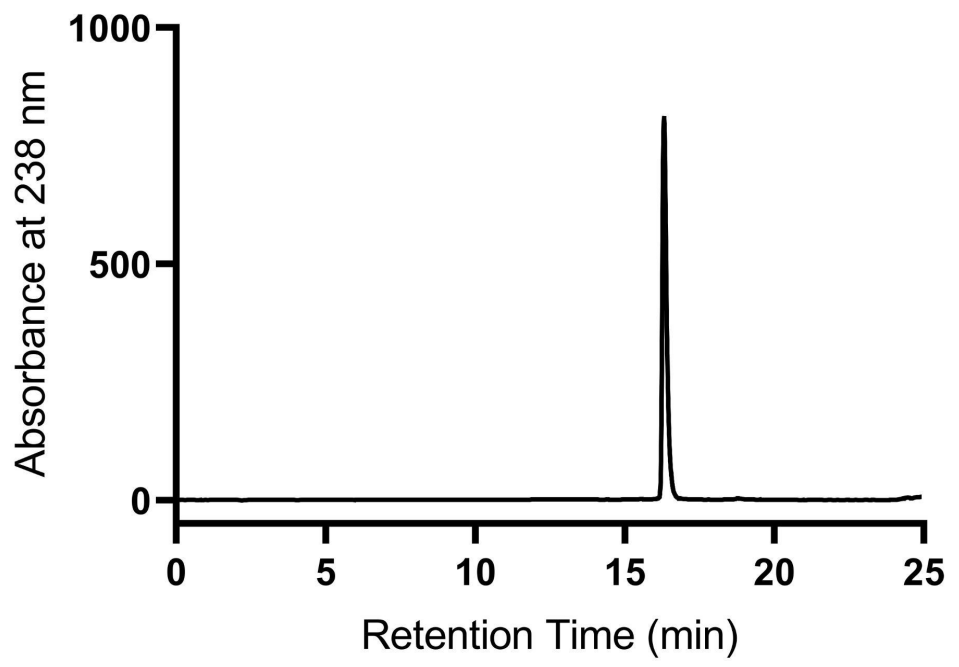

Figure S5.17. HPLC trace of $\mathrm{K}^{2 \mathrm{M}} \mathrm{SerK}^{2 \mathrm{M}}$, using the gradient described at the beginning of this section. Requires $20 \%$ solvent $\mathrm{B}$.

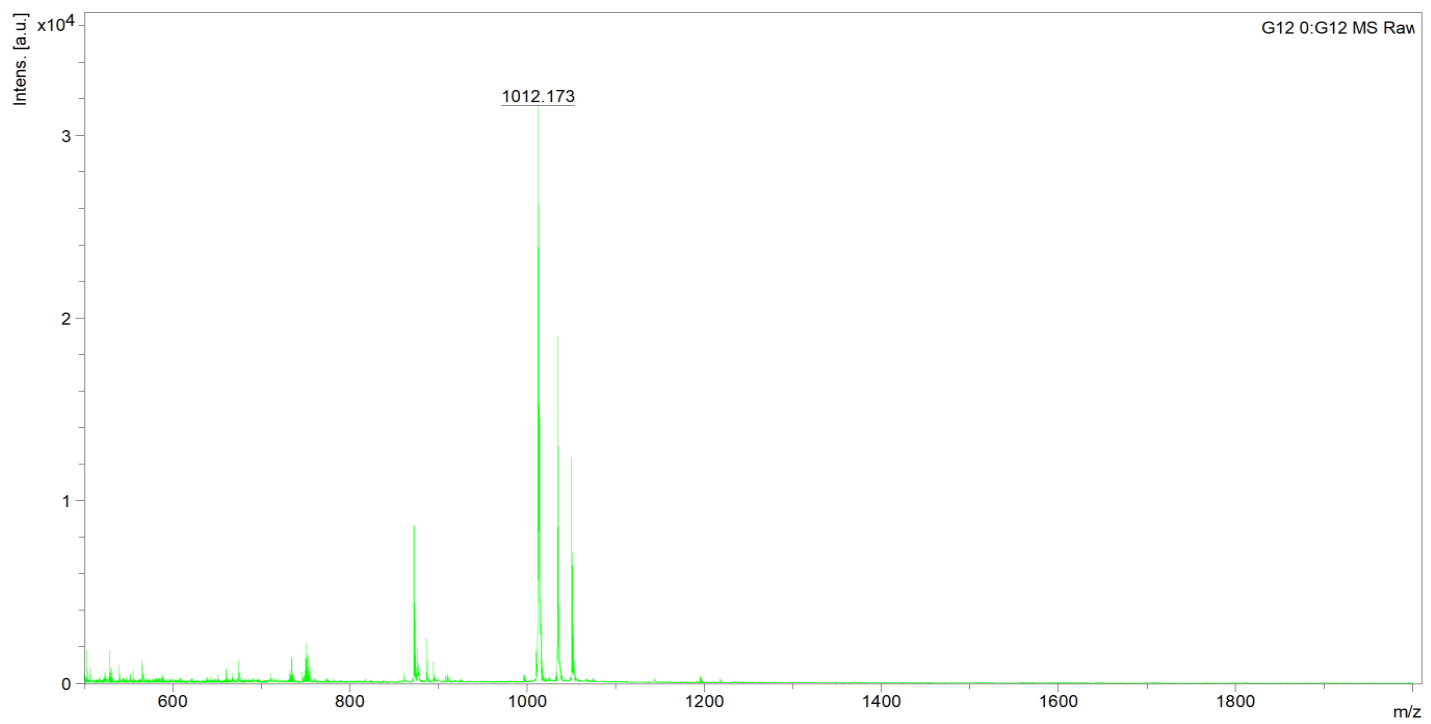

Figure S5.18. MALDI-TOF-MS of $\mathrm{K}^{2 \mathrm{M}}$ SerK $^{2 \mathrm{M}}$

Mass calculated: $[\mathrm{M}+\mathrm{H}]^{+}=1012.1400$, mass found: $[\mathrm{M}+\mathrm{H}]^{+}=1012.1725,[\mathrm{M}+\mathrm{Na}]^{+}=1034.1833,[\mathrm{M}+\mathrm{K}]^{+}=1050.1824$. 


\section{$\mathrm{K}^{2 \mathrm{M}} \mathrm{tBuGlyK}^{2 \mathrm{M}}$}

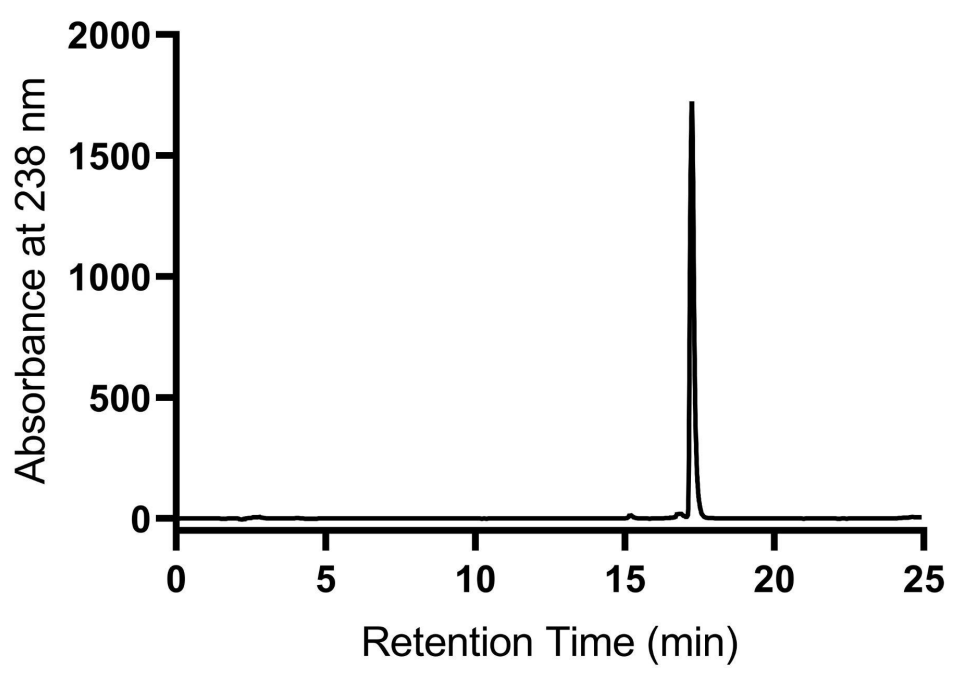

Figure S5.19. HPLC trace of $\mathrm{K}^{2 \mathrm{M}} \mathrm{tBuGlyK}{ }^{2 \mathrm{M}}$, using the gradient described at the beginning of this section. Requires $25 \%$ solvent $\mathrm{B}$.

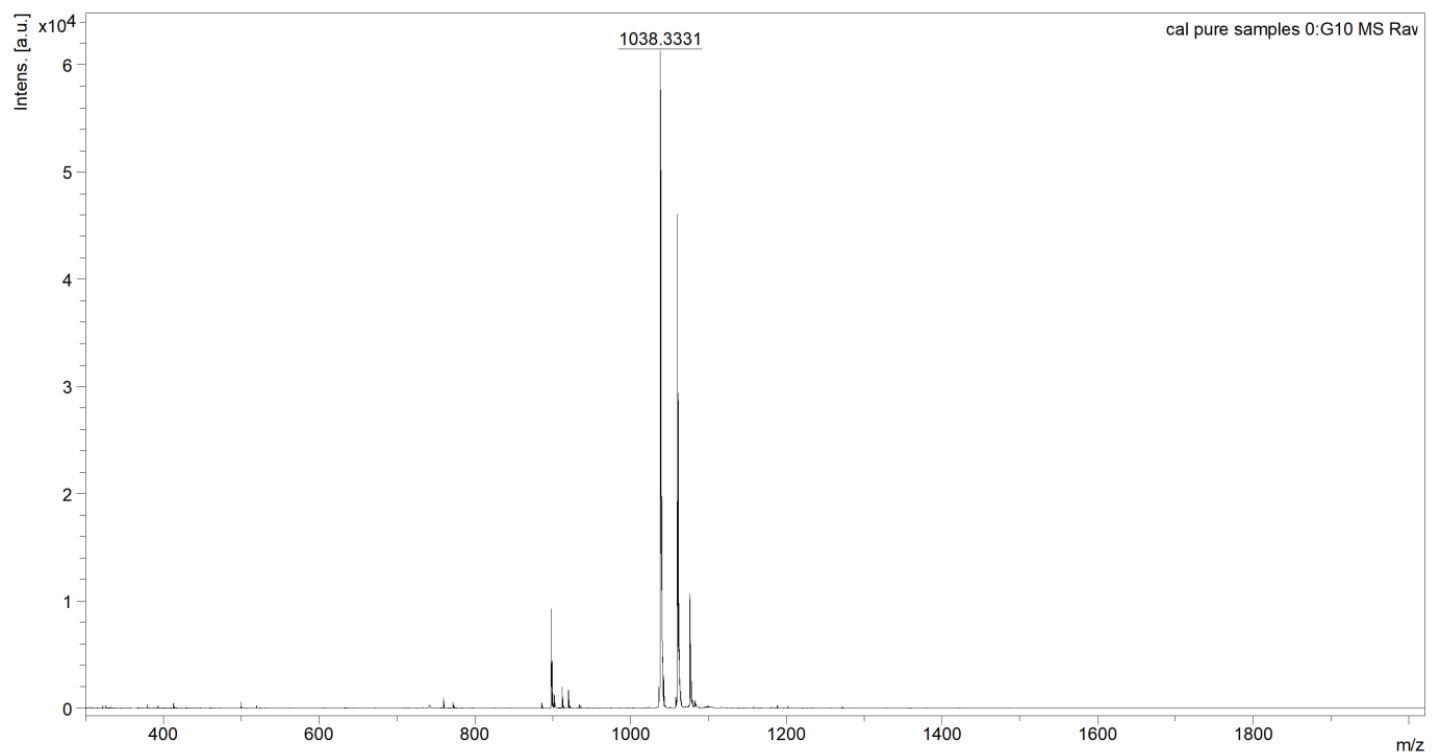

Figure S5.20. MALDI-TOF-MS of $\mathrm{K}^{2 \mathrm{M}} \mathrm{tBuGlyK}^{2 \mathrm{M}}$

Mass calculated: $[\mathrm{M}+\mathrm{H}]^{+}=1038.2220$, mass found: $[\mathrm{M}+\mathrm{H}]^{+}=1038.3331,[\mathrm{M}+\mathrm{Na}]^{+}=1060.3631,[\mathrm{M}+\mathrm{K}]^{+}=1076.3262$. 


\section{$\mathrm{K}^{2 \mathrm{M}} \mathrm{ThrK}^{2 \mathrm{M}}$}

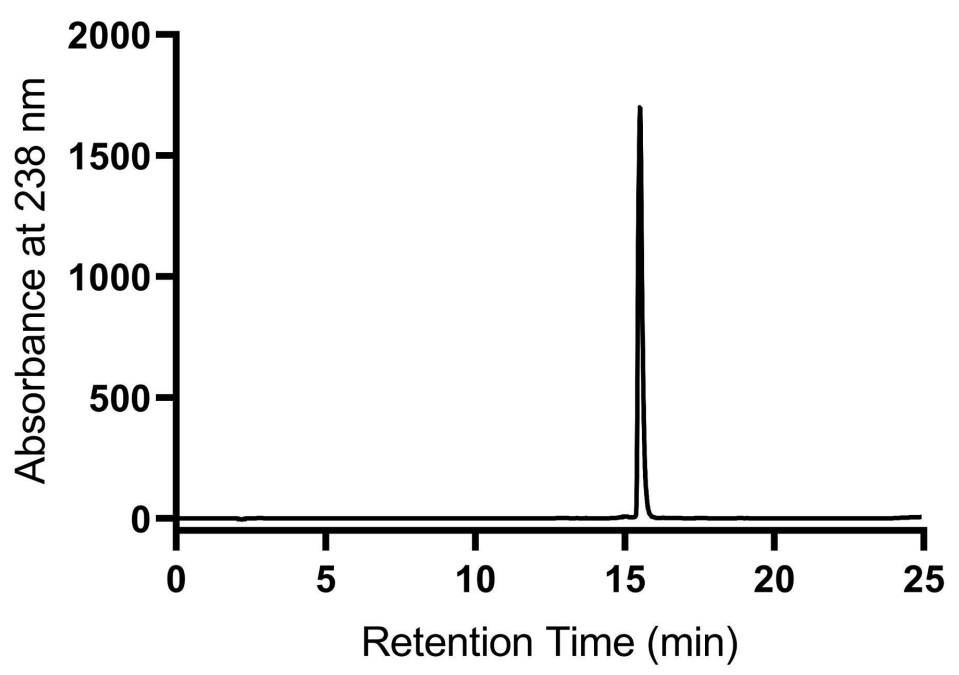

Figure S5.21. HPLC trace of $\mathrm{K}^{2 \mathrm{M}} \mathrm{ThrK}^{2 \mathrm{M}}$, using the gradient described at the beginning of this section. Requires $25 \%$ solvent $\mathrm{B}$.

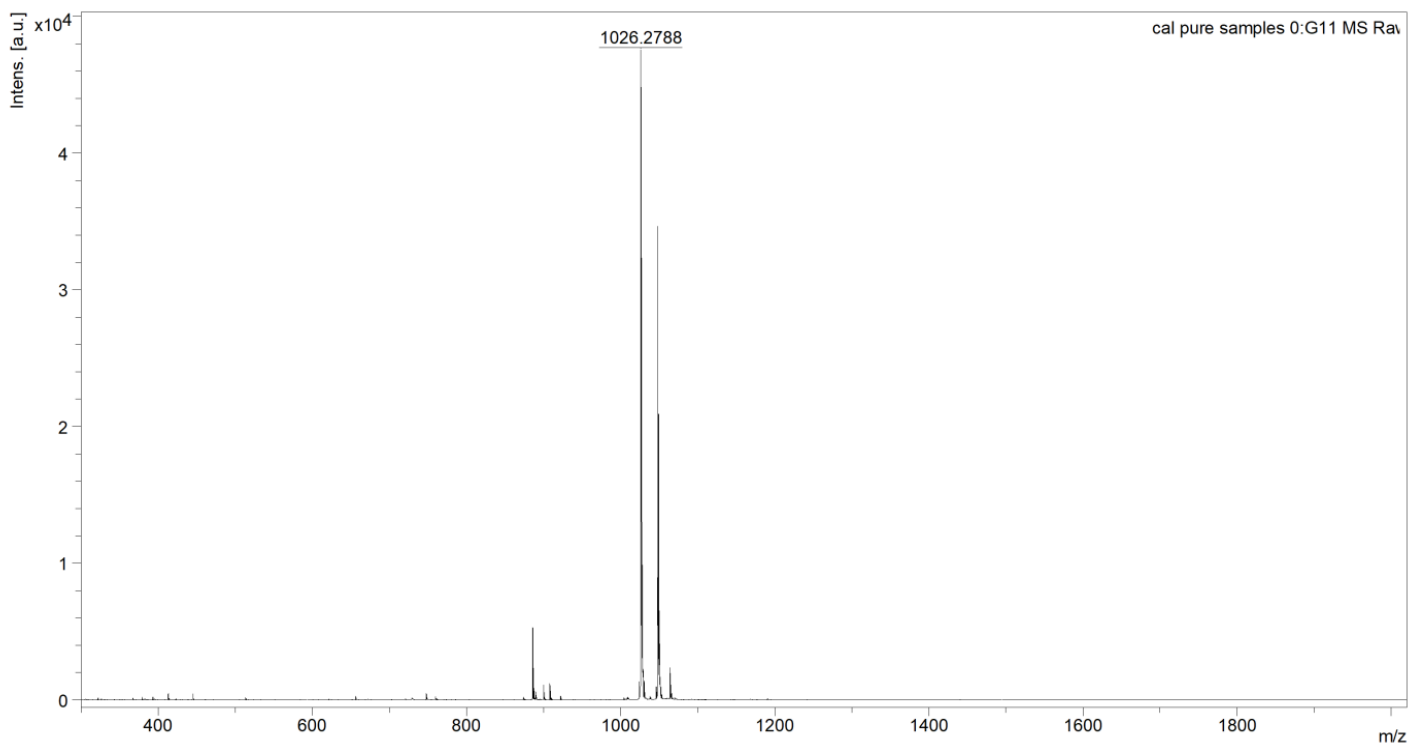

Figure S5.22. MALDI-TOF-MS of $\mathrm{K}^{2 \mathrm{M}} \mathrm{ThrK}^{2 \mathrm{M}}$

Mass calculated: $[\mathrm{M}+\mathrm{H}]^{+}=1026.1670$, mass found: $[\mathrm{M}+\mathrm{H}]^{+}=1026.2788,[\mathrm{M}+\mathrm{Na}]^{+}=1048.2992$. 


\section{$\mathrm{K}^{2 \mathrm{M}} \operatorname{TrpK}^{2 \mathrm{M}}$}

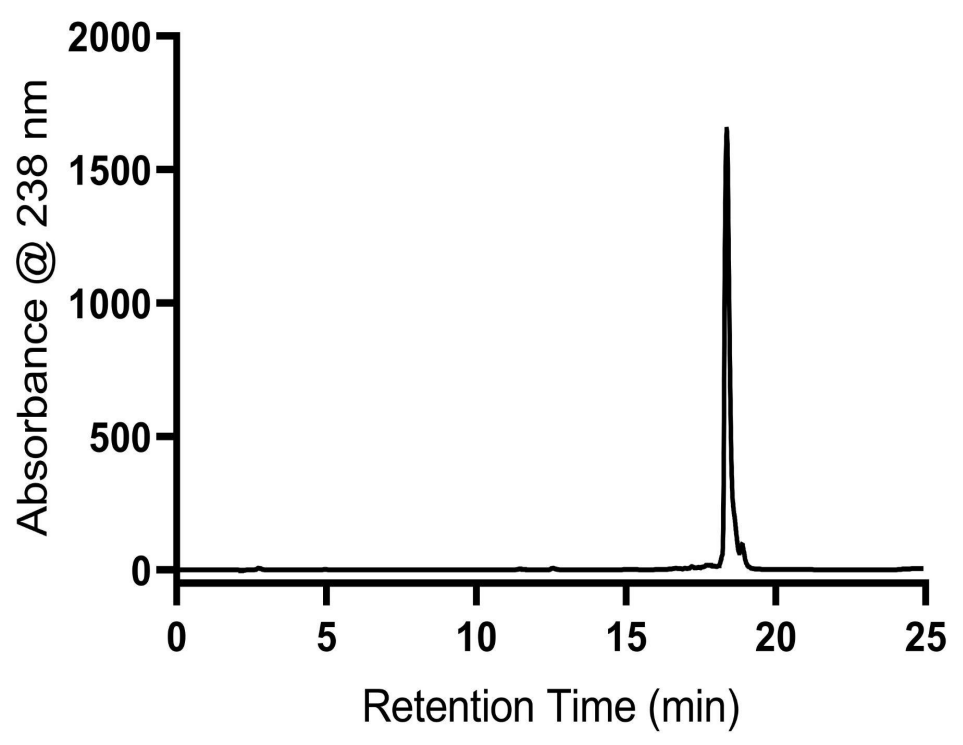

Figure S5.23. HPLC trace of $\mathrm{K}^{2 \mathrm{M}} \mathrm{TrpK}^{2 \mathrm{M}}$, using the gradient described at the beginning of this section. Requires $25 \%$ solvent B.

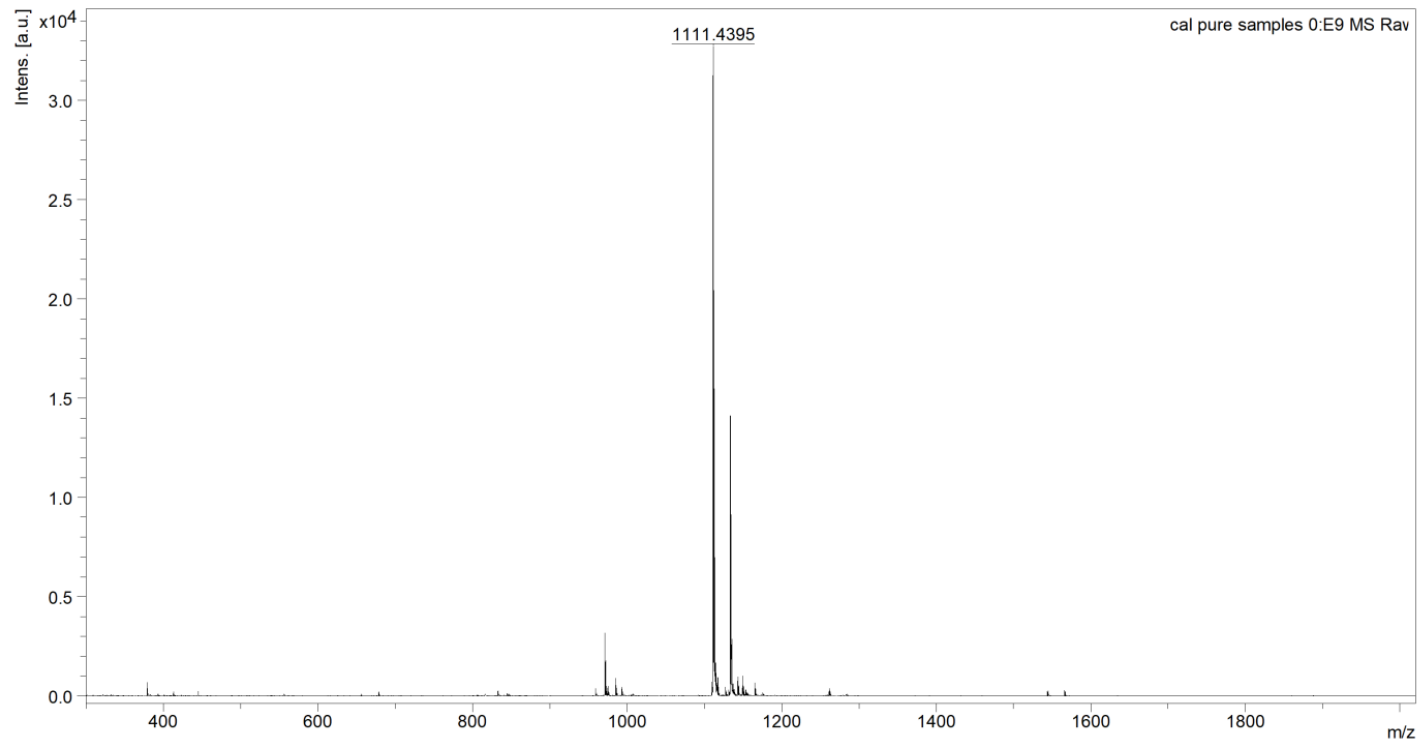

Figure S5.24. MALDI-TOF-MS of $\mathrm{K}^{2 \mathrm{M}} \mathrm{TrpK}^{2 \mathrm{M}}$

Mass calculated: $[\mathrm{M}+\mathrm{H}]^{+}=1111.2760$, mass found: $[\mathrm{M}+\mathrm{H}]^{+}=1111.4395,[\mathrm{M}+\mathrm{Na}]^{+}=1133.4299$. 


\section{$\mathrm{K}^{2 \mathrm{M}} \mathrm{TyrK}^{2 \mathrm{M}}$}

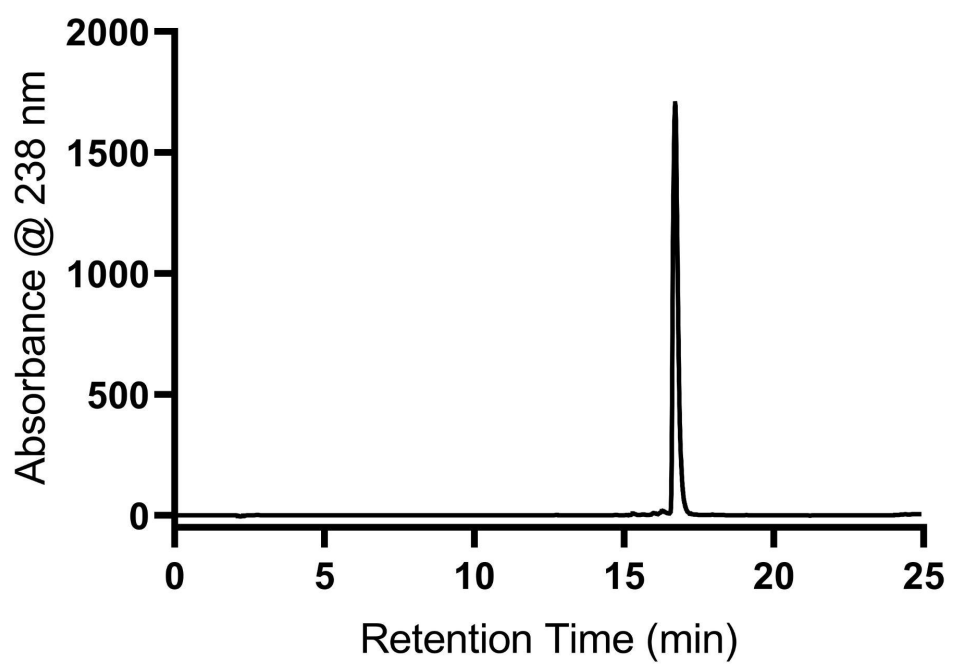

Figure S5.25. HPLC trace of $\mathrm{K}^{2 \mathrm{M}} \mathrm{TyrK}^{2 \mathrm{M}}$, using the gradient described at the beginning of this section. Requires $25 \%$ solvent $\mathrm{B}$.

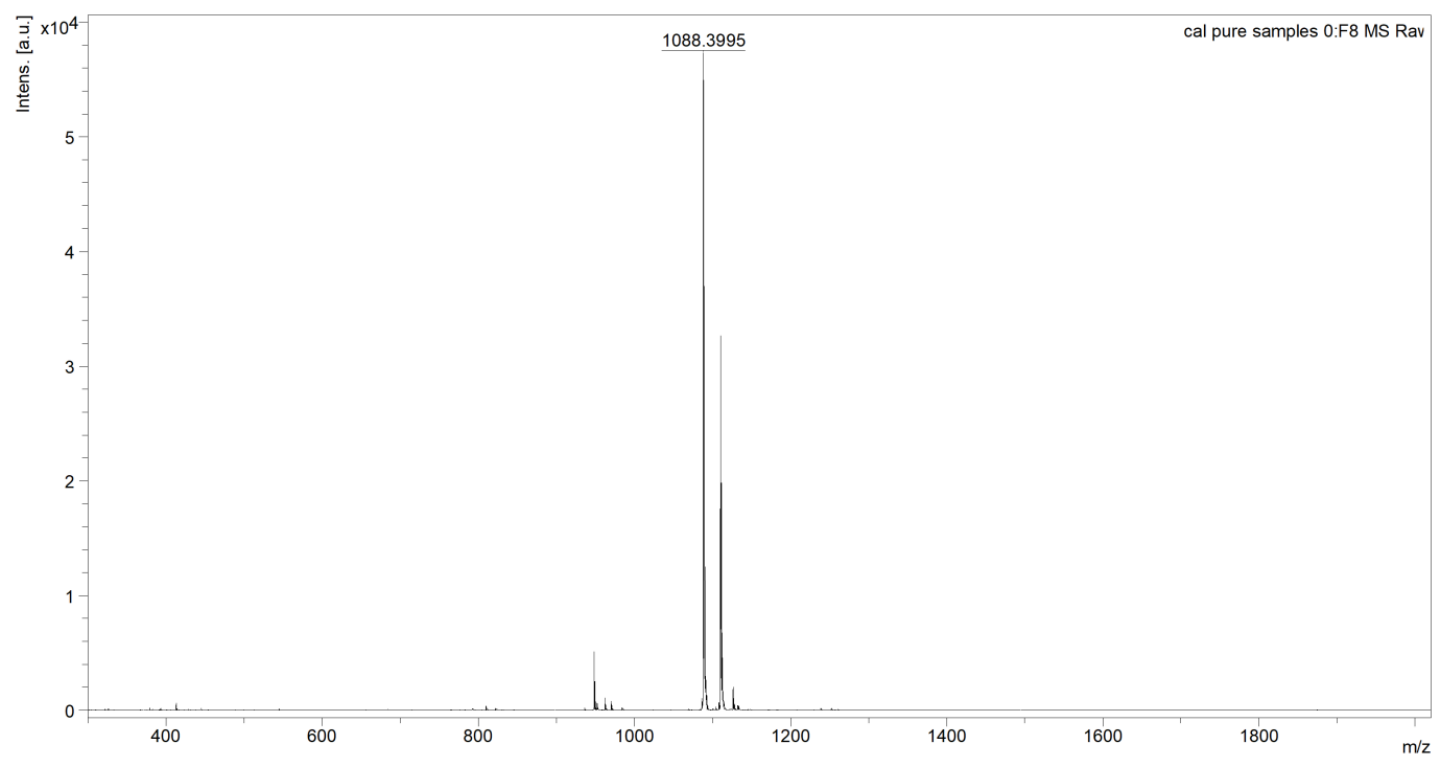

Figure S5.26. MALDI-TOF-MS of $\mathrm{K}^{2 \mathrm{M}} \mathrm{TyrK}^{2 \mathrm{M}}$

Mass calculated: $[\mathrm{M}+\mathrm{H}]^{+}=1088.2380$, mass found: $[\mathrm{M}+\mathrm{H}]^{+}=1088.3995,[\mathrm{M}+\mathrm{Na}]^{+}=1110.4049,[\mathrm{M}+\mathrm{K}]^{+}=1126.3719$. 


\section{$\mathrm{K}^{2 \mathrm{M}} \mathrm{ValK}^{2 \mathrm{M}}$}

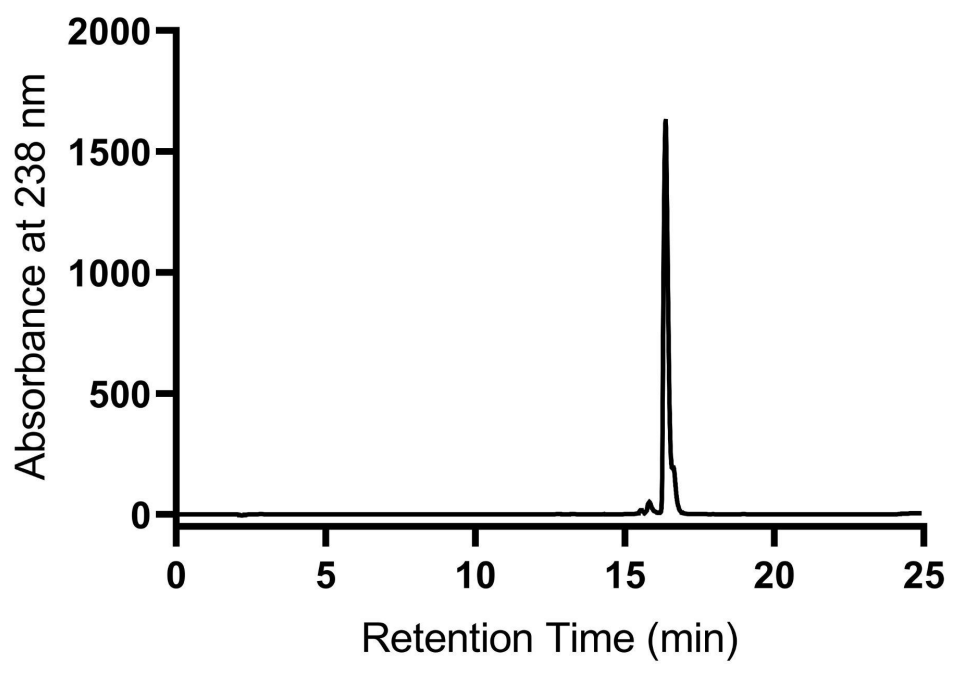

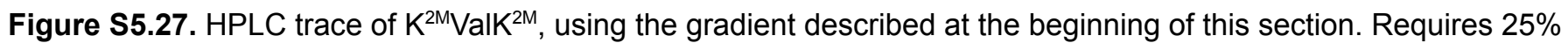
solvent $\mathrm{B}$.

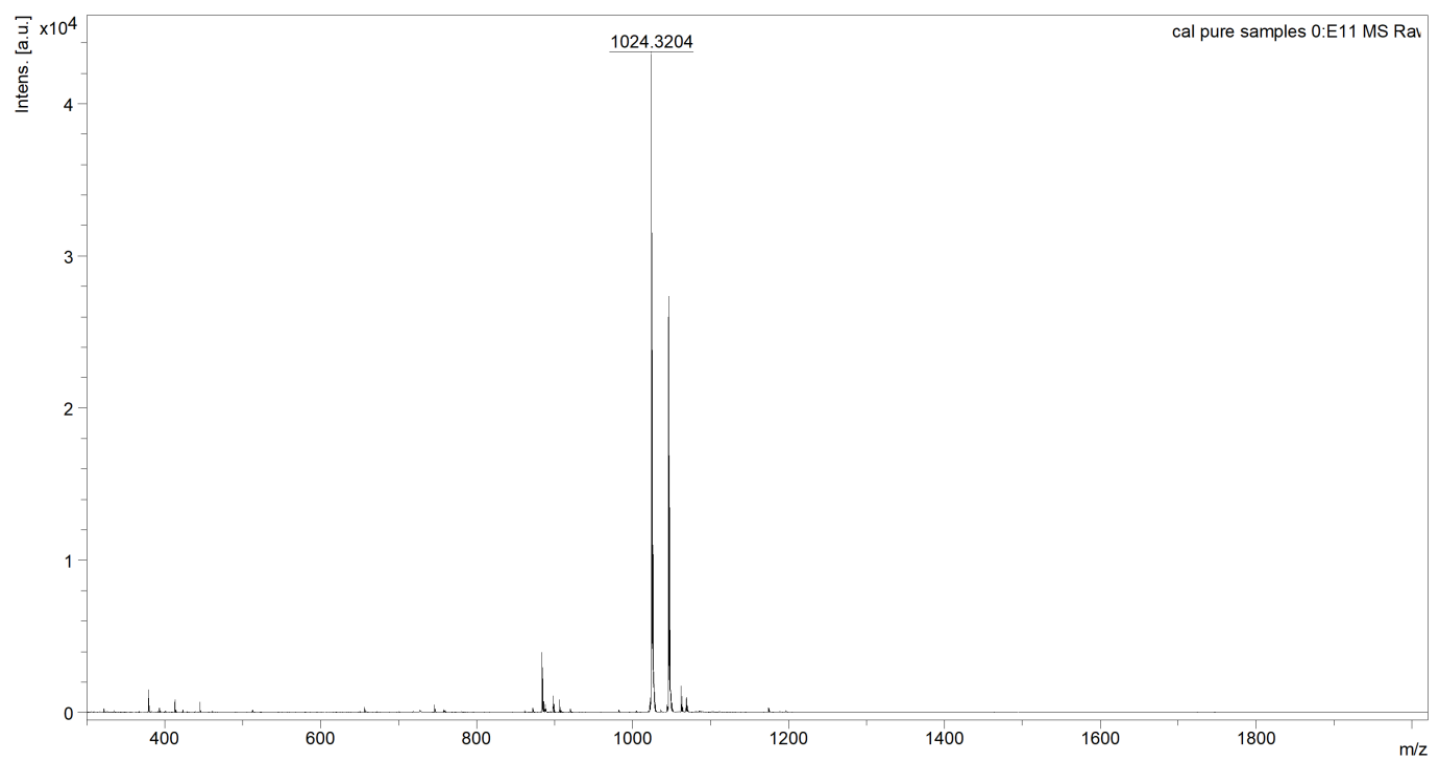

Figure S5.28. MALDI-TOF-MS of $\mathrm{K}^{2 \mathrm{M}} \mathrm{ValK}^{2 \mathrm{M}}$

Mass calculated: $[\mathrm{M}+\mathrm{H}]^{+}=1024.1950$, mass found: $[\mathrm{M}+\mathrm{H}]^{+}=1024.3204,[\mathrm{M}+\mathrm{Na}]^{+}=1046.3199$. 


\section{Fmoc-K ${ }^{2 \mathrm{M}}-\mathrm{OH}$}

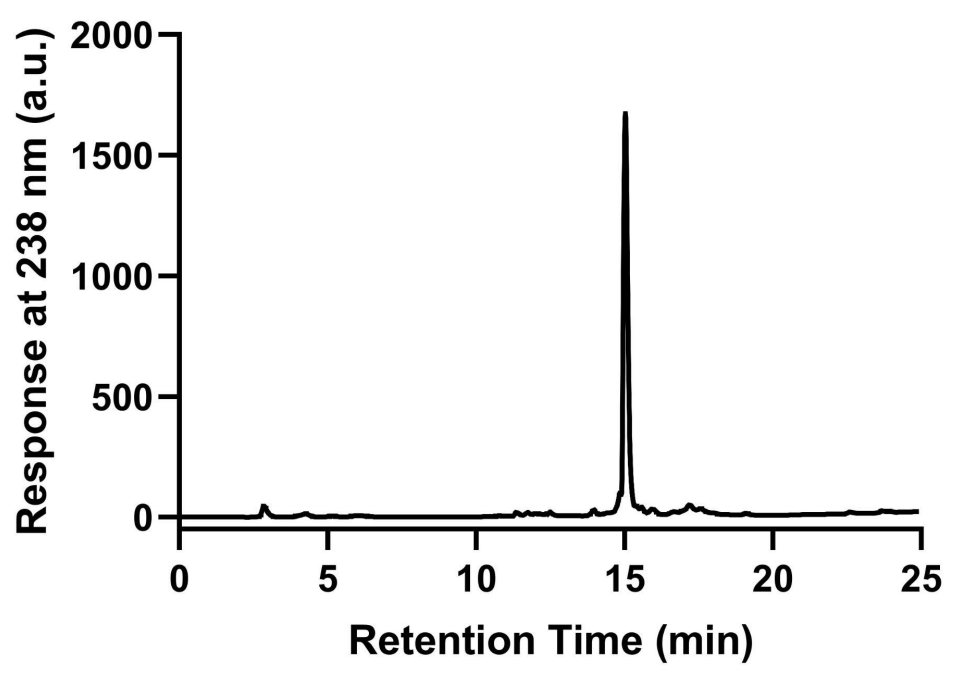

Figure S5.29. HPLC trace of $\mathrm{Fmoc}-\mathrm{K}^{2 \mathrm{M}}-\mathrm{OH}$, using the gradient described the beginning of this section. Requires $60 \%$ solvent $B$.

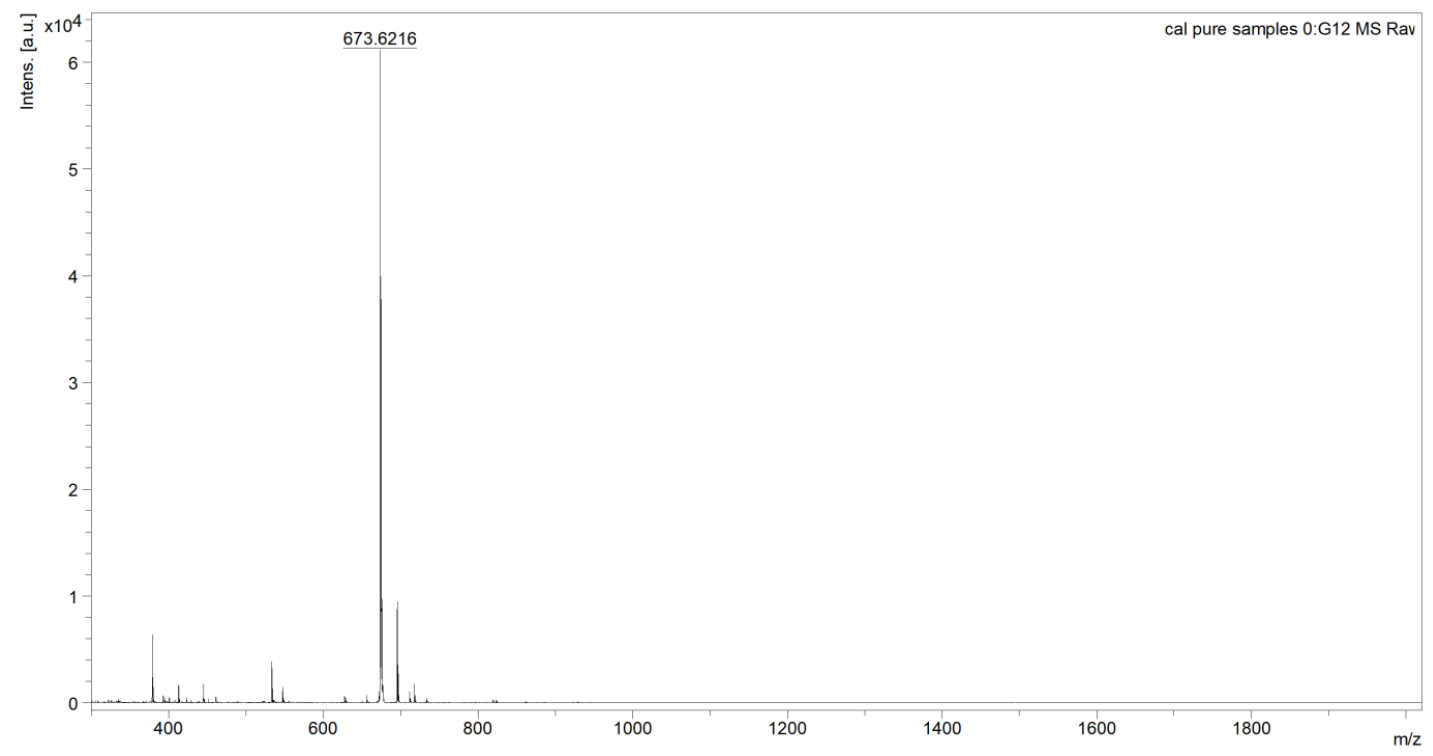

Figure S5.30. MALDI-TOF-MS of Fmoc- $\mathrm{K}^{2 \mathrm{M}} \mathrm{OH}$.

Mass calculated: $[\mathrm{M}+\mathrm{H}]^{+}=673.7550$, mass found: $[\mathrm{M}+\mathrm{H}]^{+}=673.6216,[\mathrm{M}+\mathrm{Na}]^{+}=695.5884$. 


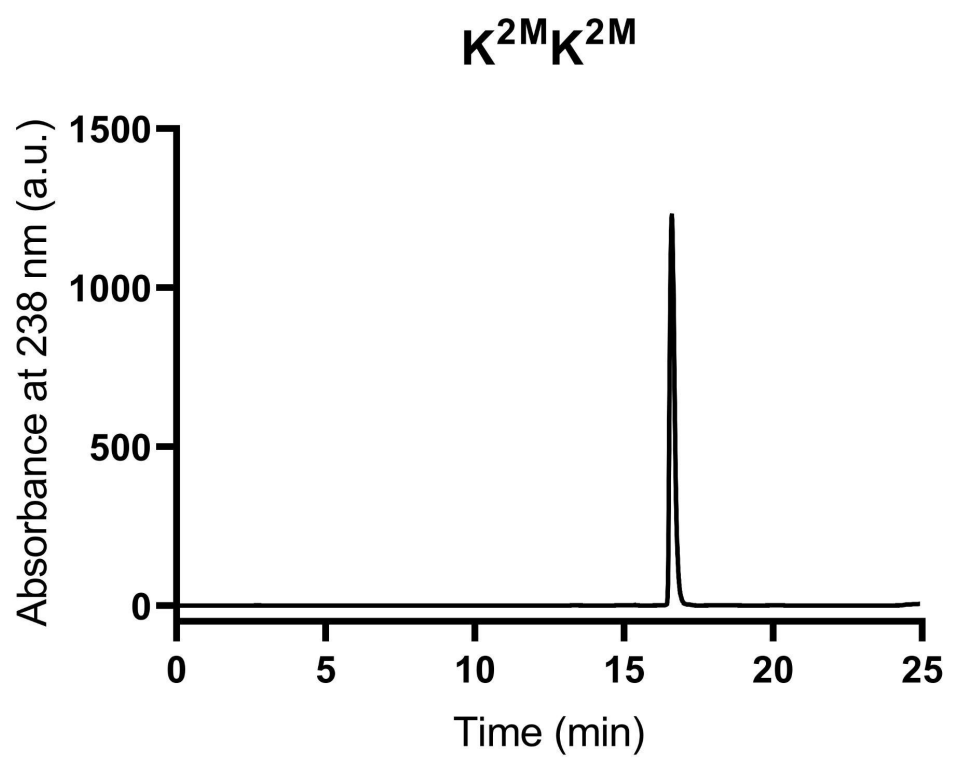

Figure S5.31. HPLC trace of $\mathrm{K}^{2 \mathrm{M}} \mathrm{K}^{2 \mathrm{M}}$. Requires $15 \%$ solvent $\mathrm{B}$

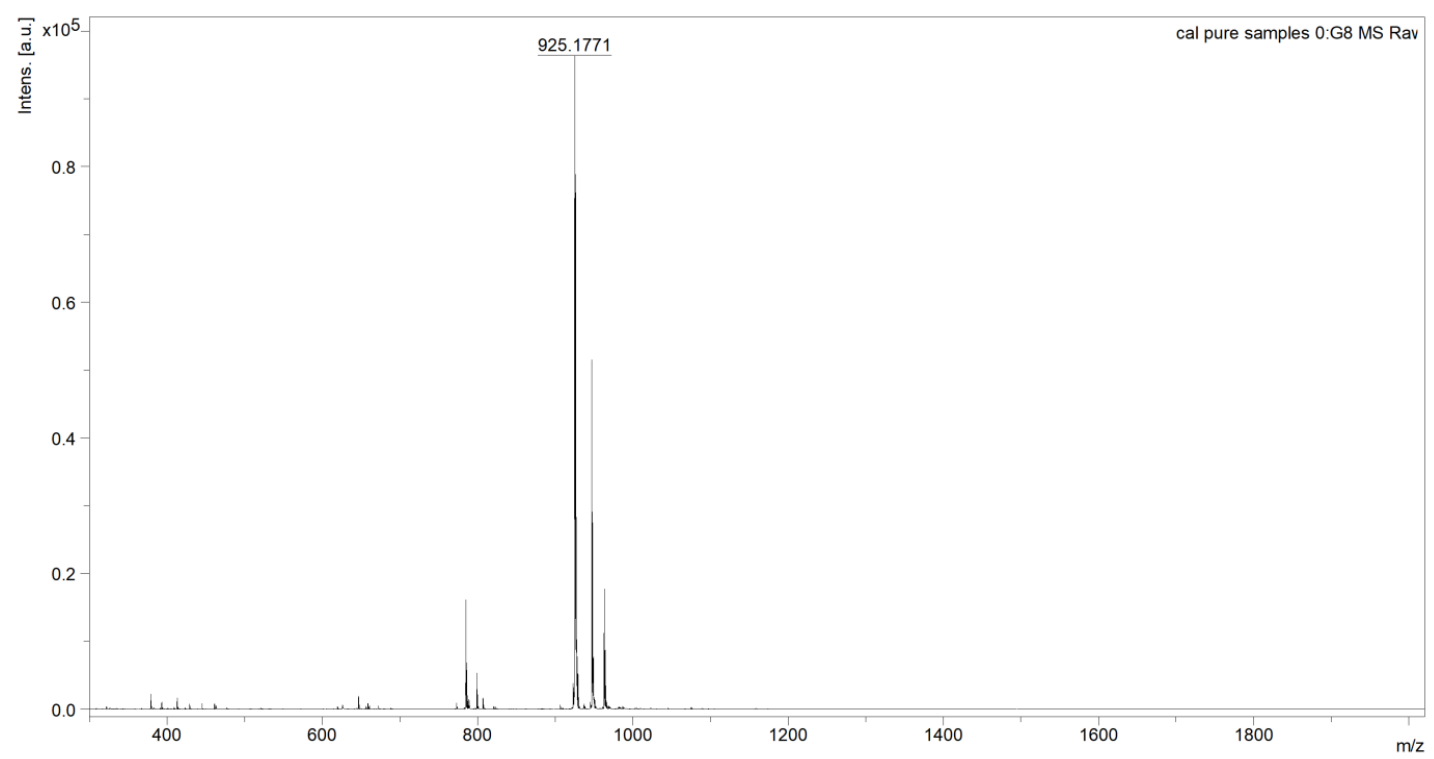

Figure S5.32. MALDI-TOF-MS of $\mathrm{K}^{2 \mathrm{M}} \mathrm{K}^{2 \mathrm{M}}$

Mass calculated: $[\mathrm{M}+\mathrm{H}]^{+}=925.0620$, mass found: $[\mathrm{M}+\mathrm{H}]^{+}=925.1771,[\mathrm{M}+\mathrm{Na}]^{+}=947.1842,[\mathrm{M}+\mathrm{K}]^{+}=963.1796$. 

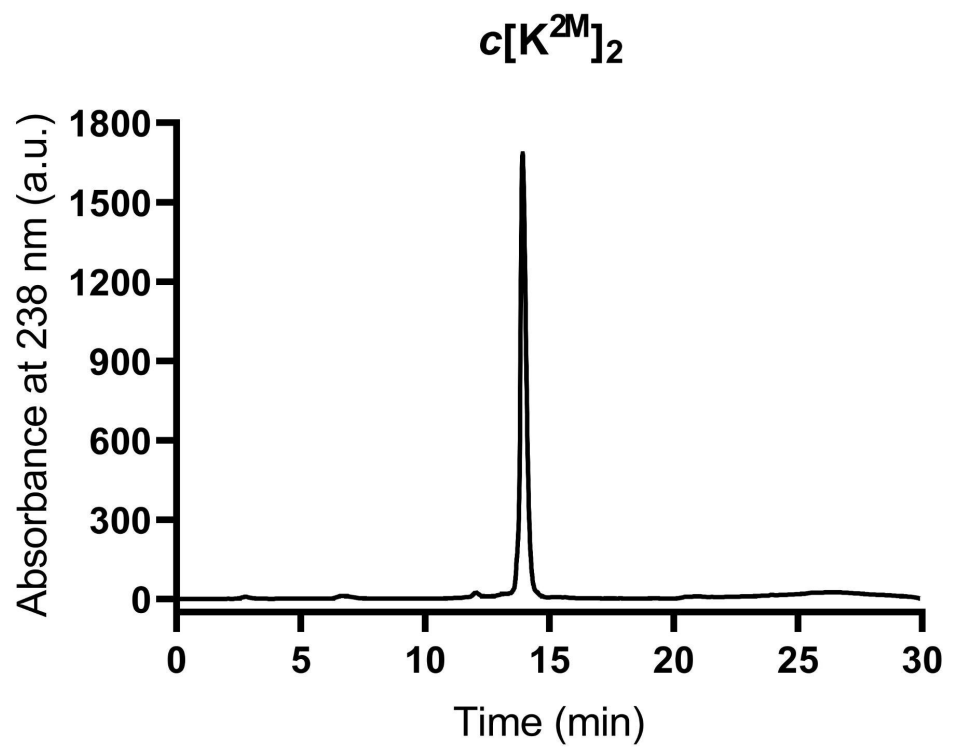

Figure S5.33. HPLC trace of $c\left[\mathrm{~K}^{2 \mathrm{M}}\right]_{2}$.

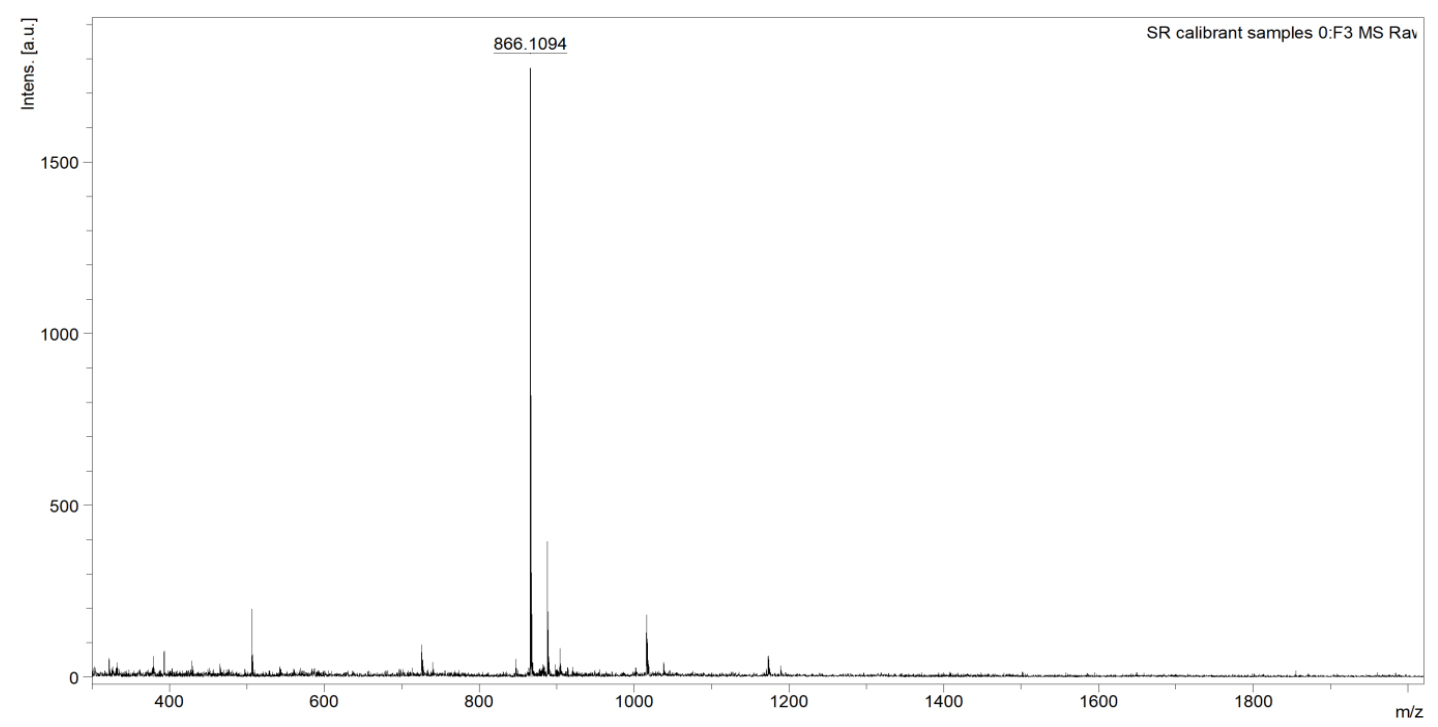

Figure S5.34. MALDI-TOF-MS of $c\left[\mathrm{~K}^{2 \mathrm{M}}\right]_{2}$

Mass calculated: $[\mathrm{M}+\mathrm{H}]^{+}=865.9940$, mass found: $[\mathrm{M}+\mathrm{H}]^{+}=866.1094,[\mathrm{M}+\mathrm{Na}]^{+}=888.1216,[\mathrm{M}+\mathrm{K}]^{+}=904.1377$. 


\section{Fmoc-k ${ }^{2 \mathrm{M}}-\mathrm{OH}$}

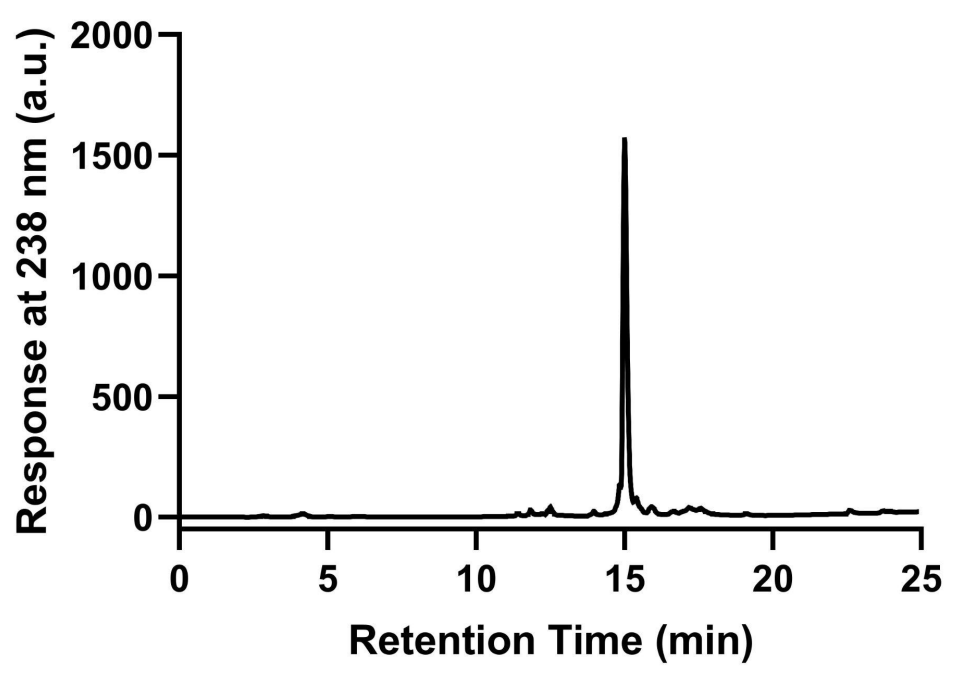

Figure S5.35. HPLC trace of Fmoc- $\mathrm{k}^{2 \mathrm{M}}-\mathrm{OH}$, using the gradient described at the beginning of this section.

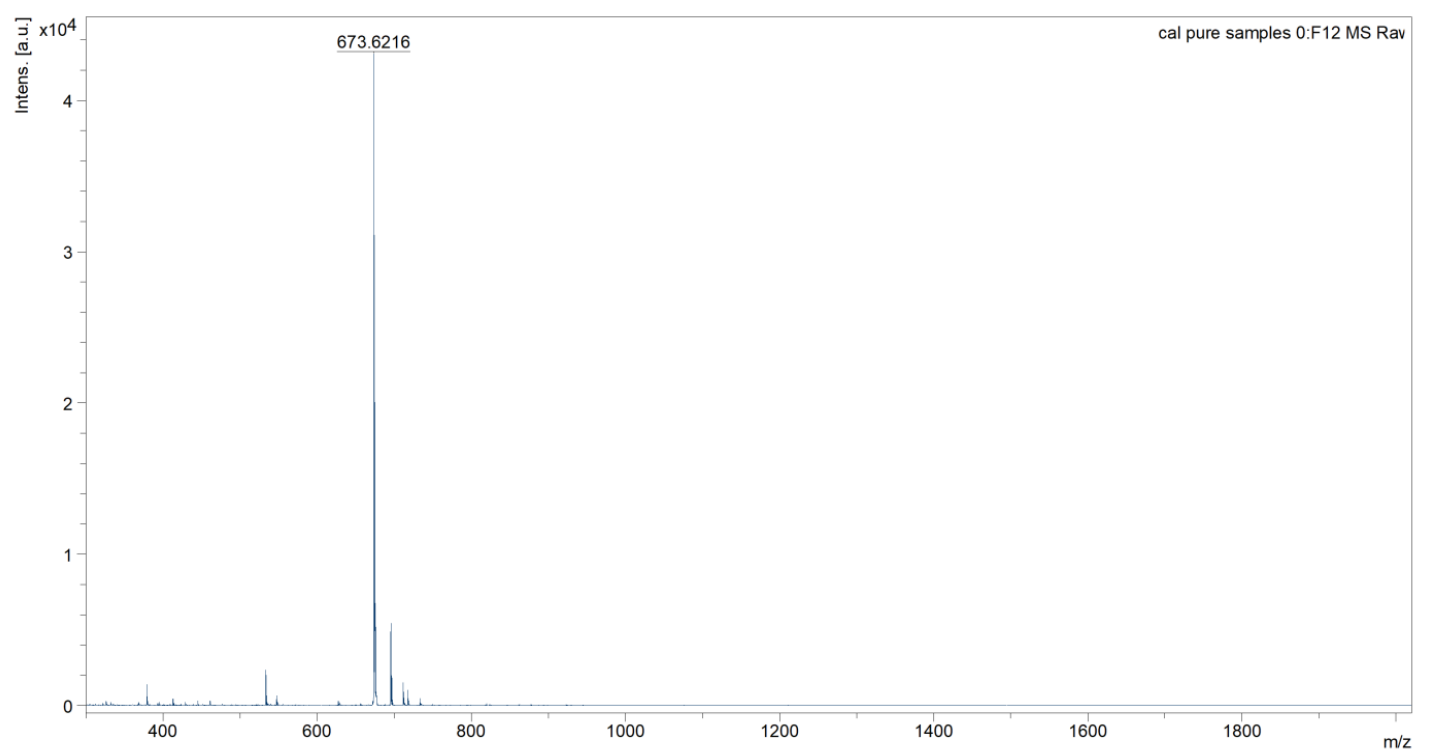

Figure S5.36. MALDI-TOF-MS of Fmoc-k ${ }^{2 \mathrm{M} O H}$.

Mass calculated: $[\mathrm{M}+\mathrm{H}]^{+}=673.7550$, mass found: $[\mathrm{M}+\mathrm{H}]^{+}=673.6216,[\mathrm{M}+\mathrm{Na}]^{+}=695.6124$. 


$$
k^{2 M} k^{2 M}
$$

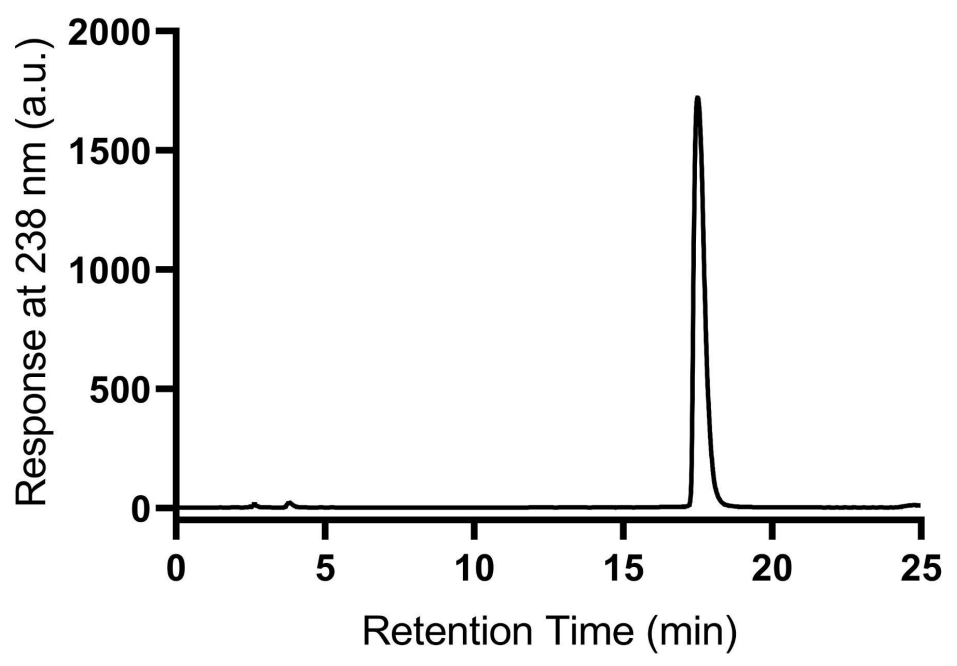

Figure S5.37. HPLC trace of $\mathrm{k}^{2 \mathrm{M}} \mathrm{k}^{2 \mathrm{M}}$. Requires $15 \%$ solvent $\mathrm{B}$

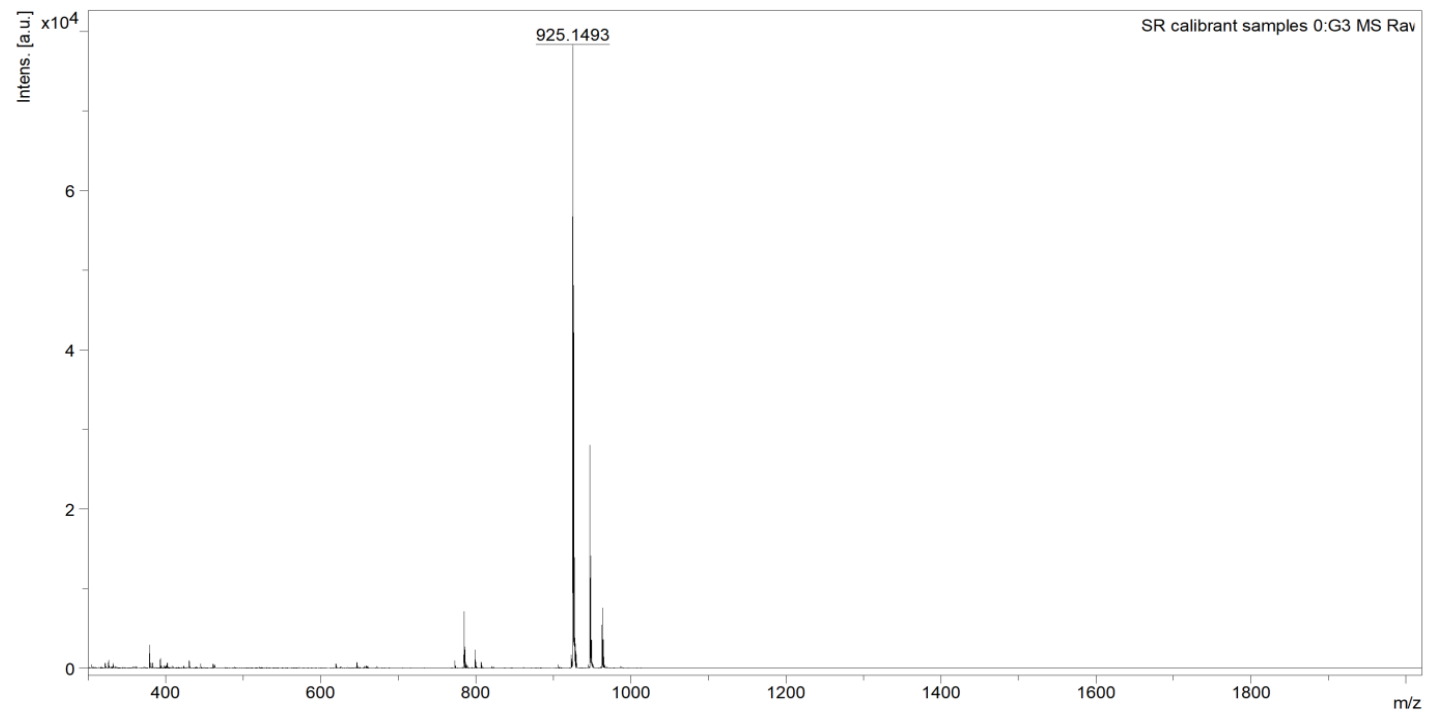

Figure S5.38. MALDI-TOF-MS of $\mathbf{k}^{2 \mathrm{M}} \mathbf{k}^{2 \mathrm{M}}$.

Mass calculated: $[\mathrm{M}+\mathrm{H}]^{+}=925.0620$, mass found: $[\mathrm{M}+\mathrm{H}]^{+}=925.1493,[\mathrm{M}+\mathrm{Na}]^{+}=947.1561,[\mathrm{M}+\mathrm{K}]^{+}=963.1513$. 

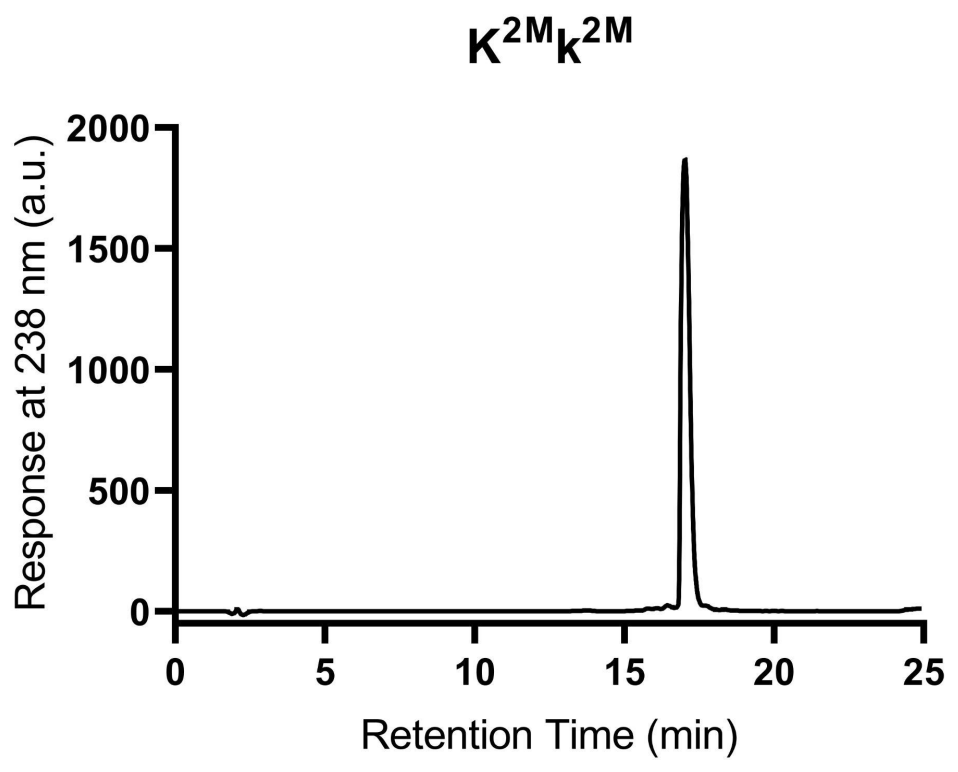

Figure S5.39. HPLC trace of $\mathrm{K}^{2 \mathrm{M}} \mathrm{k}^{2 \mathrm{M}}$. Requires $15 \%$ solvent $\mathrm{B}$.

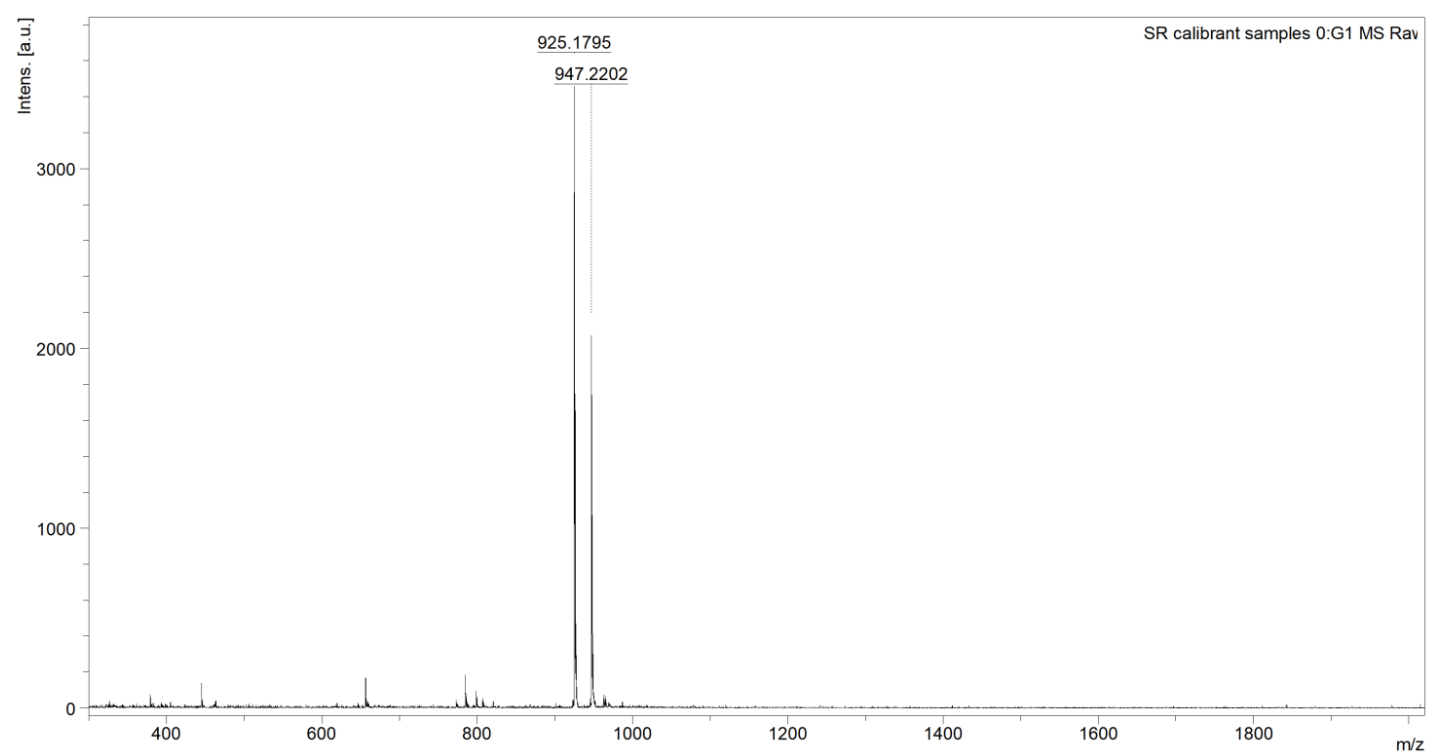

Figure S5.40. MALDI-TOF-MS of $\mathrm{K}^{2 \mathrm{M}} \mathrm{k}^{2 \mathrm{M}}$.

Mass calculated: $[\mathrm{M}+\mathrm{H}]^{+}=925.0620$, mass found: $[\mathrm{M}+\mathrm{H}]^{+}=925.1795,[\mathrm{M}+\mathrm{Na}]^{+}=947.2202,[\mathrm{M}+\mathrm{K}]^{+}=963.2544$. 

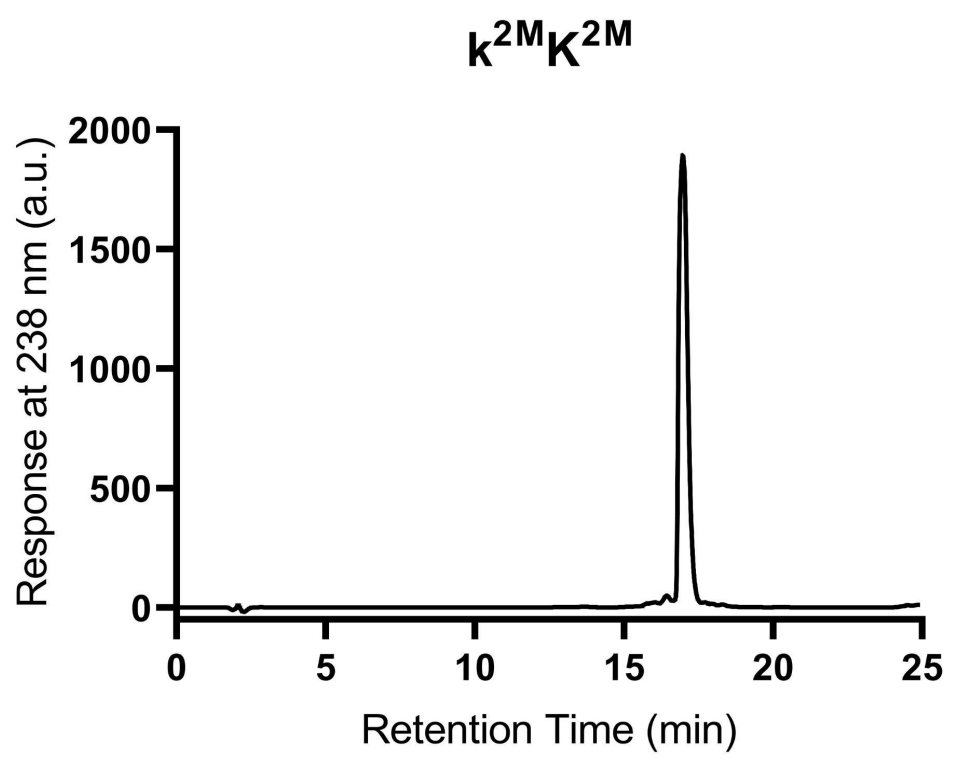

Figure S5.41. HPLC trace of $\mathrm{k}^{2 \mathrm{M}} \mathrm{K}^{2 \mathrm{M}}$. Requires $15 \%$ solvent $\mathrm{B}$.

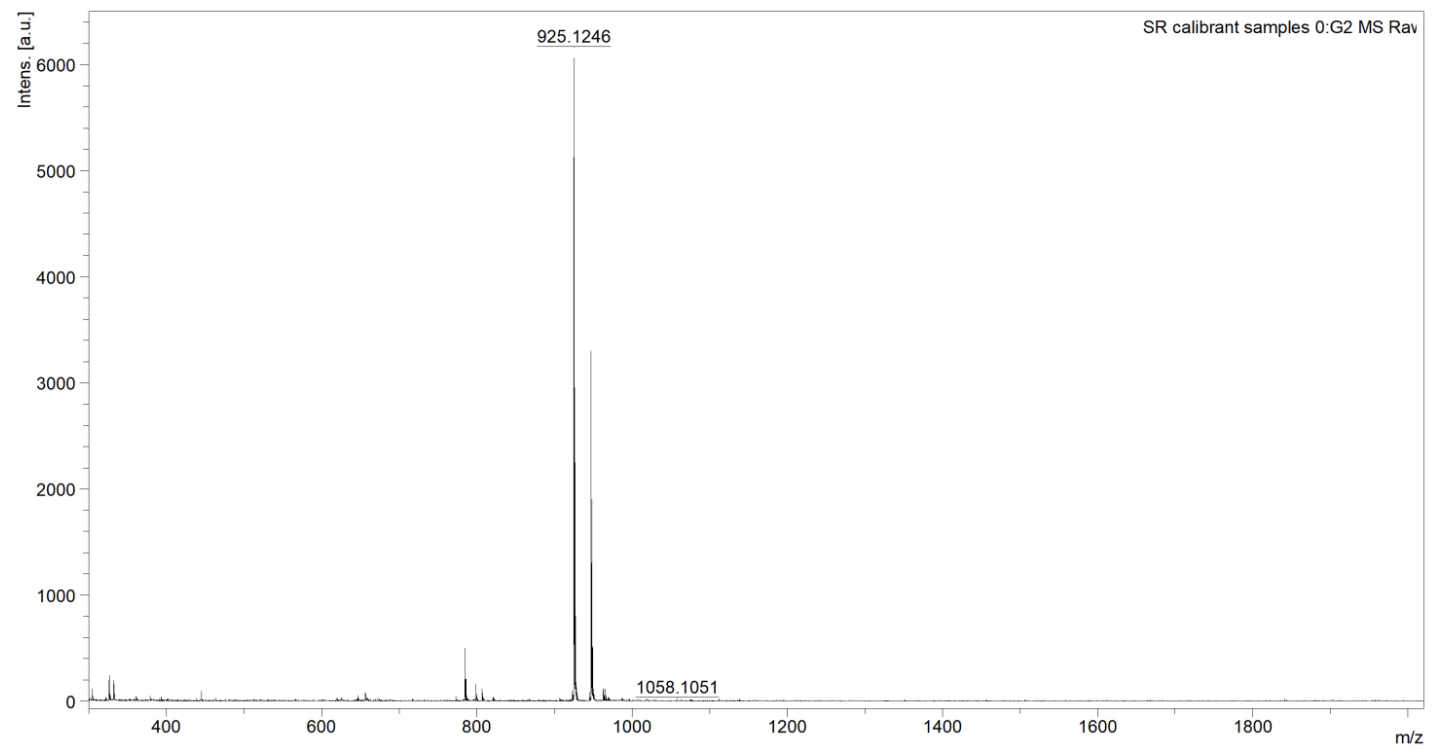

Figure S5.42. MALDI-TOF-MS of $\mathbf{k}^{2 \mathrm{M}} \mathrm{K}^{2 \mathrm{M}}$.

Mass calculated: $[\mathrm{M}+\mathrm{H}]^{+}=925.0620$, mass found: $[\mathrm{M}+\mathrm{H}]^{+}=925.1246,[\mathrm{M}+\mathrm{Na}]^{+}=947.1247,[\mathrm{M}+\mathrm{K}]^{+}=963.1155$. 


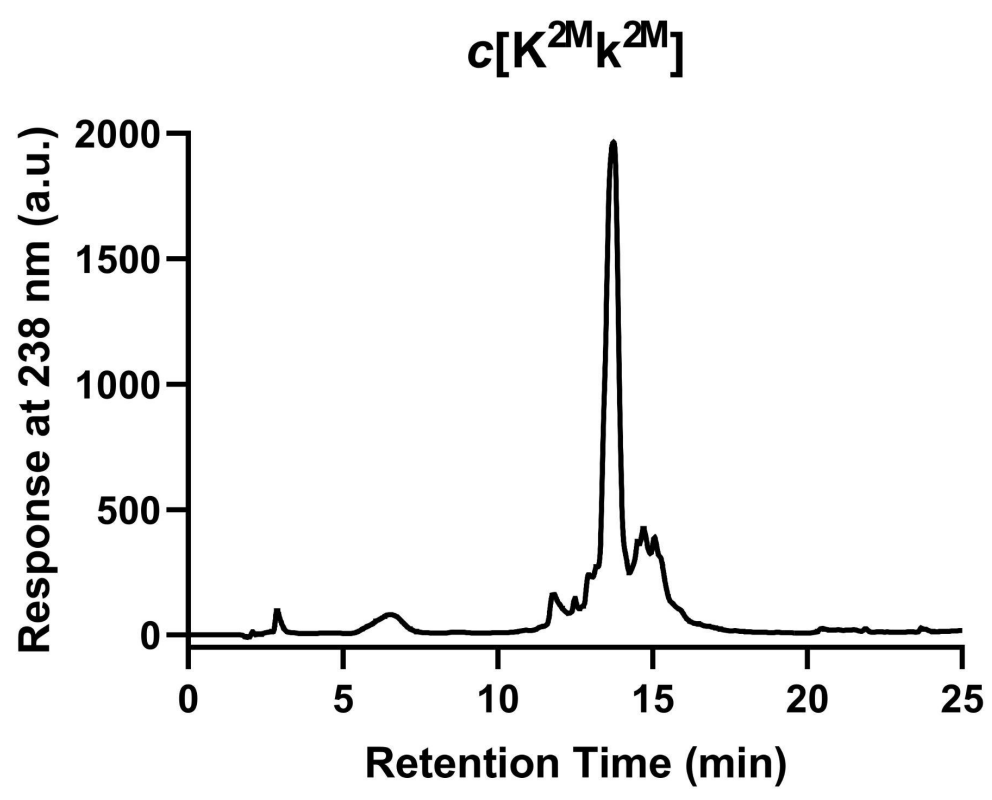

Figure S5.43. HPLC trace of $c\left[\mathrm{~K}^{2 \mathrm{M}} \mathrm{k}^{2 \mathrm{M}}\right]$.

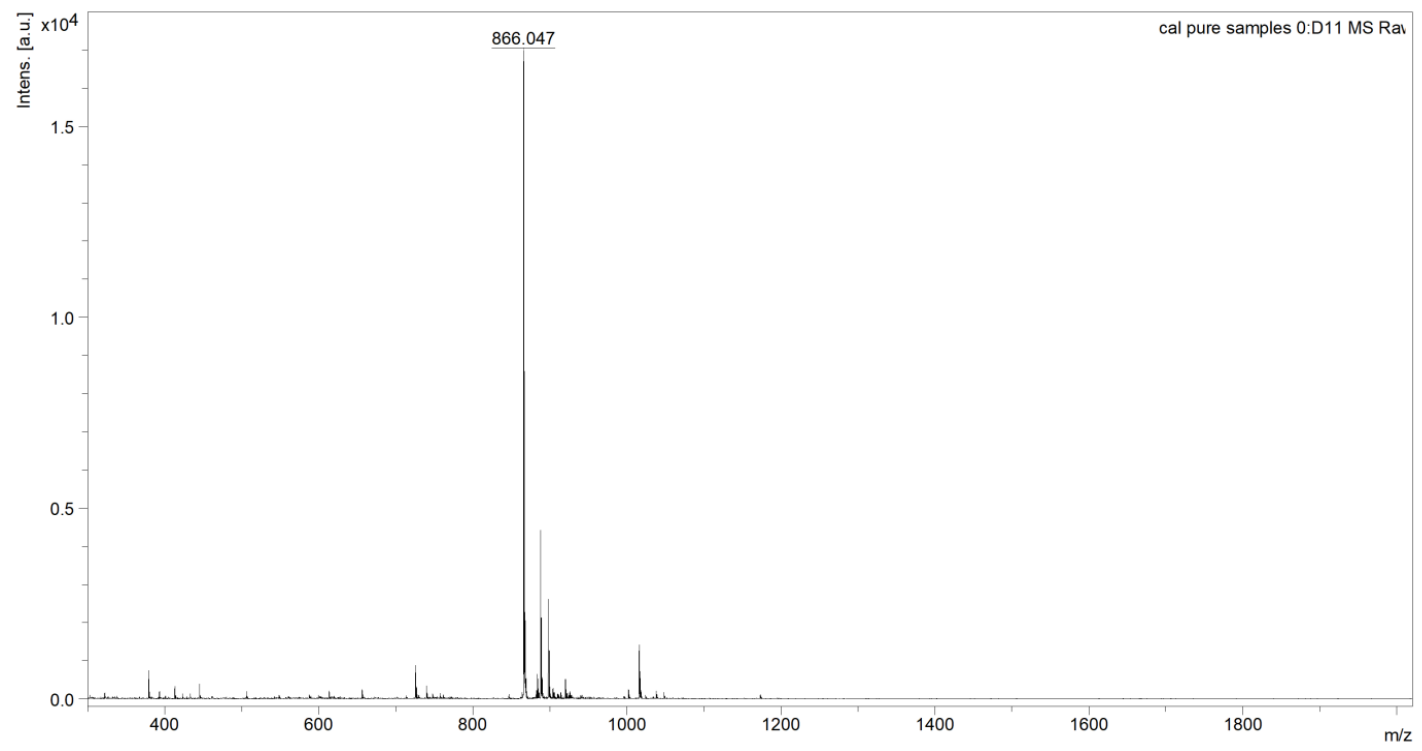

Figure S5.44. MALDI-TOF-MS of $c\left[\mathrm{~K}^{2 \mathrm{M}} \mathbf{k}^{2 \mathrm{M}}\right]$.

Mass calculated: $[\mathrm{M}+\mathrm{H}]^{+}=865.9940$, mass found: $[\mathrm{M}+\mathrm{H}]^{+}=866.0201,[\mathrm{M}+\mathrm{Na}]^{+}=888.0949$. 


\section{S6. References}

(1) Siegfried, N. A.; Bevilacqua, P. C. Chapter 13 Thinking Inside the Box: Designing, Implementing, and Interpreting Thermodynamic Cycles to Dissect Cooperativity in RNA and DNA Folding. In Methods in Enzymology; Academic Press, 2009; Vol. 455, pp 365-393.

(2) Schroeder, S. J.; Turner, D. H. Optical Melting Measurements of Nucleic Acid Thermodynamics. Methods Enzymol. 2009, 468, 371-387.

(3) Mikulecky, P. J.; Feig, A. L. Heat Capacity Changes Associated with DNA Duplex Formation: Salt- and Sequence-Dependent Effects. Biochemistry 2006, 45 (2), 604-616.

(4) Mikulecky, P. J.; Feig, A. L. Heat Capacity Changes Associated with Nucleic Acid Folding. Biopolymers 2006, 82 (1), 38-58.

(5) Kantonen, S. A.; Henriksen, N. M.; Gilson, M. K. Accounting for Apparent Deviations between Calorimetric and Van't Hoff Enthalpies. Biochim. Biophys. Acta Gen. Subj. 2018, 1862 (3), 692-704.

(6) Kantonen, S. A.; Henriksen, N. M.; Gilson, M. K. Evaluation and Minimization of Uncertainty in ITC Binding Measurements: Heat Error, Concentration Error, Saturation, and Stoichiometry. Biochim. Biophys. Acta Gen. Subj. 2017, 1861 (2), 485-498. 